\title{
HFIR Pressure Vessel and Structural Components Materials Surveillance Program
}

\section{Supplement 2}

\section{RECEIVED}

$\begin{array}{cc}\text { SEP } 271999 & \text { R. D. Cheverton } \\ \text { OSTI } & \text { E. K. Nanstad } \\ \end{array}$

MANAGED AND OPERATED BY IOCKHEED MARTN ENEREY RESEARCH CORPORATION FORTHE UNTEO STATES DEPARTUENT OF ENERGY

Office of Scientific and Technical Information

P. O. Box 62

Oak Ridge, TN 37831 
This report has been reproduced from the best available copy.

Reports are available to the public from the following source.

National Technical Information Service

5285 Port Royal Road

Springfield, VA 22161

Telephone 703-605-6000 (1-800-553-6847)

TDD 703-487-4639

Fax 703-605-6900

E-mail orders@ ntis.fedworld.gov

Web site http://www.ntis.gov/ordering.htm

Reports are available to U.S. Department of Energy (DOE) employees, DOE contractors, Energy Technology Data Exchange (ETDE) representatives, and international Nuclear Information System (INIS) representatives from the following source.

Office of Scientific and Technical Information

P.O. Box 62

Oak Ridge, TN 37831

Telephone 423-576-8401

Fax 423-576-5728

E-mail reports adonis.osti.gov

Web site http://www.osti.gov/products/sources.html

Reports produced after January 1, 1996, are generally available via the DOE Information Bridge.

Web site http://www.doe.gov/bridge 
ORNL/TM-1372/S2

HEIR PRESSURE VESSEL AND STRUCTURAL COMPONENTS MATERIALS SURVEILLANCE PROGRAM

SUPPLEMENT 2

R. D. Cheverton

Delta-21 Resources, Inc.

Oak Ridge, Tennessee 37830

R. K. Nanstad

Oak Ridge National Laboratory

Oak Ridge, Tennessee 37831

E. D. Brakeman

Oak Ridge National Laboratory

Oak Ridge, Tennessee 37831

August 1999 


\section{DISCLAIMER}

This report was prepared as an account of work sponsored by an agency of the United States Government. Neither the United States Government nor any agency thereof, nor any of their employees, make any warranty, express or implied, or assumes any legal liability or responsibility for the accuracy, completeness, or usefuiness of any information, apparatus, product, or process disclosed, or represents that its use would not infringe privately owned rights. Reference herein to any specific commercial product, process, or service by trade name, trademark, manufacturer, or otherwise does not necessarily constitute or imply its endorsement, recommendation, or favoring by the United States Government or any agency thereof. The views and opinions of authors expressed herein do not necessarily state or reflect those of the United States Government or any agency thereof. 


\section{DISCLAIMER}

Portions of this document may be illegible in electronic image products. Images are produced from the best available original document. 


\section{TABLE OF CONTENTS}

Acknowledgments

Abstract . ii

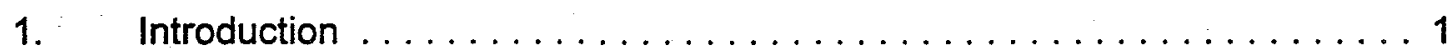

1.1 History prior to 17.5 EFPY(100 MW $\ldots \ldots \ldots \ldots \ldots \ldots \ldots$

1.2 History beyond $17.5 \mathrm{EFPY}(100 \mathrm{MW}) \ldots \ldots \ldots \ldots \ldots \ldots \ldots \ldots$

2. Dose Rates and $\triangle N D T T$ at Critical Locations in Vessel Wall ......... 2

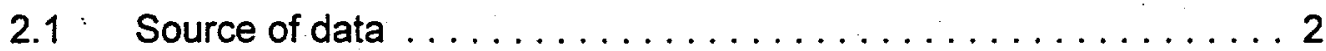

2.2 Critical areas of vessel ...................... 2

2.3 Dose rates and $\triangle$ NDTT at "critical" locations .............. 3

3. Location of Surveillance Specimens and Corresponding dpa Data.

Prior to Design Upgrade $[t=22.6$ EFPY $(100 \mathrm{MW})] \ldots \ldots \ldots \ldots \ldots \ldots 4$

4. Location of Surveillance Specimens for Period Following

Design Upgrade $\ldots \ldots \ldots \ldots \ldots \ldots \ldots \ldots \ldots \ldots \ldots . \ldots \ldots$

4.1 Damage parameter ........................ 9

4.2 Accommodating new specimens ................. 9

4.3 Design, general location, orientation, and configuration of surveillance capsules ........................ 10

4.4 Coordinates and dpa rates for each capsule in Key 2 and

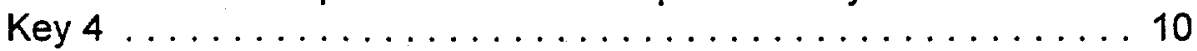

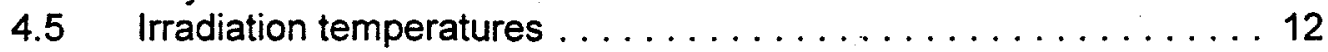

5. Specimen Availability, Locations, and Removal/Testing Schedule Specified for Upgrade Design $[t>22.6$ EFPY $(100 \mathrm{MW})] \ldots \ldots \ldots \ldots . .12$

5.1 Specimen availability ...................... 12

5.2 Capsule location and removal schedule and corresponding values of dpa and $\triangle$ NDTT . . . . . . . . . . . . . . . . . . . 13

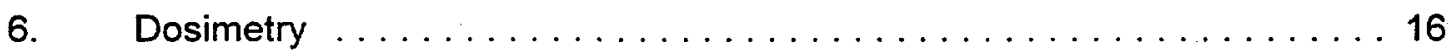

$6.1 \quad$ Type and location of dosimeters $\ldots \ldots \ldots \ldots \ldots \ldots \ldots \ldots$

6.2 Dosimetry materials ....................... 17

6.2.1 Capsule dosimeters . . . . . . . . . . . . . . . . . 17

6.2 .2 "Wire" dosimeters . . . . . . . . . . . . . . . . . 17

6.3 Evaluation of dosimetry data $\ldots \ldots \ldots \ldots \ldots \ldots \ldots \ldots$

7. Summary and Conclusions $\ldots \ldots \ldots \ldots \ldots \ldots \ldots \ldots \ldots \ldots \ldots \ldots \ldots \ldots$

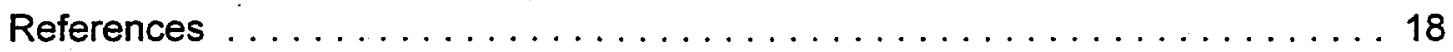




\section{TABLE OF CONTENTS}

\section{Appendices}
A. Calculated Neutron and Gamma dpa Values for Critical Areas of the HFIR Vessel
B. Data Pertaining to Surveillance Specimens Removed and Tested Prior to $t=22.6$ EFPY $(100 \mathrm{MW})$
C. Calculation of Lead Time $\ldots \ldots \ldots \ldots \ldots \ldots \ldots \ldots \ldots \ldots \ldots \ldots$
D. Heat Generation and Temperatures in Surveillance Specimens ...... D-1 


\section{ACKNOWLEDGMENTS}

The authors wish to acknowledge contributions made by J. R. Inger (ORNL/RRD responsible engineer); S. K. Iskander and K. R. Thoms (peer review); P. T. Hambaugh, R. D. Poor, and A. E. Wayland (mechanical design and graphics); and Mary Wells (preparation of manuscript). 


\begin{abstract}
A proposal has been made to increase the size of the HFIR HB-2 and HB-4 beam tubes and to extend the life of the vessel to 50 EFPY $(100 \mathrm{MW})$. Studies indicate that the increase in radiation-induced embrittlement of the vessel can be tolerated, and an appropriate expanded vessel-materials surveillance program has been devised. This program, which is the subject of this report, includes additional beam-tube nozzlematerial surveillance specimens, relocation of existing specimens of all materials, and additional dosimetry. As an aid in the placement of specimens and dosimeters, extensive two- and three-dimensional neutron and gamma flux/dpa transport calculations were made. Surveillance data will be added to the HFIR vessel $\triangle N D T T$ vs dpa data base, and dosimetry will be used to normalize the calculated fluxes. The updated $\triangle$ NDTT vs dpa correlation and the normalized dpa values will be used in the calculation of the probability of vessel failure. This procedure, in conjunction with periodic hydrostatic proof testing, is used to determine the useful life of the vessel.
\end{abstract}




\section{HFIR PRESSURE VESSEL AND STRUCTURAL COMPONENTS MATERIALS SURVEILLANCE PROGRAM-SUPPLEMENT 2}

\subsection{INTRODUCTION}

\subsection{History Prior to 17.5 EFPY(100 MW)}

Prior to an operating time of 17.5 EFPY(100 MW), the impact of radiation-induced embrittlement on the integrity of the HFIR pressure vessel was evaluated using data obtained from (1) low-temperature $\left(\leq 200^{\circ} \mathrm{F}\right)$, high-neutron-flux $[\phi(E>1 \mathrm{MeV}) \cong$ $10^{13} \mathrm{n} / \mathrm{cm}^{2} \cdot \mathrm{s}$ ] irradiations in material testing reactors (MTRs)[1], (2) HFIR vessel surveillance data[2], and (3) early criteria developed by the United States Navy[3]. The HFIR vessel surveillance program included shell material (A212B) and nozzle materials (A105II and A350LF3) but no weld or heat-affected-zone material. Irradiation capsules, each containing three Charpy V-notch (CVN) specimens, were located close to beamtube nozzle corners and elsewhere, as indicated in Figs. 1 and 2 (locations indicated by Key and Position numbers). Specimens were removed from the vessel for testing at operating times of $2.3,6.4,15.0$, and 17.5 EFPY $(100 \mathrm{MW})$ to obtain values of the nilductility transition temperature (NDTT). Specimens removed at 2.3 and 6.4 EFPY (100 MW) indicated nothing unusual, but the later two sets, both of which were tested at 17.5 EFPY (100 MW), achieved in November 1986, indicated a higher rate of embrittlement than expected and violation of criteria. As a result, HFIR was shut down for a reevaluation of vessel integrity[4].

\subsection{History beyond 17.5 EFPY(100 MW)}

The reevaluation of vessel integrity conducted at 17.5 EFPY $(100 \mathrm{MW})$ indicated that by applying hydrostatic proof testing, probabilistic fracture-mechanics analysis, and updated criteria, the higher rate of radiation-induced embrittlement could be accommodated and the vessel life extended 6 EFPY $(100 \mathrm{MW})$ beyond the original design value of 20 EFPY(100 MW), provided that the surveillance program could be extended.

By adding weld specimens and shell specimens of different orientations, an adequate extended surveillance program was defined and implemented[5]. (Heat-affected-zone material was not included because the initial toughness is greater and the damage rate about the same as for the base and weld materials, and for this reason its inclusion is no longer required by ASTM[6].)

HFIR was back in operation in 1989, and at an operating time of 19.2 EFPY(100 MW) additional surveillance specimens were removed and tested. The results were consistent with the previous results[7]. At about this same time, it was concluded, on the basis of special dosimetry measurements $[8,9]$ that gammas were responsible for the higher-than-expected embrittlement rate[9], and that the radiation-induced increase in the nil-ductility transition temperature ( $\triangle N D T T$ ) could be correlated with total (neutron plus gamma) dpa (displacements per atom)[10]. Vessel-life-extension studies accounting for the gamma contribution indicated that the life of the vessel could be extended to 50 EFPY(100 MW)[11]. About two years later, a decision was made to increase the size of the HB-2 and HB-4 beam tubes and to implement the upgrade design at 22.6 EFPY(100 MW)[12]. 
One effect of the larger beam-tube diameters is to increase the dose rate in the corresponding vessel beam-tube nozzle (Fig. 1). The increase at the HB-2 nozzle corner is a factor of 10 , and because of this increase this nozzle corner dominates the calculated probability of failure. Recent life-extension studies indicate that even with this large increase in dose rate, a vessel life of 50 EFPY $(100 \mathrm{MW})$ can be achieved[13]. An appropriate surveillance program for the upgrade design and extended life is the subject of this report. In summary, major differences, relative to the existing program [5], include additional nozzle-material specimens and upgraded dosimetry. The new dosimetry will provide neutron and gamma fluxes for correlating the embrittlement data and for normalizing the calculated neutron and gamma fluxes closer to the location of assumed flaws in the vessel wall.

\subsection{DOSE RATES AND $\triangle N D T T$ AT CRITICAL LOCATIONS IN VESSEL WALL}

\subsection{Source of Data}

Two- and three-dimensional transport calculations have been performed to obtain neutron and gamma fluxes and dpa rates (dpa) in iron in regions beyond the beryllium reflector, including critical areas of the vessel wall [14,15]. Normalization factors for the fluxes were derived from the neutron and gamma dosimetry experiments performed at HFIR in 1992 and 1993[8,10]. Additional normalization factors will be derived from the more extensive dosimetry proposed for the surveillance program described in this report.

Values of $\triangle N D T T$ were obtained from[10,13]

$$
\triangle N D T T=807.7+182.6 \ln (d p a)+10.63[\ln (d p a)]^{2},
$$

where $\triangle \mathrm{NDTT}$ is in ${ }^{\circ} \mathrm{F}$, and the applicable range of dpa is $2 \times 10^{-4} \leq \mathrm{dpa} \leq 5 \times 10^{-2}$.

\subsection{Critical Areas of Vessel}

Specific areas of the vessel are characterized by material (initial value of the reference nil-ductility transition temperature), dose rate (dpa), size of area, flaw type and density, stress level and distribution, geometry, and temperature. Each of these characteristics influences the potential for propagation of a flaw. A probabilistic fracture-mechanics analysis is used to determine the potential for each defined region[13]. The result of this type analysis for HFIR with the enlarged beam tubes[13] indicated that the HB-2 and HB-4 nozzle corners, which represent both nozzle materials, accounted for $67 \%$ and $10 \%$, respectively, of the total calculated conditional probability of failure, whereas, the corresponding nozzle welds contributed $9 \%$ and $1 \%$, for a total of $87 \%$. The girth weld below the core and the seam weld together contribute only $3 \%$. When broken down by materials, A350LF3, A105II, nozzle welds, and girth weld account for $70,14,13$, and $3 \%$ of the total probability. Thus, it is most important to obtain surveillance data for the two nozzle materials and the nozzle welds. Even so, data will be obtained for all of the materials mentioned in Sect. 1.1. 


\subsection{Dose Rates and $\triangle$ NDTT at "Critical" Locations}

Table 1 includes calculated (normalized) dose-related data and $\triangle$ NDTT values for the nozzle corners and welds, seam weld (SW) at the horizontal midplane (HMP) of the core, girth weld below the core (GW), and shell at the horizontal midplane of the core and away from the influence of the beam tubes. For $\mathrm{HB}-1,-3$, and -4 , the doses are the maximum values, which occur at the horizontal midplane on the acute side of the nozzle. The dose at 22.6 EFPY $(100 \mathrm{MW})$ is based on the dose rates for the present design, while all other data pertain to the upgrade design (enlarged beam tubes for HB-2 and HB-4).

Table 1. Dose rate, dose-rate ratios, and dose at "critical" locations

\begin{tabular}{|c|c|c|c|c|c|c|}
\hline \multirow[b]{2}{*}{ Location } & \multirow[b]{2}{*}{$\begin{array}{c}\text { dpa } \\
(t=22.6) \\
(n+y)\end{array}$} & \multirow[b]{2}{*}{$\begin{array}{c}\text { dṕa } \\
(t>22.6)^{a} \\
(n+v)\end{array}$} & \multicolumn{2}{|c|}{$\begin{array}{l}\text { dṕa ratios } \\
(t>22.6)\end{array}$} & \multirow[b]{2}{*}{$\begin{array}{c}d p a \\
\times 10^{3} \\
(t=50)\end{array}$} & \multirow[b]{2}{*}{$\begin{array}{l}\Delta N D T T \\
(t=50) \\
{ }^{\circ} \mathrm{F}\end{array}$} \\
\hline & & & $\eta / y$ & $\begin{array}{l}n(\text { th) }) \\
(n+y)\end{array}$ & & \\
\hline $\begin{array}{l}\text { HB-1 } \\
\text { Nozzle corner } \\
\text { Nozzle weld/shell }\end{array}$ & $\begin{array}{l}2.4 \times 10^{-3} \\
1.2 \times 10^{-3}\end{array}$ & $\begin{array}{l}1.08 \times 10^{-4} \\
5.4 \times 10^{-5}\end{array}$ & $\begin{array}{l}3.3 \\
0.39\end{array}$ & & $\begin{array}{l}5.36 \\
2.68\end{array}$ & $\begin{array}{r}144 \\
99\end{array}$ \\
\hline $\begin{array}{l}\text { HB-2 } \\
\text { Nozzle corner } \\
\text { Nozzle weld/shell }\end{array}$ & $\begin{array}{l}2.8 \times 10^{-3} \\
1.5 \times 10^{-3}\end{array}$ & $\begin{array}{l}1.36 \times 10^{-3} \\
1.30 \times 10^{-4}\end{array}$ & $\begin{array}{l}5.4 \\
1.2\end{array}$ & $\begin{array}{l}0.11 \\
0.002\end{array}$ & $\begin{array}{c}40.1 \\
5.06\end{array}$ & $\begin{array}{l}330 \\
139\end{array}$ \\
\hline $\begin{array}{l}\text { HB-3 } \\
\text { Nozzle corner } \\
\text { Nozzle weld/shell }\end{array}$ & $\begin{array}{l}4.3 \times 10^{-3} \\
1.7 \times 10^{-3}\end{array}$ & $\begin{array}{l}1.91 \times 10^{-4} \\
7.3 \times 10^{-5}\end{array}$ & $\begin{array}{l}3.3 \\
0.35\end{array}$ & $\begin{array}{l}0.09 \\
0.005\end{array}$ & $\begin{array}{l}9.53 \\
3.70\end{array}$ & $\begin{array}{l}188 \\
119\end{array}$ \\
\hline $\begin{array}{l}\text { HB-4 } \\
\text { Nozzle corner } \\
\text { Nozzle weld/shell }\end{array}$ & $\begin{array}{l}2.4 \times 10^{-3} \\
1.2 \times 10^{-3}\end{array}$ & $\begin{array}{l}2.7 \times 10^{-4} \\
5.1 \times 10^{-5}\end{array}$ & $\begin{array}{l}3.8 \\
0.62\end{array}$ & $\begin{array}{l}0.31 \\
0.009\end{array}$ & $\begin{array}{l}9.79 \\
2.60\end{array}$ & $\begin{array}{r}191 \\
97\end{array}$ \\
\hline SW (HMP) & $1.0 \times 10^{-3}$ & $4.4 \times 10^{-5}$ & 0.059 & & 2.21 & 88 \\
\hline GW (below core) & $7.2 \times 10^{-4}$ & $3.2 \times 10^{-5}$ & 0.042 & & 1.60 & 73 \\
\hline Shell (HMP) & $1.0 \times 10^{-3}$ & $4.4 \times 10^{-5}$ & 0.059 & & 2.21 & 88 \\
\hline
\end{tabular}

adpa/EFPY (100 MW) for time greater than 22.6 EFPY(100 MW).

'Shell adjacent to nozzle weld.

"Iso-plots" of neutron, gamma, neutron-plus-gamma and the ratio of gamma to neutron dpa and of neutron and gamma fluxes ( $E>1 \mathrm{MeV}$ ) are included in Appendix $A$ for the present- and upgrade-design "critical" locations, and more detailed digital data are available in Refs. 14 and 15. 


\section{LOCATION OF SURVEILLANCE SPECIMENS AND CORRESPONDING dpa DATA PRIOR TO DESIGN UPGRADE $[t<22.6$ EFPY $(100 \mathrm{MW})]$}

The surveillance capsules are placed in fixtures (capsule mounts) that are attached to structural members in the vessel, and the location of each mount is identified by Key number, as indicated in Figs. 1 and 2 . At Keys 1, 2, 3, and 4, the mounts are circular and surround the beam tubes. Each of these latter four mounts consists of a stationary portion that supports a slotted disc that holds the capsules and can be rotated to align capsules with a capsule insertion/removal port. The mounts at Keys 5, 6, and 7 are linear, oriented circumferentially, and consist of a single, stationary component. Details are included in Ref. 2.

Capsule available positions within the mounts are indicated schematically in Fig. 2. The coordinates corresponding to the volumetric center of the middle CVN specimen in each capsule and the corresponding dose rate (dpa) are included in Table 2. The $x$ coordinate is measured along the centerline of the beam tube from a horizontal line through the center of the core and normal to the centerline of the beam tube; $y$ is measured from the centerline of the beam tube along a horizontal line normal to the beam-tube centerline; $z$ is measured from the beam-tube centerline along a vertical line. Standing in the vessel looking out, positive $x$ is outward; positive $y$ is to the left for Keys 2, 3, 4, and 7 and to the right for Keys 1 and 6; and positive $z$ is upward.

Table 2. Coordinates and dpa rates for surveillance capsule locations used prior to the design upgrade $[t<22.6$ EFPY $(100 \mathrm{MW})]$

\begin{tabular}{|c|c|c|c|c|c|c|}
\hline \multirow[b]{2}{*}{ Key } & \multirow{2}{*}{$\begin{array}{c}\text { Key } \\
\text { position }\end{array}$} & \multicolumn{3}{|c|}{ Coordinates (in.) } & \multirow{2}{*}{$\begin{array}{c}\text { dpa }(n+y) \\
\text { dpa/EFPY }(100 \mathrm{MW})\end{array}$} & \multirow[b]{2}{*}{$d \dot{p} a(n) / d \dot{p} a(Y)$} \\
\hline & & $x$ & $y$ & $z$ & & \\
\hline \multirow[t]{6}{*}{$1^{\mathrm{a}}$} & 1 & 41.37 & 2.41 & 4.35 & $8.17 \times 10^{-5}$ & 1.22 \\
\hline & 2 & 40.85 & 4.17 & 2.51 & $8.58 \times 10^{-5}$ & 1.58 \\
\hline & 3 & 40.65 & 4.81 & 0 & $9.32 \times 10^{-5}$ & 1.93 \\
\hline & 8 & 43.51 & -4.81 & 0 & $7.50 \times 10^{-5}$ & 0.74 \\
\hline & 9 & 43.31 & -4.17 & 2.51 & $7.52 \times 10^{-5}$ & 0.68 \\
\hline & 10 & 42.80 & -2.41 & 4.35 & $7.46 \times 10^{-5}$ & 0.76 \\
\hline \multirow[t]{4}{*}{$2^{b}$} & 1 & 45.83 & -1.37 & 6.89 & $1.50 \times 10^{-4}$ & 0.87 \\
\hline & 2 & 45.83 & -3.90 & 5.84 & $1.50 \times 10^{-4}$ & 0.87 \\
\hline & 3 & 45.83 & -5.84 & 3.90 & $1.50 \times 10^{-4}$ & 0.87 \\
\hline & 4 & 45.83 & -6.89 & 1.37 & $1.50 \times 10^{-4}$ & 0.87 \\
\hline \multirow[t]{2}{*}{$3^{\mathrm{a}}$} & 1 & 45.51 & -2.45 & 4.35 & $1.05 \times 10^{-4}$ & 1.19 \\
\hline & 2 & 45.93 & -4.24 & 2.51 & $1.09 \times 10^{-4}$ & 1.07 \\
\hline
\end{tabular}


ORNL/TM-1372/S2

Table 2 (cont'd)

\begin{tabular}{|c|c|c|c|c|c|c|}
\hline \multirow[b]{2}{*}{ Key } & \multirow{2}{*}{$\begin{array}{c}\text { Key } \\
\text { position }\end{array}$} & \multicolumn{3}{|c|}{ Coordinates (in.) } & \multirow{2}{*}{$\begin{array}{c}\text { dpa }(n+y) \\
\text { dpa/EFPY }(100 \mathrm{MW})\end{array}$} & \multirow[b]{2}{*}{$\mathrm{dpa} a(n) / d \dot{p} a(\gamma)$} \\
\hline & & $x$ & $y$ & $z$ & & \\
\hline & 3 & 46.08 & -4.89 & 0 & $1.11 \times 10^{-4}$ & 1.27 \\
\hline & 8 & 43.82 & 4.89 & 0 & $1.57 \times 10^{-4}$ & 2.18 \\
\hline & 9 & 43.97 & 4.24 & 2.51 & $1.42 \times 10^{-4}$ & 1.80 \\
\hline & 10 & 44.39 & 2.45 & 4.35 & $1.30 \times 10^{-4}$ & 1.65 \\
\hline \multirow[t]{6}{*}{$4^{\mathrm{a}}$} & 1 & 42.80 & -2.41 & 4.35 & $7.46 \times 10^{-5}$ & 0.76 \\
\hline & 2 & 43.31 & -4.17 & 2.51 & $7.52 \times 10^{-5}$ & 0.68 \\
\hline & 3 & 43.51 & -4.81 & 0 & $7.50 \times 10^{-5}$ & 0.74 \\
\hline & 8 & 40.65 & 4.81 & 0 & $9.32 \times 10^{-5}$ & 1.93 \\
\hline & 9 & 40.85 & 4.17 & 2.51 & $8.58 \times 10^{-5}$ & 1.58 \\
\hline & 10 & 41.37 & 2.41 & 4.35 & $8.17 \times 10^{-5}$ & 1.22 \\
\hline \multirow[t]{7}{*}{$5^{c}$} & 1 & 46.2 & -8.1 & -9.0 & $4.0 \times 10^{-5}$ & 0.1 \\
\hline & 2 & 46.5 & -10.5 & -9.0 & $4.0 \times 10^{-5}$ & 0.1 \\
\hline & 3 & 46.6 & -12.8 & -9.0 & $4.0 \times 10^{-5}$ & 0.1 \\
\hline & 4 & 46.7 & -15.1 & -9.0 & $4.0 \times 10^{-5}$ & 0.1 \\
\hline & 5 & 46.6 & -17.4 & -9.0 & $4.0 \times 10^{-5}$ & 0.1 \\
\hline & 6 & 46.5 & -19.7 & -9.0 & $4.0 \times 10^{-5}$ & 0.1 \\
\hline & 7 & 46.2 & -20.1 & -9.0 & $4.0 \times 10^{-5}$ & 0.1 \\
\hline \multirow[t]{8}{*}{$6^{c, d}$} & 1 & 38.3 & 10.5 & 0 & $6.7 \times 10^{-5}$ & 0.25 \\
\hline & 2 & 36.8 & 12.3 & 0 & $6.5 \times 10^{-5}$ & 0.22 \\
\hline & 3 & 35.4 & 14.1 & 0 & $6.3 \times 10^{-5}$ & 0.20 \\
\hline & 4 & 33.9 & 16.0 & 0 & $6.2 \times 10^{-5}$ & 0.19 \\
\hline & 5 & 31.0 & 18.9 & 0 & $6.1 \times 10^{-5}$ & 0.16 \\
\hline & 6 & 29.2 & 20.4 & 0 & $6.1 \times 10^{-5}$ & 0.15 \\
\hline & 7 & 27.4 & 21.9 & 0 & $6.1 \times 10^{-5}$ & 0.14 \\
\hline & 8 & 25.6 & 23.4 & 0 & $6.1 \times 10^{-5}$ & 0.13 \\
\hline
\end{tabular}


Table 2 (cont'd)

\begin{tabular}{|c|c|c|c|c|c|c|}
\hline \multirow[b]{2}{*}{ Key } & \multirow{2}{*}{$\begin{array}{c}\text { Key } \\
\text { position }\end{array}$} & \multicolumn{3}{|c|}{ Coordinates (in.) } & \multirow{2}{*}{$\begin{array}{c}\text { dp̉a }(n+y) \\
\text { dpa/EFPY }(100 \mathrm{MW}) \\
\end{array}$} & \multirow[b]{2}{*}{$\mathrm{dp} a(n) / d \dot{p} a(\gamma)$} \\
\hline & & $x$ & $y$ & $z$ & & \\
\hline \multirow[t]{5}{*}{$7^{\mathrm{c}, \mathrm{d}}$} & 1 & 26.2 & 22.7 & 0 & $6.1 \times 10^{-5}$ & 0.14 \\
\hline & 2 & 27.9 & 21.0 & 0 & $6.1 \times 10^{-5}$ & 0.15 \\
\hline & 3 & 29.6 & 19.4 & 0 & $6.1 \times 10^{-5}$ & 0.16 \\
\hline & 4 & 31.3 & 17.8 & 0 & $6.2 \times 10^{-5}$ & 0.17 \\
\hline & 5 & 33.1 & 16.2 & 0 & $6.2 \times 10^{-5}$ & 0.18 \\
\hline \multirow[t]{3}{*}{. } & 6 & 34.8 & 14.6 & 0 & $6.3 \times 10^{-5}$ & 0.20 \\
\hline & 7 & 37.5 & 11.6 & 0 & $6.6 \times 10^{-5}$ & 0.23 \\
\hline & 8 & 38.8 & 9.7 & 0 & $6.8 \times 10^{-5}$ & 0.26 \\
\hline
\end{tabular}

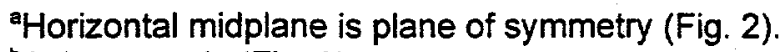

'Axisymmetric (Fig. 2).

${ }^{\circ}$ Coordinate systems for HB-1 (Key 6) and HB-4 (Keys 5 and 7).

${ }^{\circ}$ Curve smoothing used because of mesh-design-induced fluctuations in neutron and gamma dpa values.

The original positions of capsules specified for each Key are included in Ref. 2. Capsules were removed for testing at 2.3,6.4, 15.0, and 17.5 EFPY(100 MW), and in 1988 the location plan was modified, and new materials were added (nozzle weld, seam weld, and shell material with different orientations). Corresponding locations are specified in Ref. 5. Additional specimens were removed at 19.2 EFPY(100 MW) (1993). The locations of the remaining capsules, the materials contained therein, and their projected accumulated doses at 22.6 EFPY $(100 \mathrm{MW})$ are included in Table 3. Calculated doses accumulated in specimens already removed and tested are included in Appendix B.

Table 3. Location of existing HFIR surveillance capsules and corresponding specimen materials and calculated doses at 22.6 EFPY(100 MW)

\begin{tabular}{lccccc}
\hline Capsule & $\begin{array}{c}\text { Material/ } \\
\text { orientation }^{\mathrm{a}}\end{array}$ & Key & $\begin{array}{c}\text { Key } \\
\text { position }\end{array}$ & $\begin{array}{c}\text { Irradiation time } \\
\text { EFPY(100 MW) }\end{array}$ & dpa \\
\hline HB-1-22 & A105II & 1 & 8,3 & $17.5,5.1$ & $1.79 \times 10^{-3}$ \\
HB-1-23 & A105II & 1 & 7,4 & $17.5,5.1$ & $1.75 \times 10^{-3}$ \\
HB-1-24 & A105II & 1 & 5 & 22.6 & $1.84 \times 10^{-3}$ \\
HB-1-29 & A105II & 1 & 10,2 & $17.5,5.1$ & $1.74 \times 10^{-3}$ \\
HB-2-8 & A350LF3 & 2 & 11 & 22.6 & $3.39 \times 10^{-3}$ \\
HB-2-17 & A350LF3 & 2 & 10 & 22.6 & $3.39 \times 10^{-3}$
\end{tabular}


ORNL/TM-1372/S2

Table 3 (cont'd)

\begin{tabular}{|c|c|c|c|c|c|}
\hline Capsule & $\begin{array}{c}\text { Material/ } \\
\text { orientation }^{\mathbf{a}}\end{array}$ & Key & $\begin{array}{c}\text { Key } \\
\text { position }\end{array}$ & $\begin{array}{l}\text { Irradiation time } \\
\text { EFPY }(100 \mathrm{MW})\end{array}$ & dpa \\
\hline HB-2-18 & A350LF3 & 2 & 8 & 22.6 & $3.39 \times 10^{-3}$ \\
\hline HB-3-41 & A350LF3 & 3 & 10 & 22.6 & $2.94 \times 10^{-3}$ \\
\hline HB-3-46 & A350LF3 & 3 & 7 & 22.6 & $3.21 \times 10^{-3}$ \\
\hline HB-4-35 & A105II & 4 & 5,8 & $17.5,5.1$ & $1.78 \times 10^{-3}$ \\
\hline$H B-4-38$ & A105II & 4 & 7 & 22.6 & $1.94 \times 10^{-3}$ \\
\hline HB-4-39 & A105II & 4 & 10,9 & $17.5,5.1$ & $1.87 \times 10^{-3}$ \\
\hline HB-1A-62 & A212B/LT & 6 & 5,2 & $17.5,5.1$ & $1.40 \times 10^{-3}$ \\
\hline HB-1A-65 & $\mathrm{A} 212 \mathrm{~B} / \mathrm{LT}$ & 6 & 6,3 & $17.5,5.1$ & $1.39 \times 10^{-3}$ \\
\hline $\mathrm{HB}-1 \mathrm{~A}-70$ & $\mathrm{~A} 212 \mathrm{~B} / \mathrm{LT}$ & 6 & 4,1 & $17.5,5.1$ & $1.43 \times 10^{-3}$ \\
\hline $\mathrm{HB}-4 \mathrm{~A}-74$ & $\mathrm{~A} 212 \mathrm{~B} / \mathrm{LT}$ & 7 & 3,6 & $17.5,5.1$ & $1.39 \times 10^{-3}$ \\
\hline $\mathrm{HB}-4 \mathrm{~A}-75$ & $\mathrm{~A} 212 \mathrm{~B} / \mathrm{LT}$ & 7 & 5,8 & $17.5,5.1$ & $1.43 \times 10^{-3}$ \\
\hline $\mathrm{HB}-4 \mathrm{~A}-79$ & $\mathrm{~A} 212 \mathrm{~B} / \mathrm{LT}$ & 7 & 2,5 & $17.5,5.1$ & $1.38 \times 10^{-3}$ \\
\hline$H B-4 A-80$ & $\mathrm{~A} 212 \mathrm{~B} / \mathrm{LT}$ & 7 & 4,7 & $17.5,5.1$ & $1.42 \times 10^{-3}$ \\
\hline IC-A-54 & $\mathrm{A} 212 \mathrm{~B} / \mathrm{LT}$ & 5 & 2 & 22.6 & $1 \times 10^{-3}$ \\
\hline IC-A-55 & $\mathrm{A} 212 \mathrm{~B} / \mathrm{LT}$ & 5 & 3 & 22.6 & $1 \times 10^{-3}$ \\
\hline IC-A-56 & $\mathrm{A} 212 \mathrm{~B} / \mathrm{LT}$ & 5 & 4 & 22.6 & $1 \times 10^{-3}$ \\
\hline IC-A-57 & $\mathrm{A} 212 \mathrm{~B} / \mathrm{LT}$ & 5 & 5 & 22.6 & $1 \times 10^{-3}$ \\
\hline IC-A-58 & $\mathrm{A} 212 \mathrm{~B} / \mathrm{LT}$ & 5 & 6 & 22.6 & $1 \times 10^{-3}$ \\
\hline IC-A-60 & $\mathrm{A} 212 \mathrm{~B} / \mathrm{LT}$ & 5 & 7 & 22.6 & $1 \times 10^{-3}$ \\
\hline LS-1-1 & $\mathrm{A} 212 \mathrm{~B} / \mathrm{LS}$ & 1 & 1 & 5.1 & $4.2 \times 10^{-4}$ \\
\hline LS-1-2 & A212B/LS & 1 & 6 & 5.1 & $3.8 \times 10^{-4}$ \\
\hline LS-1-3 & $\mathrm{A} 212 \mathrm{~B} / \mathrm{LS}$ & 1 & 10 & 5.1 & $3.8 \times 10^{-4}$ \\
\hline LS-4-4 & $\mathrm{A} 212 \mathrm{~B} / \mathrm{LS}$ & 4 & 1 & 5.1 & $3.8 \times 10^{-4}$ \\
\hline LS-4-5 & A212B/LS & 4 & 5 & 5.1 & $3.8 \times 10^{-4}$ \\
\hline LS-4-6 & $\mathrm{A} 212 \mathrm{~B} / \mathrm{LS}$ & 4 & 6 & 5.1 & $4.2 \times 10^{-4}$ \\
\hline$L T-2-1$ & $\mathrm{~A} 212 \mathrm{~B} / \mathrm{LT}$ & 2 & 1 & 5.1 & $7.7 \times 10^{-4}$ \\
\hline LT-2-2 & $\mathrm{A} 212 \mathrm{~B} / \mathrm{LT}$ & 2 & 4 & 5.1 & $7.7 \times 10^{-4}$ \\
\hline LT-2-3 & $\mathrm{A} 212 \mathrm{~B} / \mathrm{LT}$ & 2 & 13 & 5.1 & $7.7 \times 10^{-4}$ \\
\hline
\end{tabular}


Table 3 (cont'd)

\begin{tabular}{cccccc}
\hline Capsule & $\begin{array}{c}\text { Materiall } \\
\text { orientation }\end{array}$ & Key & $\begin{array}{c}\text { Key } \\
\text { position }\end{array}$ & $\begin{array}{c}\text { Irradiation time } \\
\text { EFPY(100 MW) }\end{array}$ & dpa \\
\hline LT-2-4 & A212B/LT & 2 & 14 & 5.1 & $7.7 \times 10^{-4}$ \\
NW-2-2 & Nozzle weld & 2 & 3 & 5.1 & $7.7 \times 10^{-4}$ \\
NW-2-3 & Nozzle weld & 2 & 5 & 5.1 & $7.7 \times 10^{-4}$ \\
NW-2-5 & Nozzle weld & 2 & 7 & 5.1 & $7.7 \times 10^{-4}$ \\
NW-2-6 & Nozzle weld & 2 & 12 & 5.1 & $7.7 \times 10^{-4}$ \\
NW-2-7 & Nozzle weld & 2 & 15 & 5.1 & $7.7 \times 10^{-4}$ \\
SW-4-10 & Seam weld & 4 & 2 & 5.1 & $3.8 \times 10^{-4}$ \\
SW-4-11 & Seam weld & 4 & 3 & 5.1 & $3.8 \times 10^{-4}$ \\
SW-4-12 & Seam weld & 4 & 4 & 5.1 & $3.8 \times 10^{-4}$ \\
SW-6-4 & Seam weld & 6 & 6 & 5.1 & $3.1 \times 10^{-4}$ \\
SW-6-5 & Seam weld & 6 & 7 & 5.1 & $3.1 \times 10^{-4}$ \\
SW-6-6 & Seam weld & 6 & 8 & 5.1 & $3.1 \times 10^{-4}$ \\
SW-7-1 & Seam weld & 7 & 1 & 5.1 & $3.1 \times 10^{-4}$ \\
SW-7-2 & Seam weld & 7 & 2 & 5.1 & $3.1 \times 10^{-4}$ \\
SW-7-3 & Seam weld & 7 & 3 & 5.1 & $3.1 \times 10^{-4}$ \\
\hline
\end{tabular}

Summary of totals by materials

\begin{tabular}{llc}
\hline Material & Location & Number of capsules \\
\hline A350LF3 & HB-2, HB-3 nozzles & 5 \\
A105II & HB-1, HB-4 nozzles & 7 \\
A212B/LT & Shell & 17 \\
A212B/LS & Shell & 6 \\
Nozzle weld & Nozzle welds & 5 \\
Seam weld & Seam and girth welds & 9 \\
& & Total \\
\hline
\end{tabular}

arientation of CVN specimens relative to rolling direction of plate: $L=$ direction of rolling (longitudinal), $T=$ transverse to direction of rolling, $S=$ through thickness of plate; first letter refers to direction of length of CVN specimen, and second letter refers to direction crack tip faces (e.g., LS corresponds to axially-oriented flaw in vessel propagating through the wall). 


\section{LOCATION OF SURVEILLANCE SPECIMENS FOR PERIOD FOLLOWING DESIGN UPGRADE}

\subsection{Damage Parameter}

Based on the studies discussed in Ref. 16, a damage parameter (DP) might be defined as

$$
D P=\int\left[\phi(n) \sigma_{d p a}(n) E F(n)+\phi(Y) \sigma_{d p a}(Y) E F(Y)\right] d E
$$

where

$$
\begin{aligned}
\phi & =\text { neutron }(n) \text { and gamma }(\eta) \text { fluxes } \\
\sigma_{d p a} & =\text { neutron }(n) \text { and gamma }(\eta) \text { dpa cross sections } \\
E F= & \text { neutron }(n) \text { and gamma }(\eta) \text { efficiency factors relative to permanent } \\
& \text { displacements, }
\end{aligned}
$$

and $\phi, \sigma_{\mathrm{dpa}}$, and $E F$ are assumed to be energy dependent. Early attempts to explain the greater-than-expected embrittlement rate of the HFIR vessel indicated that based on EF (non-thermal neutrons) $=1$, values for thermal neutrons and gamma-interaction electrons would be $\sim 10$. More recent studies[17, 18], however, indicate that because HFIR's temperatures are lower than those associated with the Ref. 16 studies, values of $E F$ for thermal neutrons and electrons are closer to unity. Unity also appeared to be reasonable for correlating the available HFIR surveillance data[10], in which case total (neutron plus gamma) dpa was the correlating parameter. There are some indications, however, that a value of 3 or 4 for gammas would result in a better correlation of the data in Ref. 10 , and there are other indications that a value of 2 might be more appropriate for thermal neutrons[19]. Thus, it is prudent to locate the surveillance capsules where the fractions of gamma and neutron dpa's are nearly the same as expected at the leading edge of assumed flaws in critical areas of the vessel wall. A complicating factor in this respect is that the attenuations of neutrons and gammas in the vessel wall are different, and different flaw sizes must be considered in the vessel integrity analyses. The good news is that the HB-2 nozzle corner dominates the calculated probability of vessel failure, and at this location, dpa (fast neutrons) $\gg \mathrm{dpa}(\mathrm{V})>\mathrm{dpa}$ (thermal neutrons). Thus, small variations in EF will not have a significant effect on the calculated probability of failure.

\subsection{Accommodating New Specimens}

With reference to Table 3 , it is observed that only five capsules of HB-2 nozzle material (A350LF3) remain, and as indicated in Refs. 2 and 4, specimens in two of those capsules (HB-3-41 and HB-3-46) have a different initial value of NDTT than for the others (HB-2-8, HB-2-17, HB-2-18). Because this material dominates the calculated probability of failure, and because a minimum of two capsules (three are preferred) are required to obtain a value of NDTT[2,5], additional A350LF3 specimens must be added. This requires a dose rate greater than normal in order to make up for the dose already accumulated in the vessel and to eventually provide some lead time. This is not difficult for specimens representing the HB-2 nozzle corner because the new dose rate for the nozzle corner is ten times that for the original design (smaller beam tube). Furthermore, as indicated by Figs. A14-A17 in Appendix A, if the specimens are moved away from 
the vessel toward the core, the dose rate can be increased while maintaining nearly the same ratios of neutron to gamma dose rates. The analysis in Appendix $C$ indicates that the 50 EFPY $(100 \mathrm{MW})$ dose at the HB-2 nozzle corner can be achieved at 37 EFPY $(100$ $\mathrm{MW}$ ) in a new specimen with twice the nozzle-corner dose rate. This is considered to be adequate lead time.

The factor of ten increase in the dose rate associated with the increase in the HB-2 beam tube diameter and a specified factor of approximately two increase to be achieved by moving the specimens closer to the core introduces a concern over rate effects. Usually, a factor of five is specified as a limit[20], but most of the embrittlement at the HB-2 nozzle corner will take place at the factor of ten higher rate. Fortunately, rate-effect studies conducted for HFIR since the discovery in 1986 of higher-than-expected embrittlement rates indicate that a factor of $10^{4}$ in dose rate for HFIR conditions and materials is not significant[19,21]. Thus, rate effects are not considered to be a factor.

\subsection{Design, General Location, Orientation, and Configuration of Surveillance Capsules}

The capsule design to be used in the continuing HFIR surveillance program is the same as used previously[2,4], and as before, each capsule will contain three CVN specimens and a stainless steel dosimeter. New dosimetry-dedicated capsules will be included for the continuing program, as discussed in Sect. 6.0.

The capsule orientations for Key 2 and Key 4 will be different than they were because the larger diameters of the two beam tubes do not allow the notch region of the CVN specimens to be directly opposite the nozzle corner with the capsules oriented radially, as before[2]. The desired proximity to the nozzle corner can be achieved, however, if the CVN specimens, and thus capsules, are parallel to the beam tube (Fig. 3). The CVN notch will be displaced from the vessel toward the core, but, as mentioned above, this is a desired means of accelerating the damage rate in order to eventually achieve lead time.

Capsules are also being located opposite the HB-2 nozzle weld so as to achieve the correct ratio of neutron-to-gamma dpa for nozzle welds. The orientation for these capsules will be radial (Fig. 3).

The two orientations at Key 2 are included in a single capsule mount, as illustrated in Figs. 4 and 5. The section of the mount containing the "parallel" capsules is referred to as Key $2 \mathrm{C}$ (" $\mathrm{C}$ " for nozzle corner), and the section containing the "radial" capsules is referred to as Key $2 W$ ("W" for nozzle weld). The two are joined and thus are rotated in unison to position capsules at the insertion/removal ports.

Assembly/installation drawings for the Key 4 upgrade are included in Figs. 6 and 7, and similar drawings for Keys 1, 3, 5, 6, and 7 are included in Ref. 2. Detailed drawings for Keys 2 and 4 are included in ORNL drawings $M-11531-O H-025-E$ through $-039-E$ for HB-2 and M-11531-OH-055-E through -063-E for HB-4.

\subsection{Coordinates and dpa Rates for each Capsule in Key 2 and Key 4}

The coordinates and dpa rates for all capsules in upgrade-design Key 2 and Key 4 are given in Table 4. The coordinates and dpa values correspond to the volumetric center 
of the central CVN specimen in the capsule. The definition of the coordinate system is given in Sect. 3. Coordinates and dpa values for Keys 1, 3, 5, 6, and 7 are the same as those in Table 2.

Table 4. Coordinates and dpa rates for Key 2 and Key 4 locations for upgrade design [ $t>22.6 \mathrm{EFPY}(100 \mathrm{MW})]$

\begin{tabular}{|c|c|c|c|c|c|c|}
\hline \multirow[t]{2}{*}{ Key } & \multirow{2}{*}{$\begin{array}{c}\text { Key } \\
\text { position }\end{array}$} & \multicolumn{3}{|c|}{ Coordinates (in.) } & \multirow{2}{*}{$\begin{array}{c}\text { dpja }(n+y) \\
\text { dpa/EFPY }(100 \mathrm{MW})\end{array}$} & \multirow[t]{2}{*}{$d \dot{p} a(n) / d \dot{p} a(Y)$} \\
\hline & & $x$ & $y$ & $z$ & & \\
\hline \multirow[t]{5}{*}{$2 C^{a}$} & 1 & 38.94 & 0 & 6.50 & $3.41 \times 10^{-3}$ & 5.1 \\
\hline & 2 & 38.94 & -2.49 & 6.01 & $3.41 \times 10^{-3}$ & 5.1 \\
\hline & 3 & 38.94 & -4.60 & 4.60 & $3.41 \times 10^{-3}$ & 5.1 \\
\hline & 4 & 38.94 & -6.01 & 2.49 & $3.41 \times 10^{-3}$ & 5.1 \\
\hline & 5 & 38.94 & -6.50 & 0 & $3.41 \times 10^{-3}$ & 5.1 \\
\hline \multirow[t]{9}{*}{$2 W^{a}$} & 1 & 39.69 & 0 & 12.00 & $2.28 \times 10^{-4}$ & 0.59 \\
\hline & 2 & 39.69 & -2.34 & 11.77 & $2.28 \times 10^{-4}$ & 0.59 \\
\hline & 3 & 39.69 & -4.59 & 11.09 & $2.28 \times 10^{-4}$ & 0.59 \\
\hline & 4 & 39.69 & -6.67 & 9.98 & $2.28 \times 10^{-4}$ & 0.59 \\
\hline & 5 & 39.69 & -8.49 & 8.49 & $2.28 \times 10^{-4}$ & 0.59 \\
\hline & 6 & 39.69 & -9.98 & 6.67 & $2.28 \times 10^{-4}$ & 0.59 \\
\hline & 7 & 39.69 & -11.09 & 4.59 & $2.28 \times 10^{-4}$ & 0.59 \\
\hline & 8 & 39.69 & -11.77 & 2.34 & $2.28 \times 10^{-4}$ & 0.59 \\
\hline & 9 & 39.69 & -12.00 & 0 & $2.28 \times 10^{-4}$ & 0.59 \\
\hline \multirow[t]{6}{*}{$4^{b}$} & 1 & 35.92 & -2.28 & 3.95 & $3.07 \times 10^{-4}$ & 2.4 \\
\hline & 2 & 35.92 & -3.95 & 2.28 & $3.12 \times 10^{-4}$ & 2.3 \\
\hline & 3 & 35.92 & -4.56 & 0 & $3.54 \times 10^{-4}$ & 2.7 \\
\hline & 8 & 35.92 & 4.56 & 0 & $5.00 \times 10^{-4}$ & 3.7 \\
\hline & 9 & 35.92 & 3.95 & 2.28 & $3.97 \times 10^{-4}$ & 3.7 \\
\hline & 10 & 35.92 & 2.28 & 3.95 & $3.42 \times 10^{-4}$ & 2.9 \\
\hline
\end{tabular}

axisymmetric (Fig. 2)

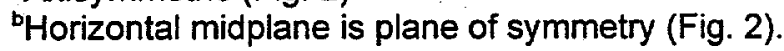




\subsection{Irradiation Temperatures}

There is a tendency for the radiation-induced embrittlement rate to decrease with increasing irradiation temperature. Thus, to avoid having to make a correction for temperature, it is necessary that the temperature of the surveillance specimens not differ excessively from that of critical areas of the vessel wall.

Increasing the size of the $\mathrm{HB}-2$ and $\mathrm{HB}-4$ beam tubes and positioning the surveillance capsules closer to the core increases the radiation-induced heat-generation rate and thus the temperature in the corresponding surveillance specimens. For Key $2 \mathrm{C}$, which has the highest heat-generation rate, the calculated centerline temperature for the CVNspecimens during normal operation at $100 \mathrm{MW}$ is $157^{\circ} \mathrm{F}$ (see Appendix D). The temperature of the vessel wall is somewhat less but not less than $110^{\circ} \mathrm{F}$.

Irradiation data for the HFIR vessel class of materials indicate that in the temperature range 80 to $250^{\circ} \mathrm{F}$, the sensitivity of embrittlement rate to irradiation temperature is not detectable[19,22,23,24]. Thus, the differences in temperatures of the surveillance specimens and vessel are not excessive.

\section{SPECIMEN AVAILABILITY, LOCATION, AND REMOVALITESTING SCHEDULE SPECIFIED FOR UPGRADE DESIGN $[t>22.6$ EFPY $(100 \mathrm{MW})]$}

\subsection{Specimen Availability}

As indicated in Table 3, there are 49 previously irradiated capsules, and they include all of the materials of interest. However, there are only five capsules of A350LF3, and as indicated in Sect. 2.2, this material dominates the calculated probability of failure. Thus, more capsules of A350LF3 are required to properly track the embrittlement over time. There is space for 11 new capsules in Key $2 \mathrm{C}$, and they will be used for A350LF3. Two new capsules of A350LF3 will also be added to Key $2 W$ and Key 6 . These four capsules and two of the new A350LF3 capsules added to Key $2 \mathrm{C}$ will contain half-size CVN specimens that will be used to investigate the relative values of EF. The three keys involved $(2 \mathrm{C}, 2 \mathrm{~W}$, and 6$)$ have very different neutron to gamma dpa ratios. The corresponding capsule numbers are HB-2C-10, HB-2C-11, HB-2C-12, HB-2C-13, HB$2 \mathrm{C}-14$, and $\mathrm{HB}-2 \mathrm{C}-15$.

Material for the new A350LF3 specimens will be taken from one of the two nozzle forging prolongations that were used for the existing specimens. It is identified as "HB No. 2 ASTM A-350-GRLF-3" on drawing E-M-56012 in Ref. 2 (page 13). Capsules containing these specimens are labeled $\mathrm{HB}-2 \mathrm{C}$. The specimen identification numbers and the corresponding capsules are included in Table 5.

Table 5. CVN specimen identification and corresponding capsules for capsules HB-2C-1 through HB-2C-15

\begin{tabular}{ll}
\hline Capsule number & CVN specimen numbers \\
\hline HB-2C-1 & C-63, C-64, C-65 \\
HB-2C-2 & C-66, C-67, C-68 \\
HB-2C-3 & C-69, C-70, C-71
\end{tabular}


Table 5 (cont'd)

\begin{tabular}{ll}
\hline Capsule number & CVN specimen numbers \\
\hline HB-2C-4 & C-72, C-73, C-74 \\
HB-2C-5 & C-75, C-76, C-77 \\
HB-2C-6 & C-78, C-79, C-80 \\
HB-2C-7 & C-81, C-82, C-83 \\
HB-2C-8 & C-84, C-85, C-86 \\
HB-2C-9 & C-87, C-88, C-89 \\
HB-2C-10 & C-93A through C-116A \\
HB-2C-11 & C-93B through C-116B \\
HB-2C-12 & C-93C through C-116C \\
HB-2C-13 & C-93D through C-116D \\
HB-2C-14 & C-93E through C-116E \\
HB-2C-15 & C-93F through C-116F \\
\hline
\end{tabular}

\subsection{Capsule Location .and Removal Schedule and Corresponding Values of dpa and $\triangle$ NDTT}

An effort has been made to locate capsules where dpa is somewhat higher than the maximum value in the vessel for the same material and also where the neutron/gamma dpa ratio is about the same. These ratios for the vessel wall are given in Table 1 and for Key/Position locations in Table 4. The Key/Position location, removal schedule, and corresponding calculated values of dpa and $\triangle N D T T$ for each capsule are given in Table 6. The times are somewhat arbitrary and can deviate by $\pm 0.5 \mathrm{EFPY}(100 \mathrm{MW})$ for the convenience of reactor operations.

Table 6. Capsule Key/Position locations and the corresponding removal/testing schedule for the upgrade design [ $(t>22.6$ EFPY $(100 \mathrm{MW})]$

\begin{tabular}{llcccccc}
\hline Capsule & Material & Key & Position & \multicolumn{5}{c}{$\begin{array}{c}\text { Removal/testing } \\
\text { schedule }\end{array}$} & $\begin{array}{c}\text { dpa }{ }^{\mathrm{d}} \\
\times 10^{3}\end{array}$ & $\begin{array}{c}\Delta \text { NDTT }^{\mathrm{d}} \\
{ }^{\circ} \mathrm{F}\end{array}$ \\
\hline HB-1-22 & A105II & 4 & 1 & 12.5 & 35 & 5.63 & 147 \\
HB-1-23 & A105II & 4 & 5 & 12.5 & 35 & 5.59 & 147 \\
HB-1-24 & A105II & 4 & 6 & 7.5 & 30 & 4.41 & 130 \\
HB-1-29 & A105II & 4 & 10 & 7.5 & 30 & 4.31 & 128 \\
HB-4-35 & A105II & 4 & 7 & 2.5 & 25 & 2.77 & 101 \\
HB-4-38 & A105II & 4 & 8 & 2.5 & 25 & 3.19 & 109
\end{tabular}


Table 6 (cont'd)

\begin{tabular}{|c|c|c|c|c|c|c|c|}
\hline \multirow{2}{*}{ Capsule } & \multirow{2}{*}{ Material } & \multirow{2}{*}{ Key } & \multirow{2}{*}{ Position } & \multicolumn{2}{|c|}{$\begin{array}{l}\text { Removal/testing } \\
\text { schedule }\end{array}$} & \multirow{2}{*}{$\begin{array}{l}d p a^{d} \\
\times 10^{3}\end{array}$} & \multirow{2}{*}{$\underset{{ }^{\circ} \mathrm{F}}{\Delta \mathrm{NDTT}^{\mathrm{d}}}$} \\
\hline & & & & $\Delta t^{a}$ & $\sim t^{a}$ & & \\
\hline $\mathrm{HB}-4-39$ & A105II & 4 & 9 & 2.5 & 25 & 2.86 & 103 \\
\hline HB-2-8 & A350LF3 & $2 C$ & 16 & 1.0 & 23.6 & 6.80 & 161 \\
\hline HB-2-17 & A350LF3 & $2 \mathrm{C}$ & 1 & 1.0 & 23.6 & 6.80 & 161 \\
\hline HB-2-18 & A350LF3 & $2 C$ & 2 & 1.0 & 23.6 & 6.80 & 161 \\
\hline $\mathrm{HB}-3-41$ & A350LF3 & $2 \mathrm{C}$ & 3 & 2.5 & 25 & 11.5 & 204 \\
\hline HB-3-46 & A350LF3 & $2 C$ & 4 & 2.5 & 25 & 11.7 & 206 \\
\hline $\mathrm{HB}-2 \mathrm{C}-1$ & A350LF3 & $2 C$ & 5 & 2.5 & 25 & 8.53 & 179 \\
\hline $\mathrm{HB}-2 \mathrm{C}-2$ & A350LF3 & $2 \mathrm{C}$ & 6 & 2.5 & 25 & 8.53 & 179 \\
\hline HB-2C-3 & A350LF3 & $2 \mathrm{C}$ & 7 & 2.5 & 25 & 8.53 & 179 \\
\hline$H B-2 C-4$ & A350LF3 & $2 C$ & 8 & 7.5 & 30 & 25.6 & 281 \\
\hline HB-2C-5 & A350LF3 & $2 \mathrm{C}$ & 9 & 7.5 & 30 & 25.6 & 281 \\
\hline $\mathrm{HB}-2 \mathrm{C}-6$ & A350LF3 & $2 \mathrm{C}$ & 10 & 7.5 & 30 & 25.6 & 281 \\
\hline HB-2C-7 & A350LF3 & $2 C$ & 11 & 12.5 & 35 & 42.6 & 337 \\
\hline HB-2C-8 & A350LF3 & $2 \mathrm{C}$ & 12 & 12.5 & 35 & 42.6 & 337 \\
\hline HB-2C-9 & A350LF3 & $2 \mathrm{C}$ & 13 & 12.5 & 35 & 42.6 & 337 \\
\hline $\mathrm{HB}-2 \mathrm{C}-10^{\mathrm{b}}$ & A350LF3 & $2 \mathrm{C}$ & 14 & 2.5 & 25 & 8.53 & 179 \\
\hline $\mathrm{HB}-2 \mathrm{C}-11^{\mathrm{b}}$ & A350LF3 & $2 \mathrm{C}$ & 15 & 7.5 & 30 & 25.6 & 281 \\
\hline HB- $2 \mathrm{C}-12^{b}$ & A350LF3 & $2 W$ & 29 & 7.5 & 30 & 25.6 & 281 \\
\hline $\mathrm{HB}-2 \mathrm{C}-13^{\mathrm{b}}$ & A350LF3 & $2 W$ & 30 & 12.5 & 35 & 42.6 & 337 \\
\hline$H B-2 C-14^{b}$ & A350LF3 & 6 & 1 & 12.5 & 35 & 42.6 & 337 \\
\hline $\mathrm{HB}-2 \mathrm{C}-15^{\mathrm{b}, \mathrm{c}}$ & A350LF3 & 6 & 2 & c & c & & \\
\hline$N W-2-2$ & NWe & $2 W$ & 1 & 7.5 & 30 & 2.48 & 95 \\
\hline NW-2-3 & NW & $2 W$ & 2 & 7.5 & 30 & 2.48 & 95 \\
\hline$N W-2-5$ & NW & $2 W$ & 3 & 12.5 & 35 & 3.62 & 117 \\
\hline NW-2-6 & NW & $2 W$ & 4 & 12.5 & 35 & 3.62 & 117 \\
\hline NW-2-7 & NW & $2 W$ & 5 & 12.5 & 35 & 3.62 & 117 \\
\hline HB-1A-62 & $A 212 B(L T)$ & $2 W$ & 6 & 2.5 & 25 & 1.87 & 83 \\
\hline HB-1A-65 & $A 212 B(L T)$ & $2 W$ & 7 & 2.5 & 25 & 1.87 & 83 \\
\hline
\end{tabular}


Table 6 (cont'd)

\begin{tabular}{|c|c|c|c|c|c|c|c|}
\hline \multirow{2}{*}{ Capsule } & \multirow{2}{*}{ Material } & \multirow{2}{*}{ Key } & \multirow{2}{*}{ Position } & \multicolumn{2}{|c|}{$\begin{array}{l}\text { Removal/testing } \\
\text { schedule }\end{array}$} & \multirow{2}{*}{$\begin{array}{l}\mathrm{dpa} \\
\times 10^{3}\end{array}$} & \multirow{2}{*}{$\underset{{ }^{\circ} \mathrm{F}}{\Delta \mathrm{NDTT}^{\circ}}$} \\
\hline & & & & $\Delta t^{a}$ & $-t^{a}$ & & \\
\hline HB-1A-70 & $\mathrm{A} 212 \mathrm{~B}(\mathrm{LT})$ & $2 W$ & 8 & 2.5 & 25 & 2.00 & 84 \\
\hline $\mathrm{HB}-4 \mathrm{~A}-74$ & $\mathrm{~A} 212 \mathrm{~B}(\mathrm{LT})$ & $2 W$ & 9 & 2.5 & 25 & 1.96 & 82 \\
\hline HB- $4 A-75$ & $A 212 B(L T)$ & $2 W$ & 10 & 2.5 & 25 & 2.00 & 84 \\
\hline HB-4A-79 & $A 212 B(L T)$ & $2 W$ & 11 & 2.5 & 25 & 1.96 & 82 \\
\hline $\mathrm{HB}-4 \mathrm{~A}-80$ & $\mathrm{~A} 212 \mathrm{~B}(\mathrm{LT})$ & $2 W$ & 12 & 2.5 & 25 & 1.99 & 83 \\
\hline IC-A-54 & $\mathrm{A} 212 \mathrm{~B}(\mathrm{LT})$ & $2 W$ & 13 & 7.5 & 30 & 2.71 & 100 \\
\hline IC-A-55 & $\mathrm{A} 212 \mathrm{~B}(\mathrm{LT})$ & $2 W$ & 14 & 7.5 & 30 & 2.71 & 100 \\
\hline IC-A-56 & $\mathrm{A} 212 \mathrm{~B}(\mathrm{LT})$ & $2 W$ & 15 & 7.5 & 30 & 2.71 & 100 \\
\hline IC-A-57 & $\mathrm{A} 212 \mathrm{~B}(\mathrm{LT})$ & $2 W$ & 16 & 12.5 & 35 & 3.85 & 121 \\
\hline IC-A-58 & $\mathrm{A} 212 \mathrm{~B}(\mathrm{LT})$ & $2 W$ & 17 & 12.5 & 35 & 3.85 & 121 \\
\hline IC-A-60 & $\mathrm{A} 212 \mathrm{~B}(\mathrm{LT})$ & $2 W$ & 18 & 12.5 & 35 & 3.85 & 121 \\
\hline LT-2-1 & $\mathrm{A} 212 \mathrm{~B}(\mathrm{LT})$ & $2 W$ & 19 & 7.5 & 30 & 2.48 & 95 \\
\hline LT-2-2 & $\mathrm{A} 212 \mathrm{~B}(\mathrm{LT})$ & $2 W$ & 20 & 7.5 & 30 & 2.48 & 95 \\
\hline LT-2-3 & $\mathrm{A} 212 \mathrm{~B}(\mathrm{LT})$ & $2 W$ & 21 & 12.5 & 35 & 3.62 & 117 \\
\hline LT-2-4 & $\mathrm{A} 212 \mathrm{~B}(\mathrm{LT})$ & $2 W$ & 22 & 12.5 & 35 & 3.62 & 117 \\
\hline LS-1-1 & $\mathrm{A} 212 \mathrm{~B}(\mathrm{LS})$ & $2 W$ & 23 & 7.5 & 30 & 2.13 & 87 \\
\hline LS-1-2 & $A 212 B(L S)$ & $2 W$ & 24 & 7.5 & 30 & 2.09 & 86 \\
\hline LS-1-3 & $\mathrm{A} 212 \mathrm{~B}(\mathrm{LS})$ & $2 W$ & 25 & 7.5 & 30 & 2.09 & 86 \\
\hline LS-4-4 & $A 212 B(L S)$ & $2 W$ & 26 & 12.5 & 35 & 3.23 & 110 \\
\hline LS-4-5 & $\mathrm{A} 212 \mathrm{~B}(\mathrm{LS})$ & $2 W$ & 27 & 12.5 & 35 & 3.23 & 110 \\
\hline LS-4-6 & $\mathrm{A} 212 \mathrm{~B}(\mathrm{LS})$ & $2 W$ & 28 & 12.5 & 35 & 3.27 & 111 \\
\hline SW-6-4 & SWIGW & 6 & 6 & 2.5 & 25 & 0.46 & 32 \\
\hline SW-6-5 & SWIGW & 6 & 7 & 2.5 & 25 & 0.46 & 32 \\
\hline SW-6-6 & SWIGW & 6 & 8 & 2.5 & 25 & 0.46 & 32 \\
\hline SW-7-1 & SWIGW & 7 & 1 & 12.5 & 35 & 1.07 & 56 \\
\hline SW-7-2 & SW/GW & 7 & 2 & 12.5 & 35 & 1.07 & 56 \\
\hline SW-7-3 & SWIGW & 7 & 3 & 12.5 & 35 & 1.07 & 56 \\
\hline$S W-4-10$ & SW/GW & 4 & 2 & 7.5 & 30 & 2.72 & 100 \\
\hline
\end{tabular}


Table 6 (cont'd)

\begin{tabular}{|c|c|c|c|c|c|c|c|}
\hline \multirow{2}{*}{ Capsule } & \multirow{2}{*}{ Material } & \multirow{2}{*}{ Key } & \multirow{2}{*}{ Position } & \multicolumn{2}{|c|}{$\begin{array}{l}\text { Removal/testing } \\
\text { schedule }\end{array}$} & \multirow{2}{*}{$\begin{array}{l}\mathrm{dpa}^{d} \\
\times 10^{3}\end{array}$} & \multirow{2}{*}{$\underset{{ }^{\circ} \mathrm{F}}{\Delta N T^{\mathrm{d}}}$} \\
\hline & & & & $\Delta t^{a}$ & $\sim t^{a}$ & & \\
\hline SW-4-11 & SW/GW & 4 & 3 & 7.5 & 30 & 3.04 & 106 \\
\hline SW-4-12 & SWIGW & 4 & 4 & 7.5 & 30 & 2.72 & 100 \\
\hline
\end{tabular}

'EFPY(100 MW)

${ }^{b}$ Capsules containing half-sized CVN specimens.

'Removal time dependent on results from earlier removals.

Total accumulated value.

'Nozzle weld.

'Seam weld/girth weld.

\section{0 - DOSIMETRY}

\subsection{Type and Location of Dosimeters}

As mentioned in Sect. 4.3, all capsules containing CVN specimens will have a stainless steel dosimeter located in the aligned vee grooves. Stainless steel of the composition described in Refs. 2 and 4 is appropriate for measuring the fast ( $E>0.1 \mathrm{MeV}$ ) neutron flux.

Some of the capsules in Keys 2, 3, 4, and 7 will be dedicated to dosimetry for the first fuel cycle or so and will contain materials appropriate for measuring thermal and nonthermal neutron fluxes and gamma fluxes. Positions 1 and 4 in Key $2 \mathrm{C}$, Positions 8 and 32 in Key 2W, Positions 3, 8, and 10 in Keys 3 and 4, and Position 1 in Key 7, will be used for this purpose. Irradiation of these capsules for one or two full-power fuel cycles. will be sufficient. Upon removal, these capsules will be replaced with the standard capsules specified in Table 6.

Because Keys 2 and 4 will be located inboard of the vessel inner surface by several inches, special "wire"-type dosimeters will be located at the HB-2 nozzle corner and weld and at the HB-4 nozzle corner. The specific locations are indicated in Figs. 4-7. These dosimeters will contain appropriate materials for measuring fast $(E>0.1 \mathrm{MeV})$ neutron fluxes and gamma fluxes and will require only one or two full-power fuel cycles of irradiation.

The dosimetry data obtained from the dosimetry-dedicated capsules in Keys 2, 3, 4, and 7 will be used for correlating the embrittlement data $[\triangle N D T T$ vs dpa $(n+y)]$, and the data from the "wire" dosimeters will be used for normalizing the calculated neutron and gamma fluxes close to the areas of assumed flaws in the vessel wall. These fluxes and the updated embrittlement correlation will be used to calculate flaw-tip fracture toughness in the probabilistic fracture-mechanics analysis, which is performed to estimate vessel life expectancy. 


\subsection{Dosimetry Materials}

\subsubsection{Capsule dosimeters}

All existing and new capsules containing CVN specimens will include a stainless steel (type 304) dosimeter in the aligned CVN specimen vee grooves for measuring the fast neutron flux. The specified dosimetry material contains ${ }^{58} \mathrm{Ni}$ and ${ }^{54} \mathrm{Fe}$, which result in the unstable isotopes ${ }^{58} \mathrm{Co}$ and ${ }^{54} \mathrm{Mn}$ from the reactions ${ }^{58} \mathrm{Ni}(n, p){ }^{58} \mathrm{Co}$, and ${ }^{54} \mathrm{Fe}(n, p){ }^{54} \mathrm{Mn}$.

The dosimetry-dedicated capsules will be similar to those described in Ref. 8 and will contain gadolinium-shielded ${ }^{59} \mathrm{Co}, \mathrm{Ni}, \mathrm{Fe},{ }^{237} \mathrm{~Np}$ and $\mathrm{Be}$, and bare ${ }^{59} \mathrm{Co}, \mathrm{Ni}$ and $\mathrm{Fe} .{ }^{59} \mathrm{Co}$ is used for determining the thermal neutron flux; ${ }^{9} \mathrm{Be},{ }^{58} \mathrm{Ni}$. Fe, and ${ }^{237} \mathrm{~Np}$ are used for determining the fast neutron flux; and ${ }^{9} \mathrm{Be}$ and ${ }^{237} \mathrm{~Np}$ are used for determining the gamma flux. Photoneutron reactions produce helium in beryllium, and photofission takes place with ${ }^{237} \mathrm{~Np}[9]$.

All of the above dosimetry materials were used successfully in the HFIR DOS series of experiments $[8,9,10]$ for the measurements indicated above.

\subsection{2 "Wire" Dosimeters}

The wire-type dosimeters will contain the same dosimetry materials as specified for the dosimetry-dedicated capsules. However, because of the steep gradients normal to the beam-tube surface in the vicinity of the nozzle corners, two irradiations may be necessary to obtain the thermal neutron flux. For the first irradiation, all dosimetry materials in the wire dosimeters at the zero-degree (top-most) positions, including $\mathrm{Ni}$ and $\mathrm{Co}$, would be shielded with gadolinium. All other wire dosimeters would include bare $\mathrm{Ni}$ and $\mathrm{Co}$, as well. The second irradiation would include only the dosimeter at the zerodegree location and only $\mathrm{Ni}$ and $\mathrm{Co}$, both of which would be bare. This procedure will allow all dosimetry materials in the wire dosimeters to be placed at the "same" radial location relative to the longitudinal axis of the beam tube.

\subsection{Evaluation of Dosimetry Data}

All activities can be counted at ORNL. Measurement of the helium concentration in beryllium takes special equipment that exists at Pacific Northwest National Laboratory (PNNL). This equipment and PNNL personnel were used for helium measurements during the HFIR DOS experiments $[8,9]$.

The experimental data are used to normalize calculated neutron and gamma fluxes, including both magnitude and energy spectrum. The normalization procedure is discussed in Ref. 9, calculated fluxes and dpa rates are included in Refs. 14 and 15, and calculated dpa rates are also included in this report (Tables 2 and 4 and Appendix A).

\subsection{Summary and Conclusions}

Increasing the design life of the HFIR vessel to 50 EFPY $(100 \mathrm{MW})$ and the increased dose rate at the beam tube nozzle areas around HB-2 and HB-4, a result of increasing the diameters of the respective beam tubes, require augmentation of the vesselmaterials surveillance program. This has been accomplished by adding HB-2 nozzle material (A35OLF3), which will receive the highest dose and which is available from an original nozzle forging prolongation, and by positioning specimens so as to achieve 
reasonable lead times and appropriate ratios of neutron to gamma dpa rates. The dosimetry has also been enhanced in order that thermal neutrons and gamma fluxes, as well as fast-neutron fluxes, can be measured at the specimens and at critical locations of the vessel wall. As an aid in the selection of locations for surveillance specimens and dosimeters, two- and three-dimensional neutron- and gamma-flux/dpa transport calculations were made for each beam-tube region. Normalization was accomplished using previous dosimetry data.

The surveillance data will be added to the $\triangle$ NDTT vs dpa data base to improve the accuracy of the correlation, and "vessel" dosimetry will be used to normalize the calculated dpa rates in the vessel wall. The correlation and dpa rates are used in the calculation of the probability of vessel failure. This procedure, combined with periodic hydrostatic proof testing will provide an adequate means of "continuously" evaluating the integrity of the vessel.

\section{REFERENCES}

1. L. E. Steele and J. R. Hawthorne, Effect of Irradiation Temperature on the Neutron-Induced Changes in Notch Ductility of Pressure-Vessel Steels, NRL Report 5629, Naval Res. Lab., Washington, D.C., June 28, 1961.

2. J. R. McWherter, R. E. Schappel, and J. R. McGuffey, HFIR Pressure Vessel and Structural Components Material Surveillance Program, ORNL/TM-1372, Union Carbide Corp. Nuclear Div., Oak Ridge Natl. Lab., January 1966.

3. W. S. Pellini, L. E. Steele, and J. R. Hawthorne, Analysis of Engineering and Basic Research Aspects of Neutron Embrittlement of Steels, NRL Report 5780, April 17, 1962; also, Weld. J., Research Supplement, 41(10), p. 465S-467S, October 1962.

4. R. D. Cheverton, J. G. Merkle, and R. K. Nanstad, Eds, Evaluation of HFIR Pressure-Vessel Integrity Considering Radiation Embrittlement, ORNL/TM10444, April 1988.

5. R. D. Cheverton, et al., HFIR Pressure Vessel and Structural Components Materials Surveillance Program, Supplement 1, ORNL/TM-1372/S1, October 1987.

6. ASTM Standards E-185, 1979 and 1998 issues.

7. R. D. Cheverton and R. K. Nanstad, Evaluation of HFIR Vessel Surveillance Data and Hydro-Test Conditions, ORNL/TM-12758, August 5, 1994.

8. K. Farrell, et. al., The DOS 1 Neutron Dosimetry Experiment at the HB-4-A Key 7 Surveillance Site on the HFIR Pressure Vessel, ORNL/TM-12511, January 1994.

9. I. Remec and F.B.K. Kam, Neutron Spectra at Different High Flux Isotope Reactor (HFIR) Pressure Vessel Surveillance Locations, Oak Ridge National Lab, NUREG/CR-6117 (ORNL/TM-12484), December 1993. 
10. I. Remec, J. A. Wang, F.B.K. Kam, K. Farrell, Effects of Gamma-Induced Displacements on HFIR Pressure Vessel Materials, Journal of Nuclear Materials 217 (1994) 258-268.

11. R. D. Cheverton, An Evaluation of Life Extension of the HFIR Pressure Vessel, Supplement 1, ORNL/TM-12877/S1, August 1996.

12. M. B. Farrar, et al., DCM-HFIR-197M, HFIR Beam Experiment Facilities Upgrade, August 1998.

13. R. D. Cheverton and T. L. Dickson, HFIR Vessel Life Extension with Enlarged HB-2 and HB-4 Beam Tubes, ORNL/TM-13698, December 1998.

14. E. D. Blakeman, Neutron and Gamma. Fluxes and dpa Rates for the HFIR Vessel Beltline Region (Present and Upgrade Designs), ORNL/TM-12693, Oak Ridge National Laboratory, in preparation.

15. E. D. Blakeman, Neutron and Gamma Fluxes and dpa Rates for the HFIR Vessel Beltline Region (Present and Upgrade Designs) Supplement 1, ORNLTM12693/S1, Oak Ridge National Laboratory, in preparation.

16. L. K. Mansur and K. Farrell, Journal of Nuclear Materials, 170 (1990) 236-245.

17. R. E. Stoller, K. Farrell, L. K. Mansur, ORNL/NRC/LTR-96/3, February 1996.

18. D. E. Alexander, et al., Journal of Nuclear Materials, 228 (1996) 68-76.

19. Odette, G. R., Lucas, G. E., Klingensmith, D., "Irradiation Hardening of Pressure Vessel Steels at $60^{\circ} \mathrm{C}$ : The Role of Thermal Neutrons and Boron" Effects of Radiation on Materials: 18th International Symposium, ASTM-STP-1325, R. K. Nanstad, M. L. Hamilton, F. A. Garner, and A. S. Kumar Eds., American Society for Testing and Materials, Philadelphia, PA, 1997.

20. ASTM E-185-98 para. 7.2.1.

21. K. Farrell and R. E. Stoller, ORNL, report in preparation.

22. R. G. Berggren, W. J. Stelzman, and T. N. Jones, USAEC, ORNL-4097, January 1967.

23. G. D. Whitman, G. C. Robinson, and A. W. Savolainen, Eds., Technology of Steel Pressure Vessels for Water-Cooled Nuclear Reactors, ORNL/NSIC-21, Oak Ridge National Lab, December 1967.

24. D. N. Braski and K. Farrell, Annealing Experiments, Sect. D.6.2.6 in Evaluation of HFIR Pressure-Vessel Integrity Considering Radiation Embrittlement, ORNL/TM-10444, R. D. Cheverton, J. G. Merkle, R. K. Nanstad, Eds., April 1988.

25. B. V. Karlekar and R. M. Desmond, Engineering Heat Transfer, West Publishing Co., NY, 1977. 


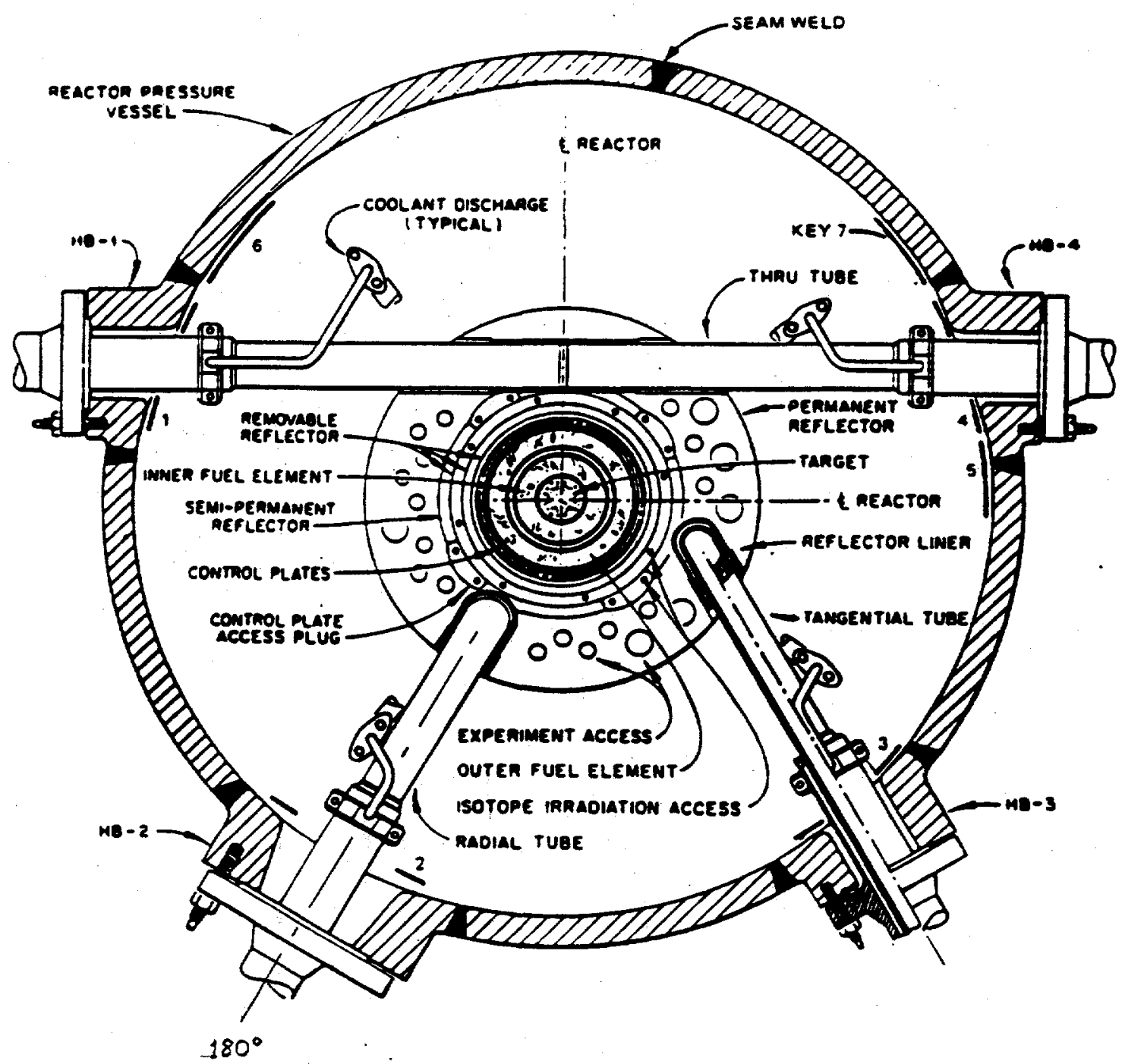

Fig. 1. Cross section of HFIR core and pressure vessel at core horizontal midplane showing location of surveillance specimens (Keys 1-7). 
ORNLITM-1372/S2

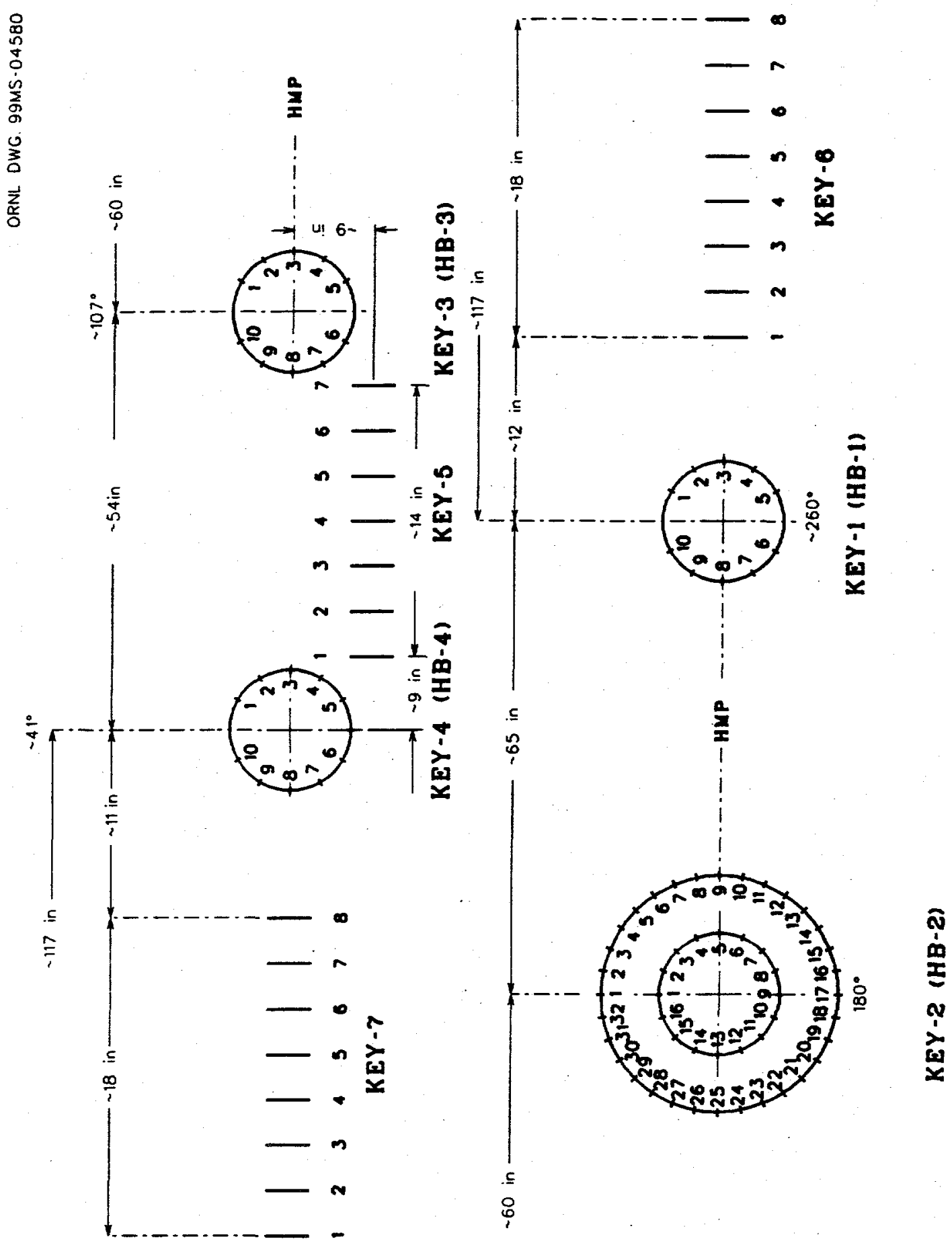

Fig. 2. Developed view of inner surface of HFIR vessel showing locations of surveillance-specimen capsules. 

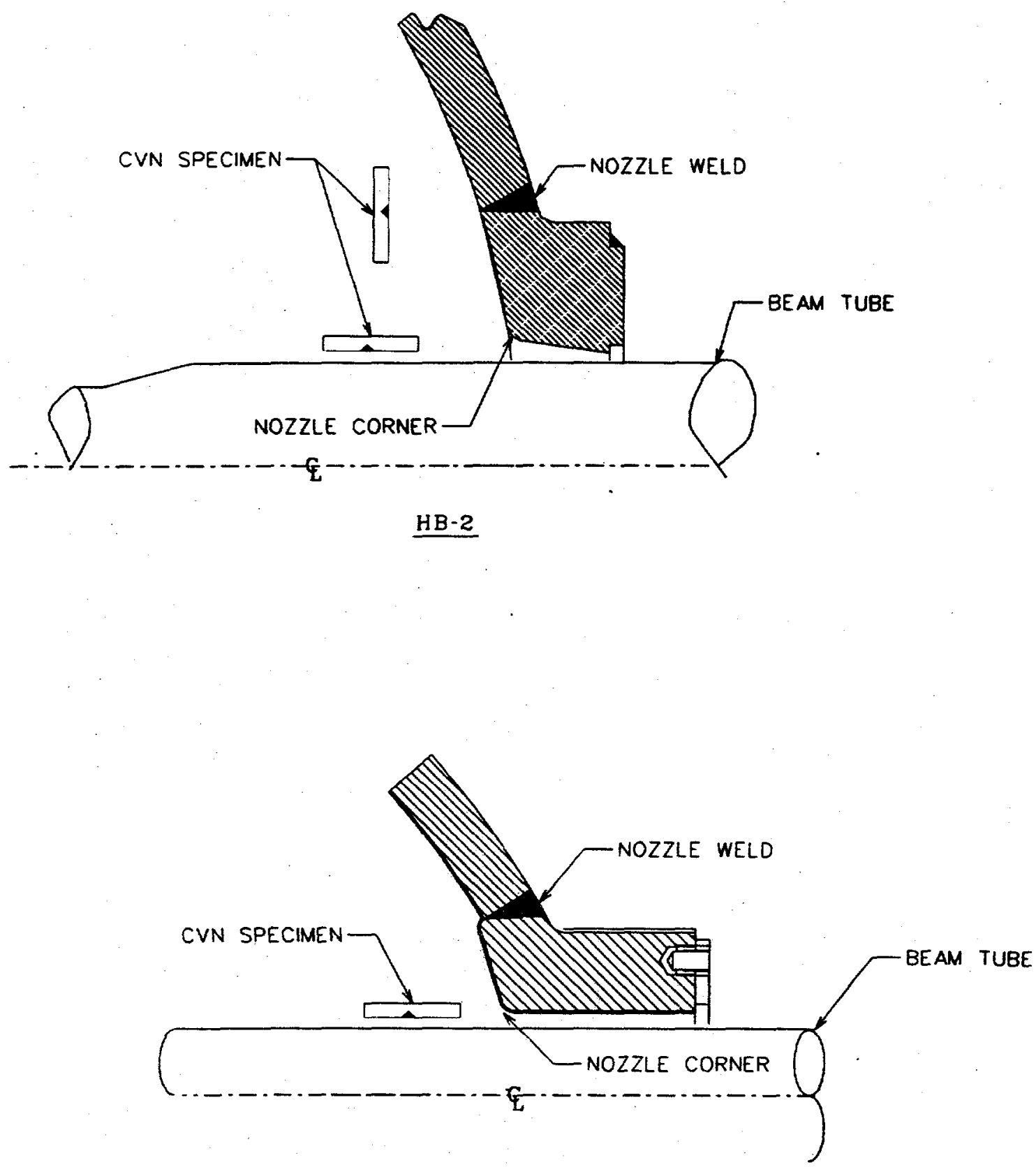

HB-4

Fig. 3. Schematic of location and orientation of CVN specimens for upgrade design. 


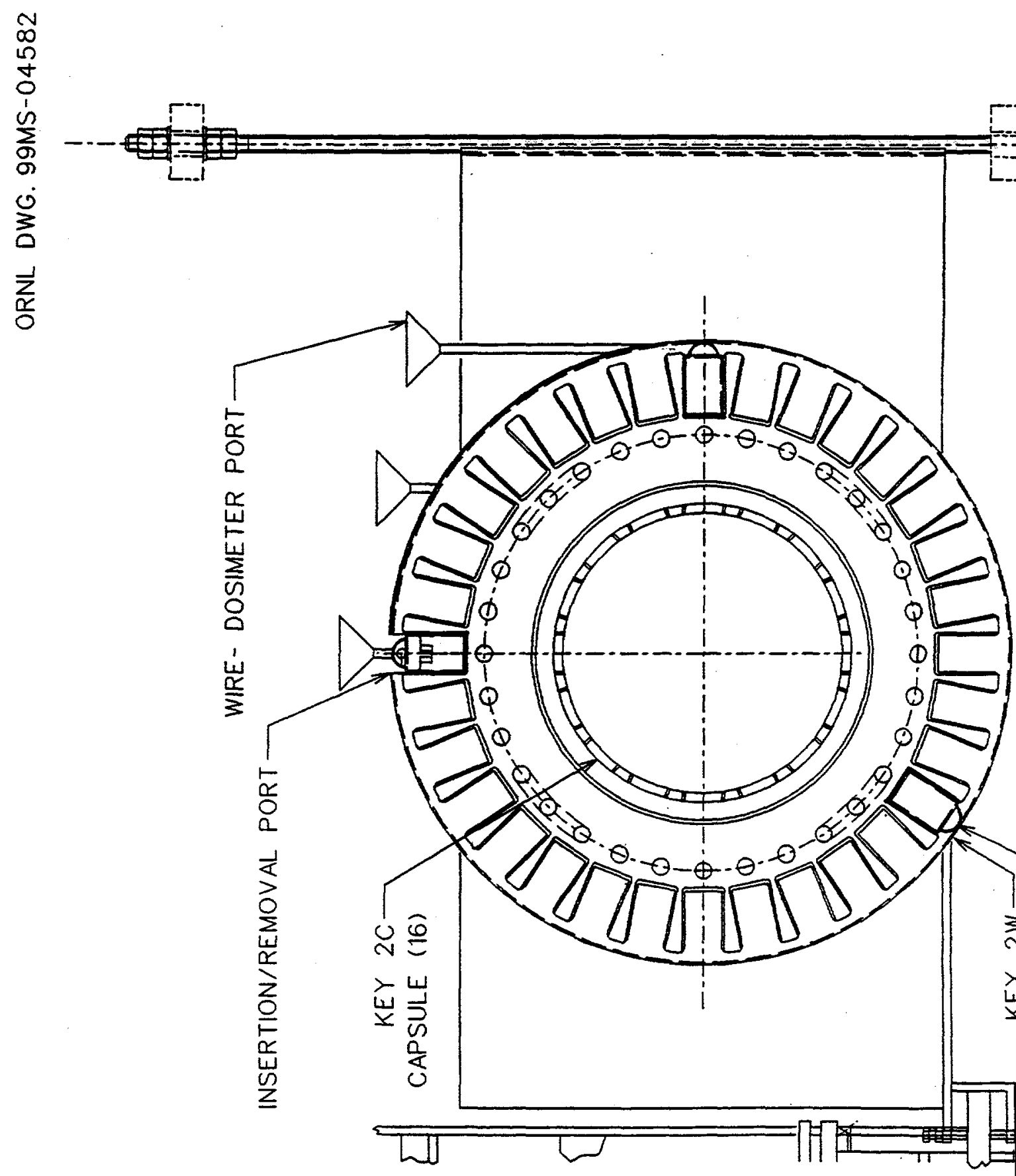




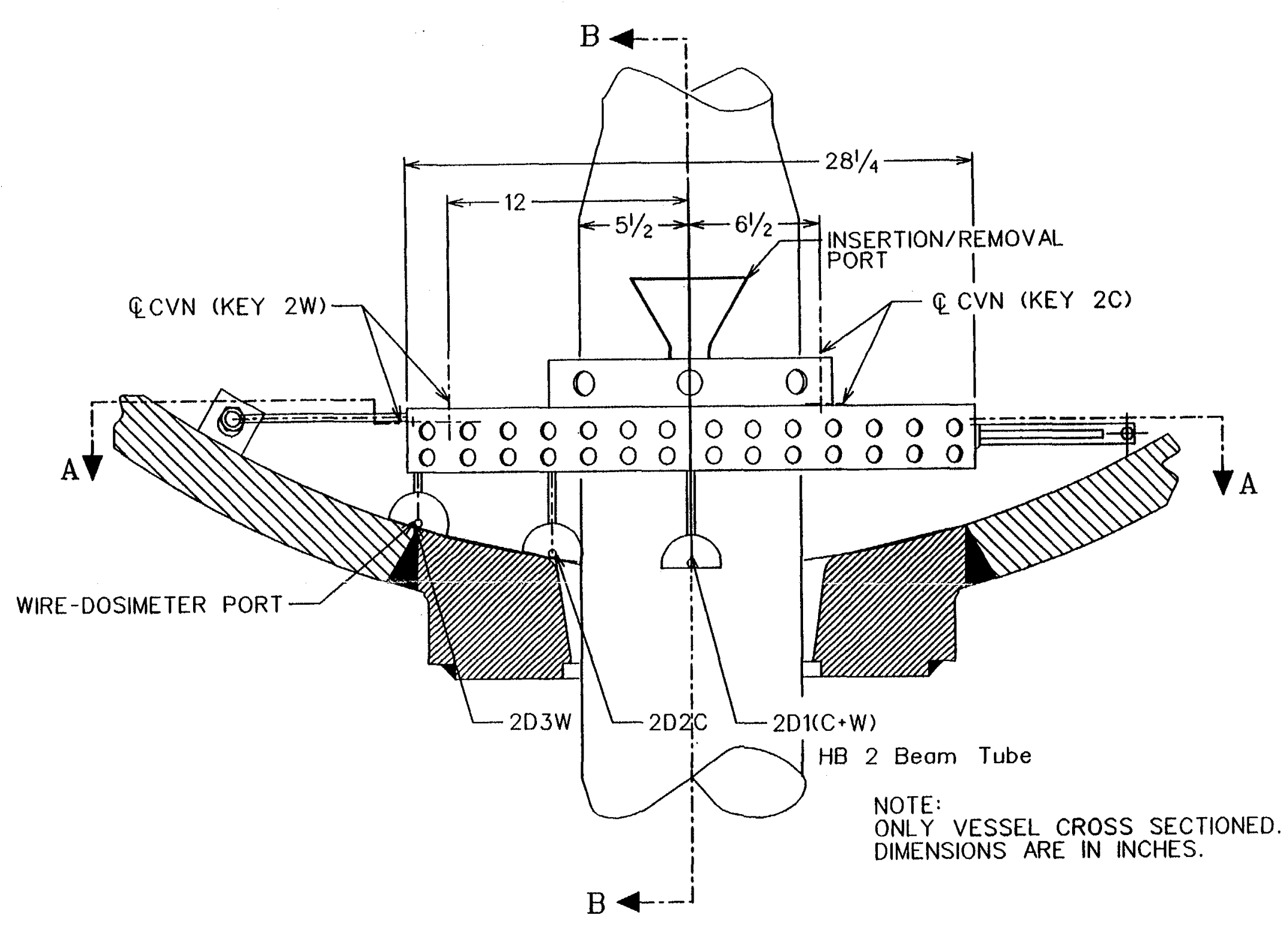

Fig. 4. Assembly and installation of the Key 2 surveillance-specimen capsule mount. 


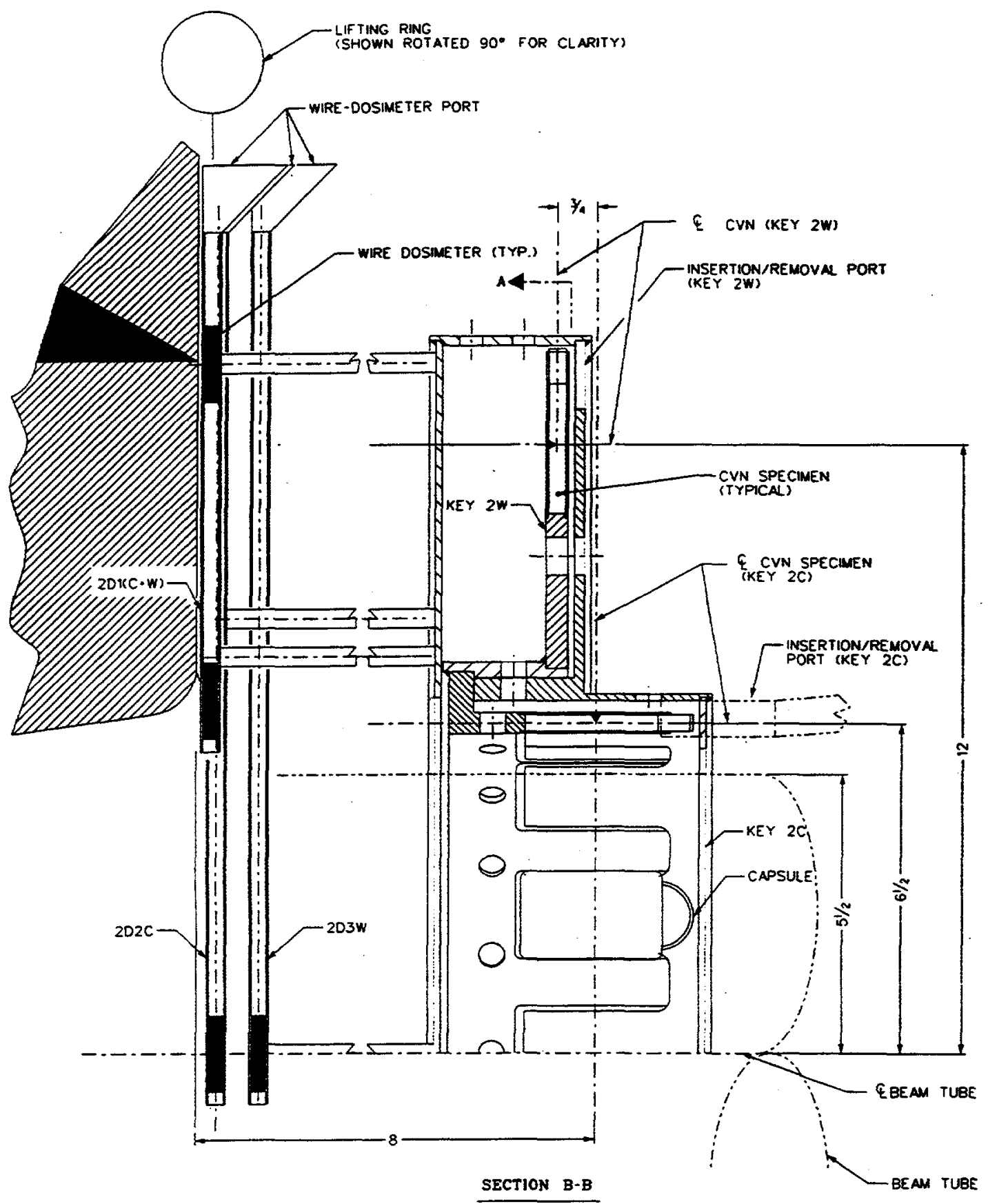

Fig. 5. Vertical cross-section of Key 2 capsule-mount assembly. 


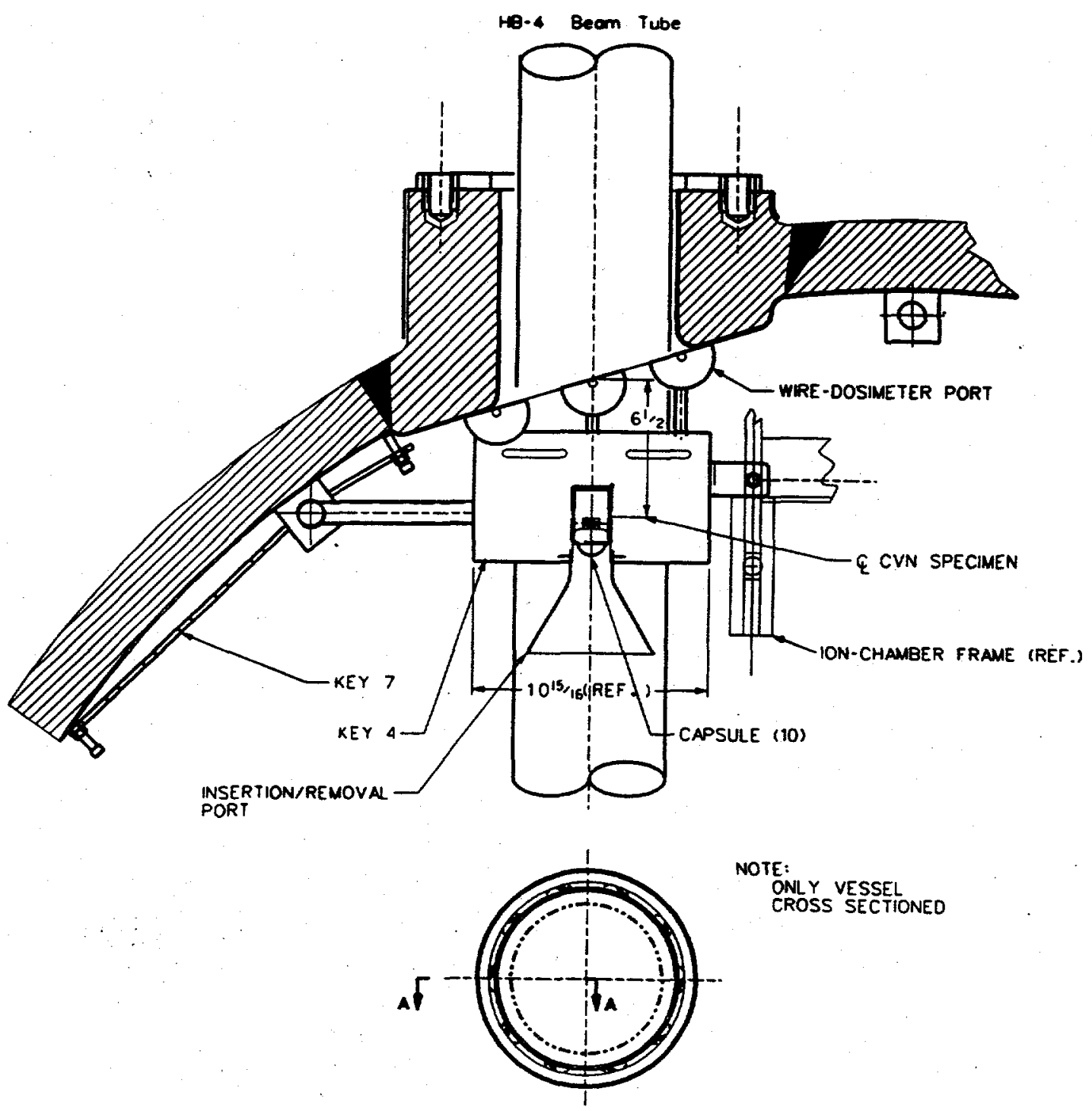

Fig. 6. Assembly and installation of the Key 4 surveillance-specimen capsule mount. 


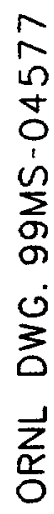

ORNLTM-1372/S2

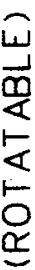

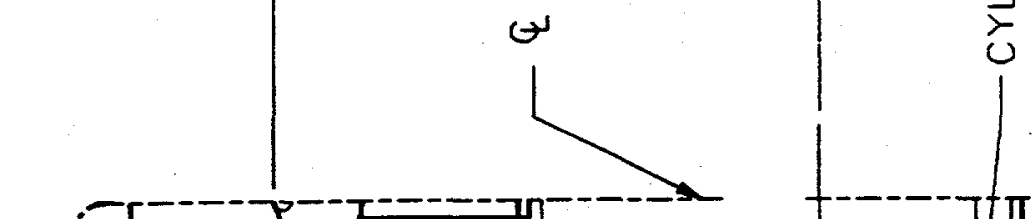

岗

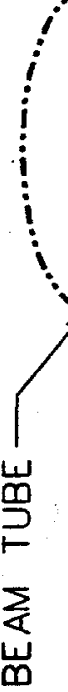

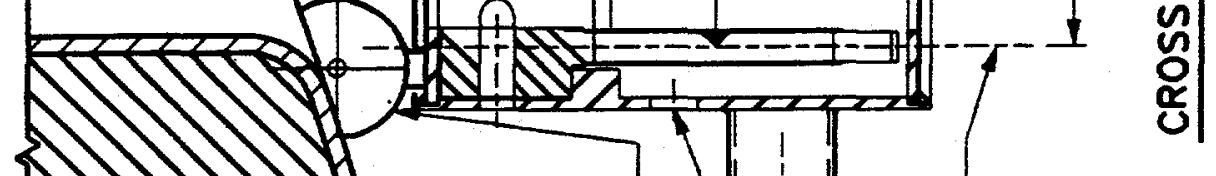

Fig. 7. Horizontal cross section of Key 4 capsule-mount assembly. 
ORNL/TM-1372/S2

\section{APPENDIX A}

\section{CALCULATED NEUTRON AND GAMMA FLUXES AND dp̉a VALUES FOR CRITICAL AREAS OF THE HFIR VESSEL}

Neutron and gamma fluxes and dpa rates for the beam-tube nozzle regions have been calculated as a part of the HFIR vessel life-extension studies and are reported in Refs. 14 and 15. Data particularly germane to the vessel-material surveillance program are included in this appendix. The basic geometry/materials models are depicted in Figs. A1 through A5, and iso-plots of neutron, gamma, and neutron plus gamma dpa values, the ratio of neutron dpa to gamma dpa, and the neutron and gamma fluxes above 1.0 MeV are given in Figs. A6-A11 (HB-1 and present design of $\mathrm{HB}-4$, which are mirror images), Figs. A12-A17 (HB-2 present design), Fig. 18-23 (HB-2 new design), Figs. A24-A29 (HB-3), and Figs. A30-A35 (HB-4 new design). All calculated values of dpa were normalized on the basis of dosimetry data included in Ref. 10. Selected values of dpa are included in Tables 1, 2, and 4. 


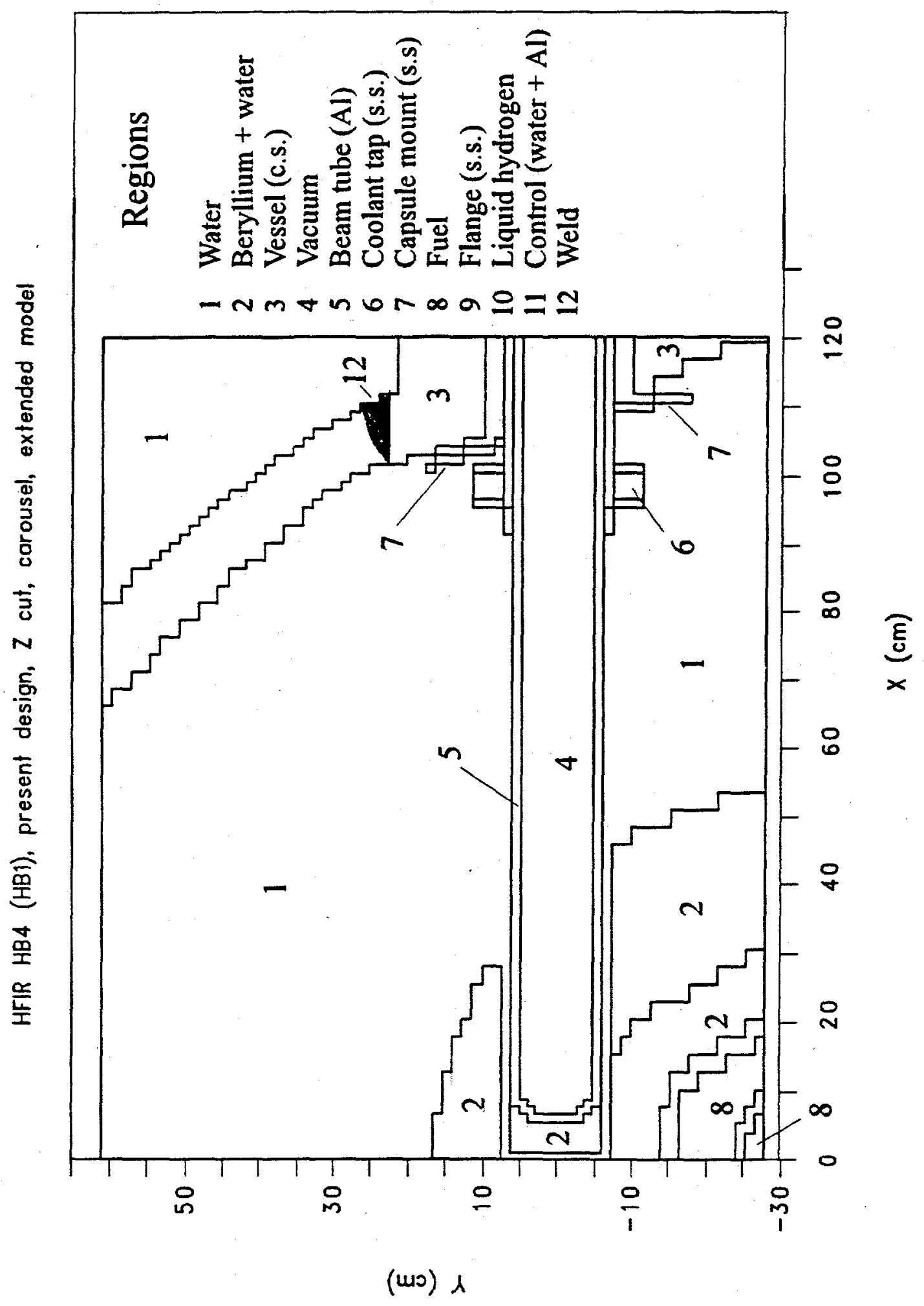

Fig. A1. Geometry/material model for HB-1 and HB-4 (present design; HB-4 shown; HB-1 is mirror image). 
HFIR HB2, 4 in. diometer, present design

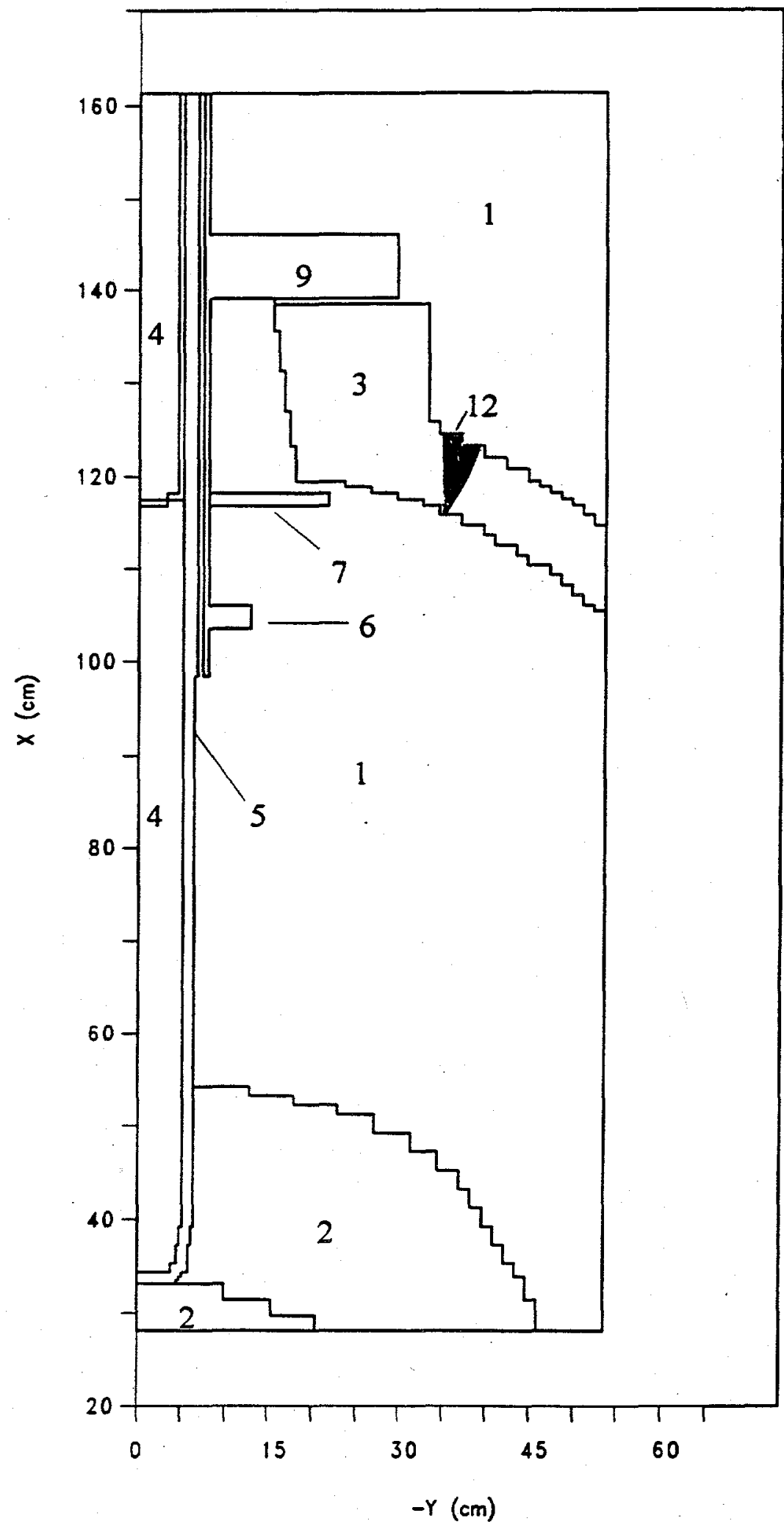

Fig. A2. Geometry/material model for HB-2 (present design). 
HFIR HB2, 9 in. dia., modified design w/ carousel (rev)

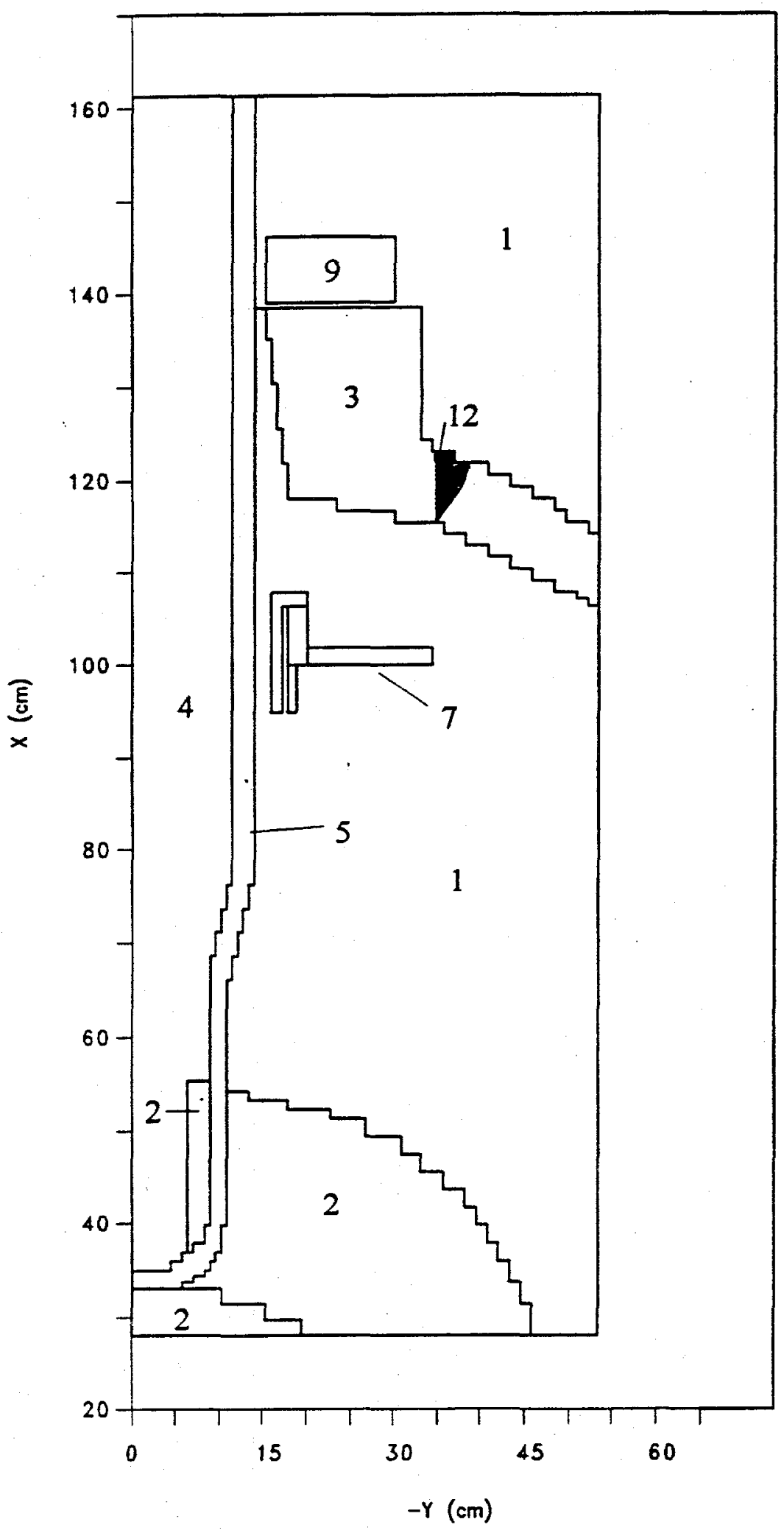

Fig. A3. Geometry/material model for HB-2 (new design). 


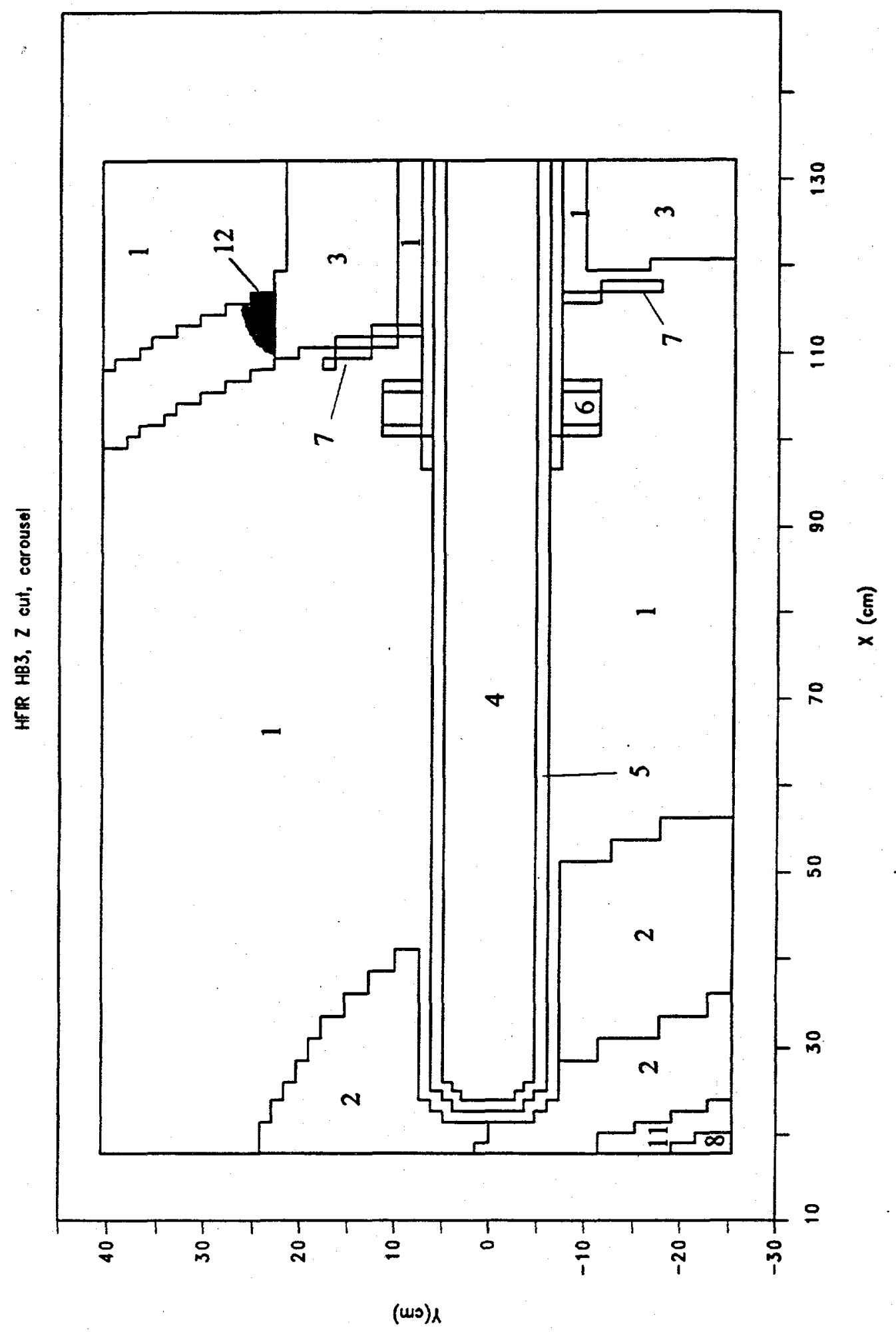

Fig. A4. Geometry/material model for HB-3. 


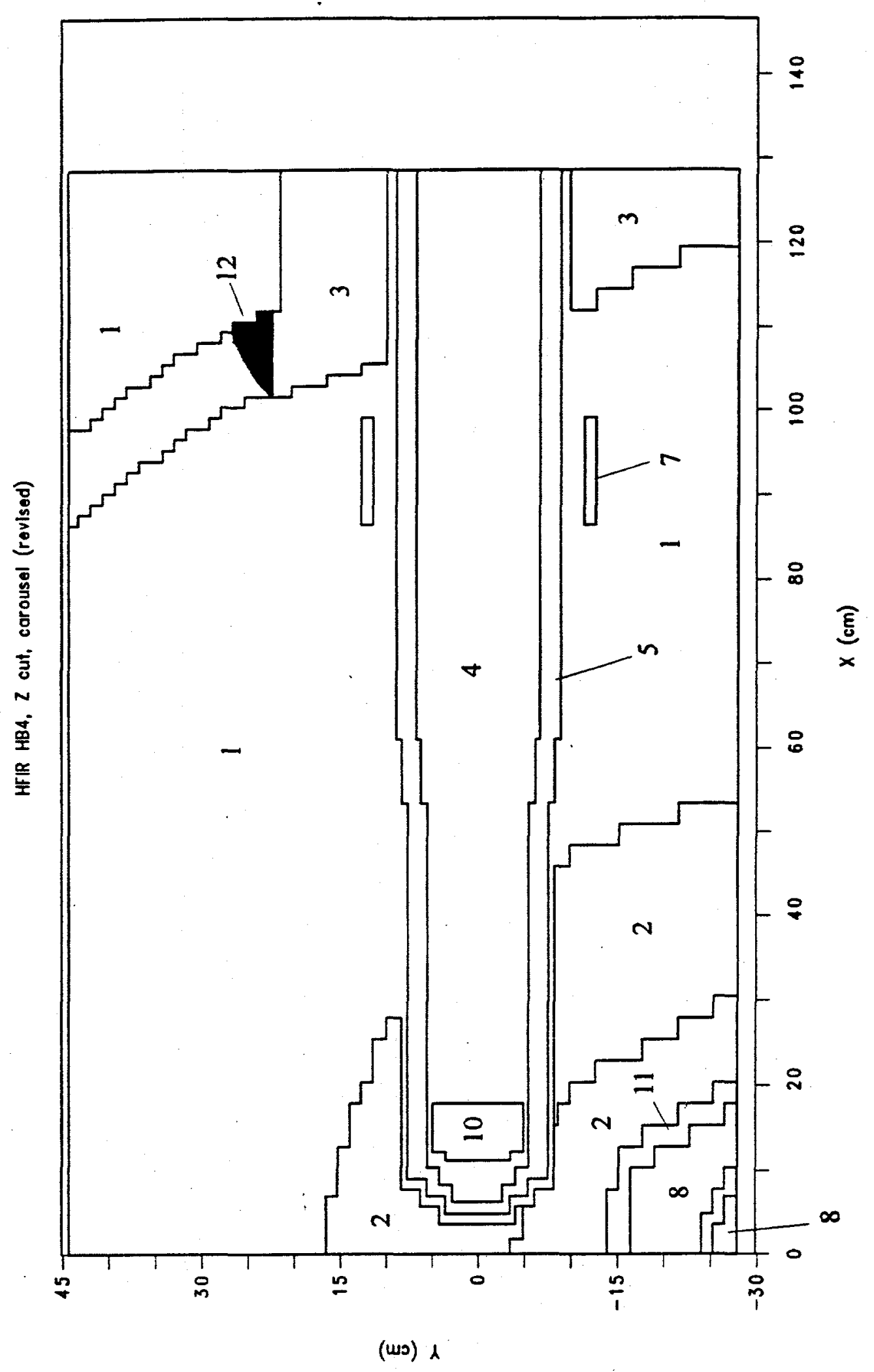

Fig. A5. Geometry/material model for HB-4 (new design). 


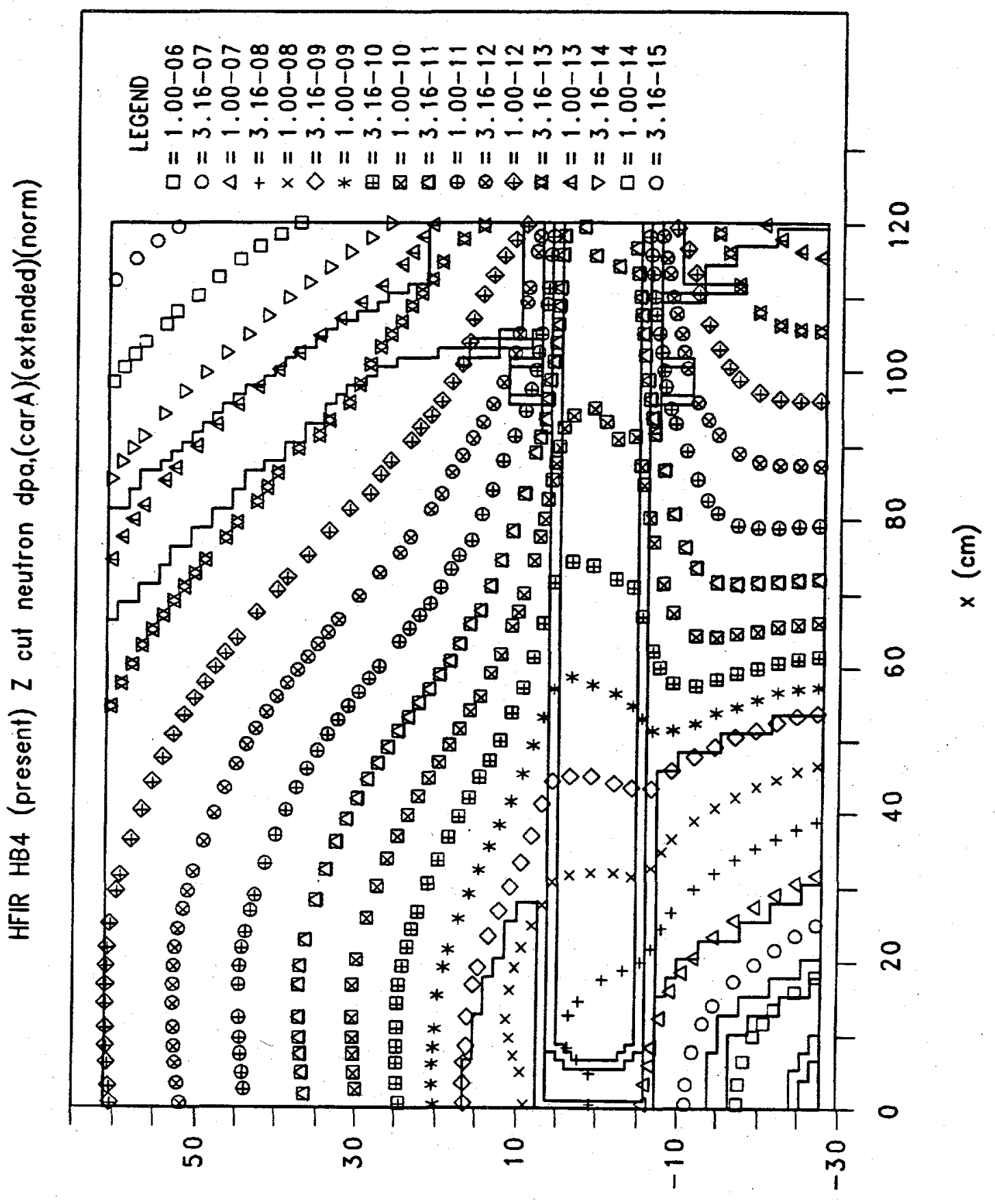

(wo) $k$

Fig. A6. Neutron iso-dpa for HB-1 and HB-4 (present design; HB-4 shown; HB-1 is mirror image). 


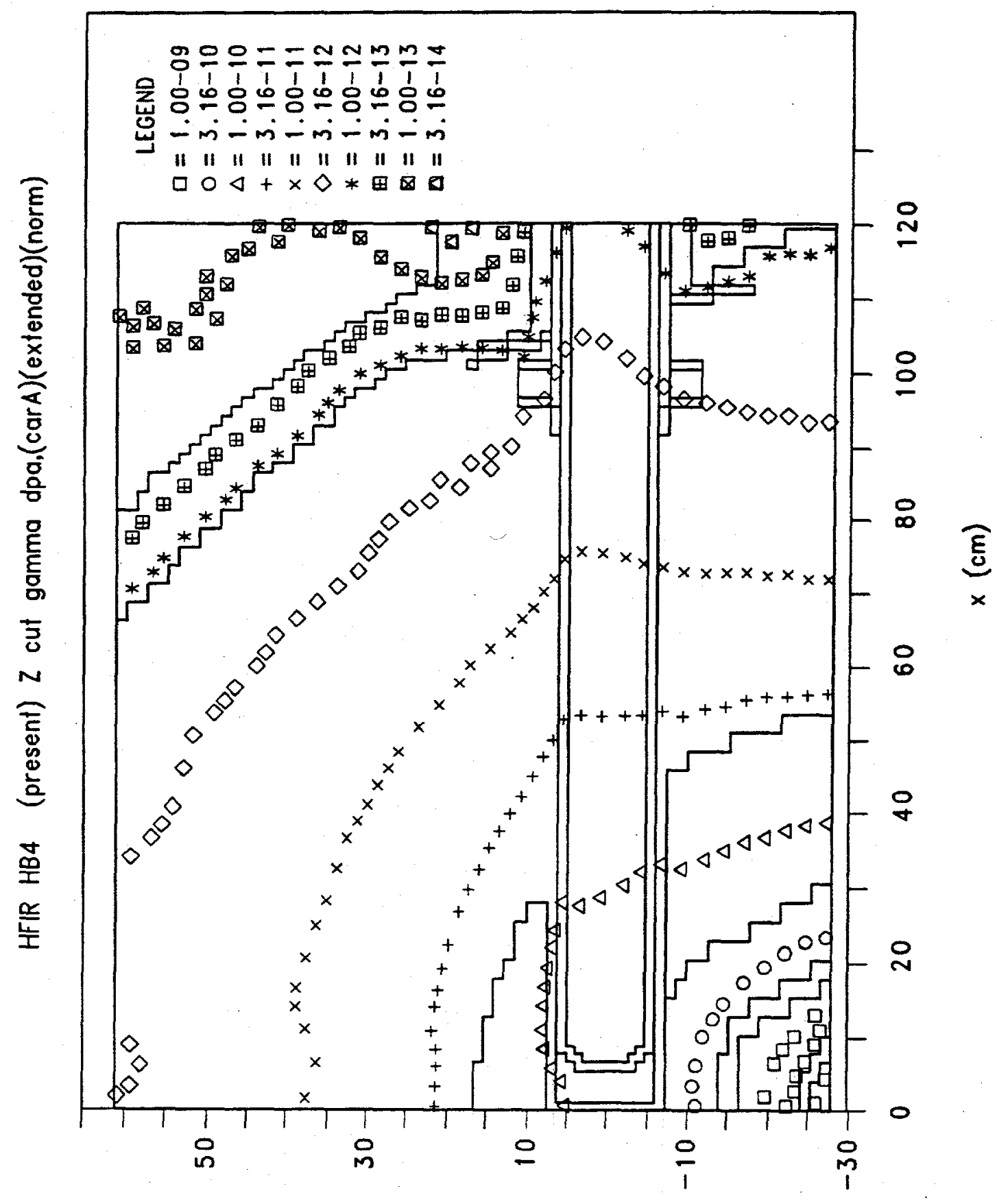

(wo) 1

Fig. A7. Gamma iso dpa for HB-1 and HB-4 (present design; HB-4 shown; HB-1 is mirror image). 


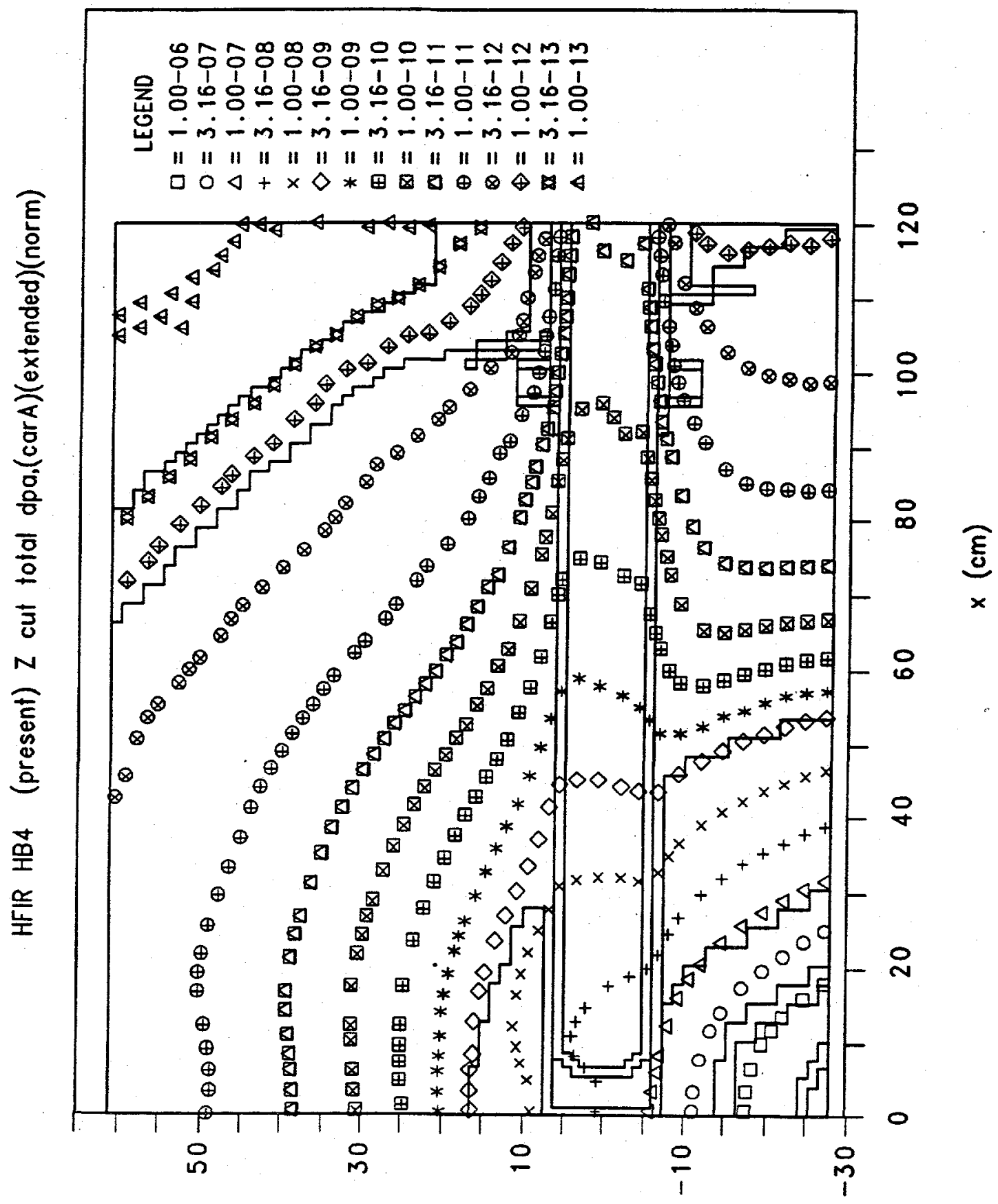

(wo) $\wedge$

Fig. A8. Neutron plus gamma iso-dpa for $\mathrm{HB}-1$ and $\mathrm{HB}-4$ (present design; $\mathrm{HB}-4$ shown; HB-1 is mirror image). 


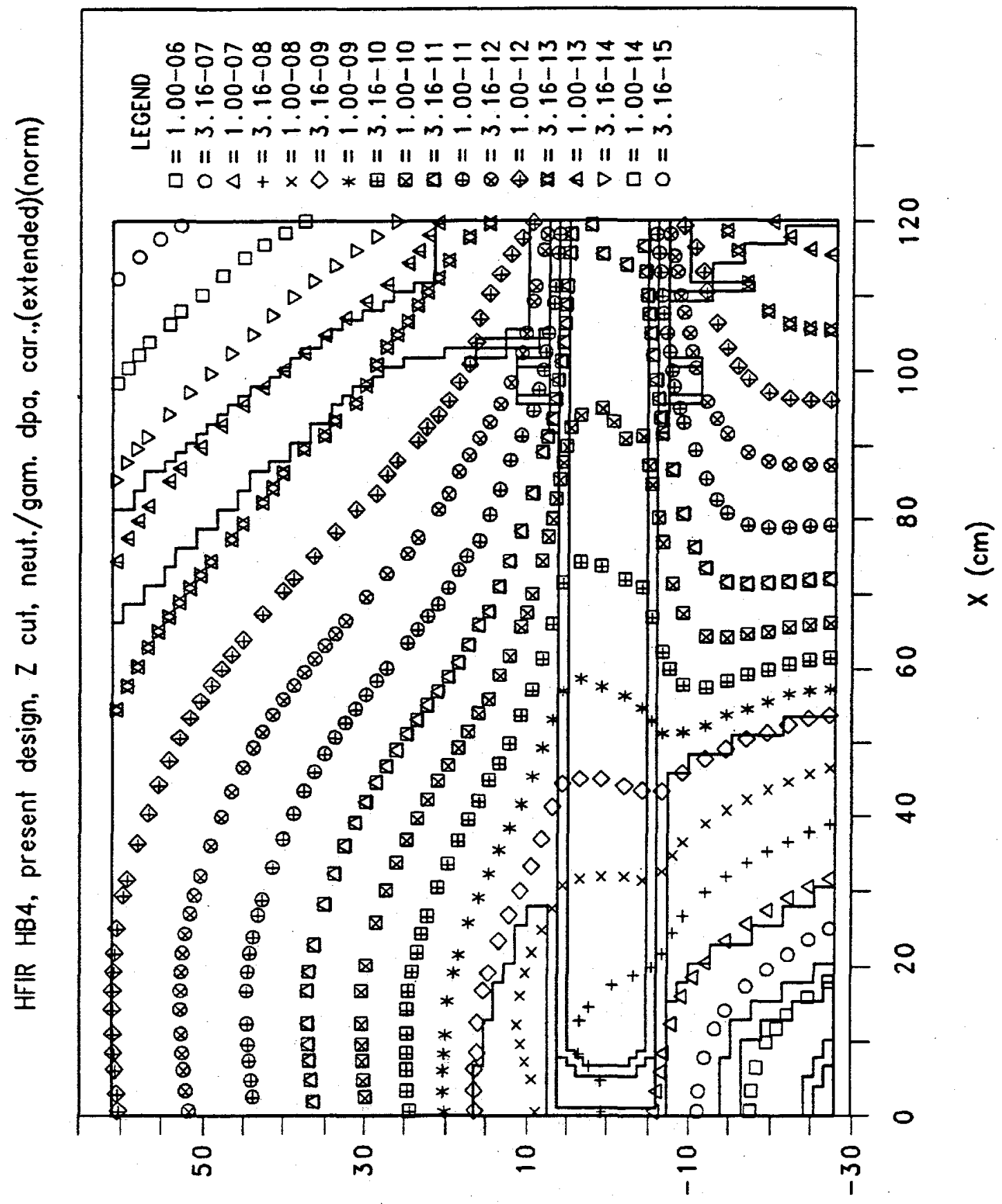

(wo) $\lambda$

Fig. A9. Ratio of neutron to gamma iso dpa for HB-1 and HB-4 (present design; HB-4 shown; HB-1 is mirror image). 
HFIR HB4 (present) $Z$ cut neutron flux $>\mathbb{M e V}$, (carA)(extended)(norm)

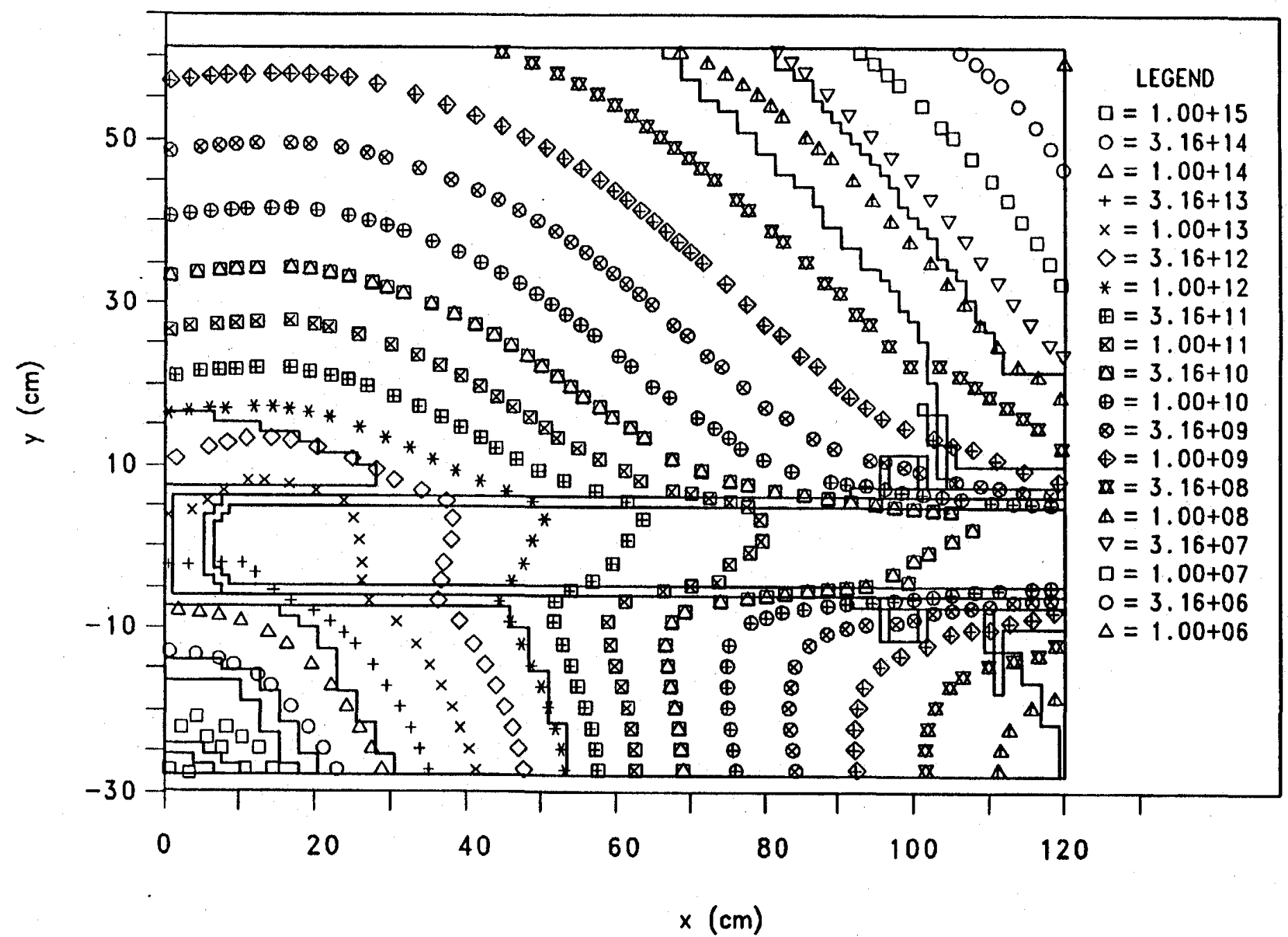




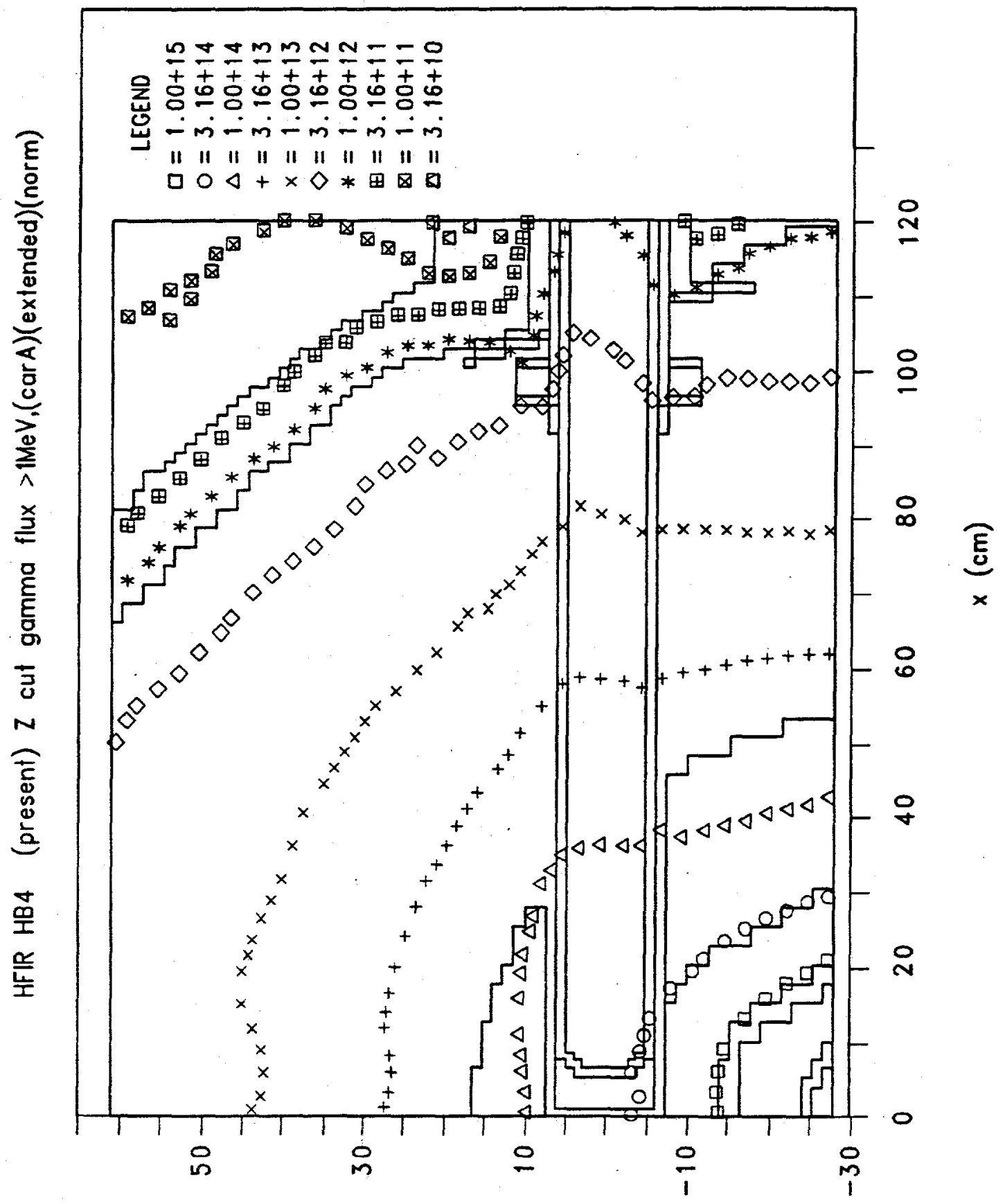

(wo) 1

Fig. A11. Gamma iso-flux (E $>1 \mathrm{MeV}$ ) for HB-1 and HB-4 (present design; HB-4 shown; HB-1 is mirror image). 
HFIR HB2 present (4 in.) $100 \mathrm{NW} 84 \mathrm{gp}$, neutron-dpo (norm)

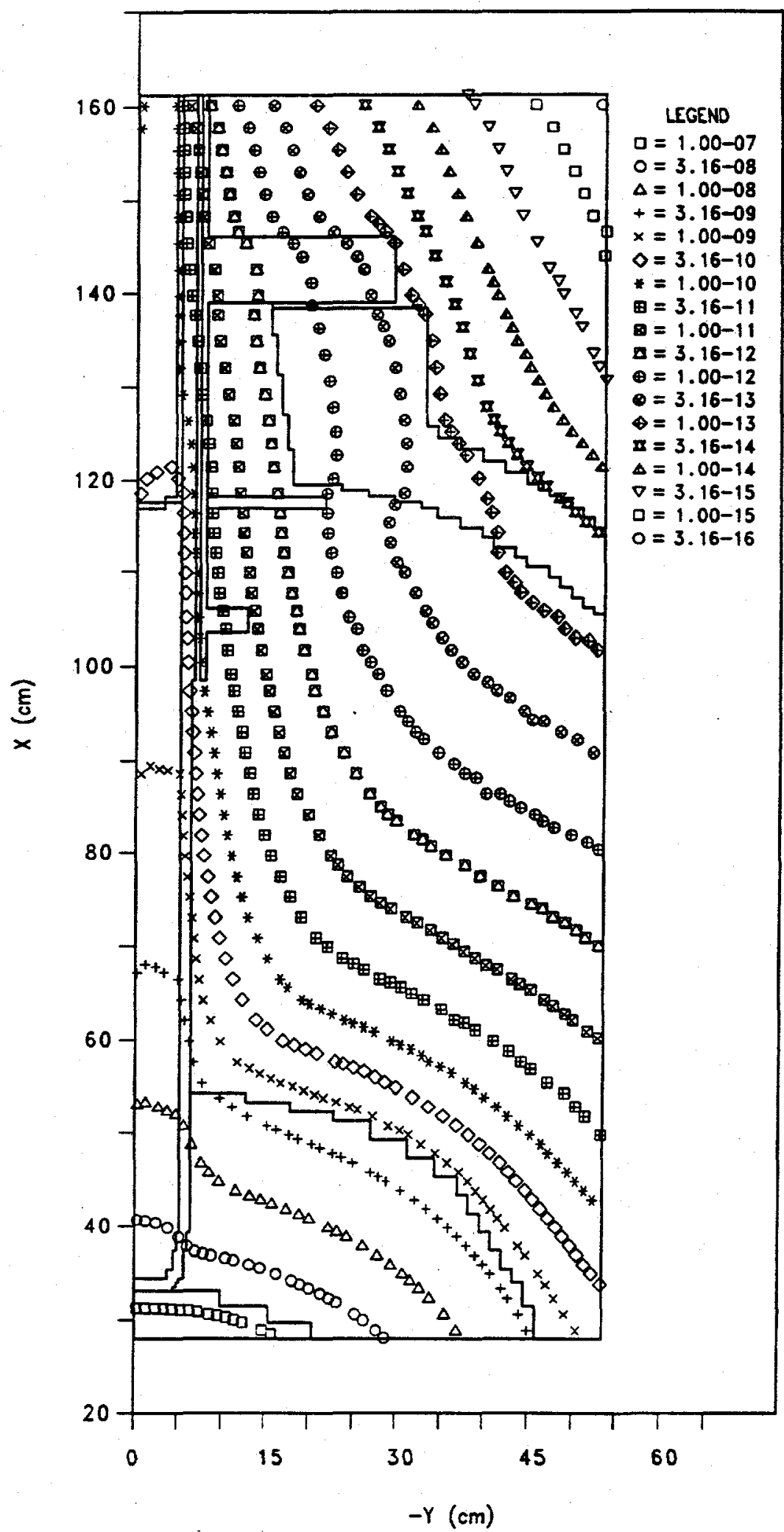

Fig. A12. Neutron iso dpa for HB-2 (present design). 
HFIR HB2 present (4 in.) $100 \mathrm{MW} 84$ gp, garmme-dpo (norm)

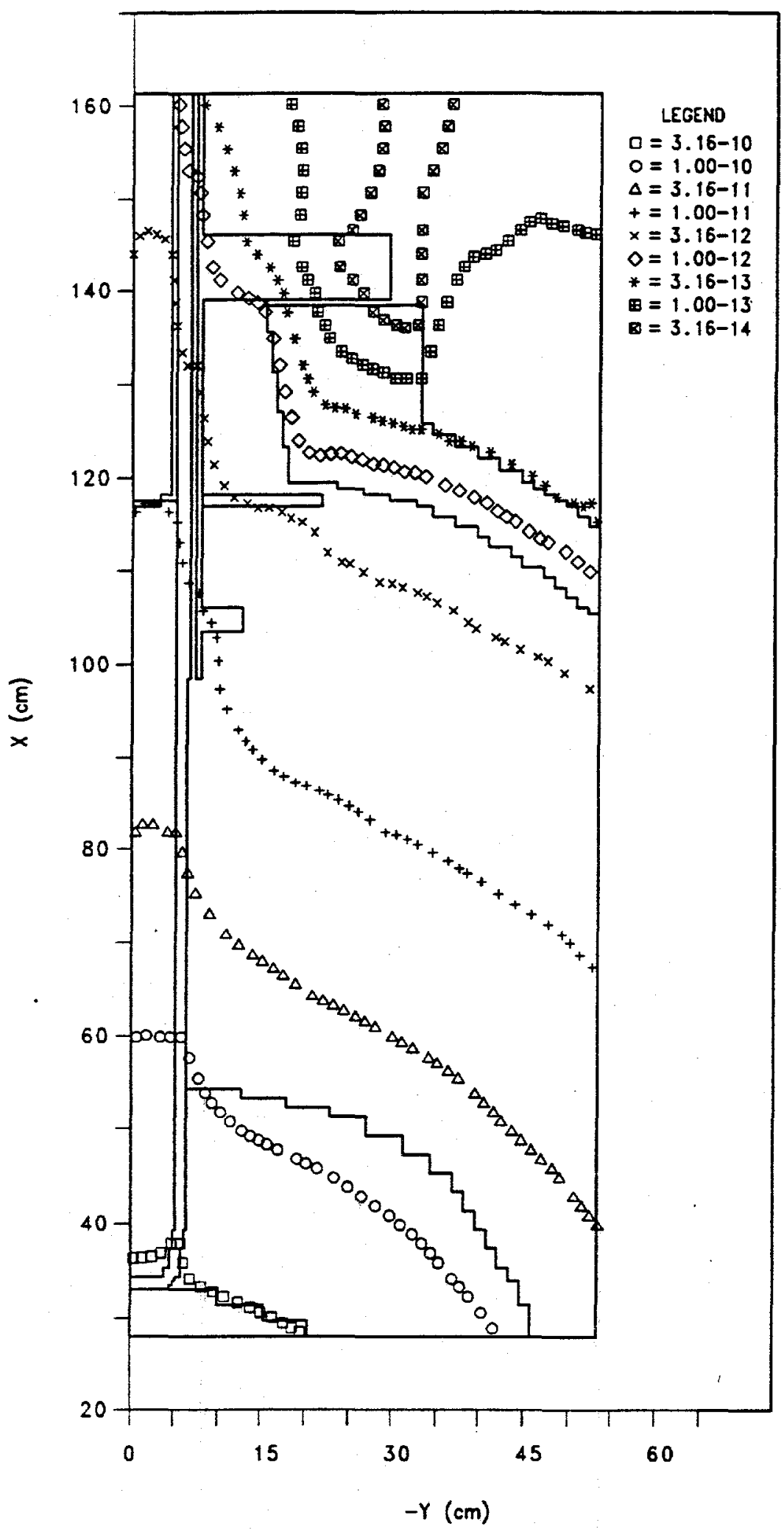

Fig. A13. Gamma iso-dpa for HB-2 (present design). 
HFIR HQ2 present (4 in.) $100 \mathrm{MW} 84$ gp, total-dpo (norm)

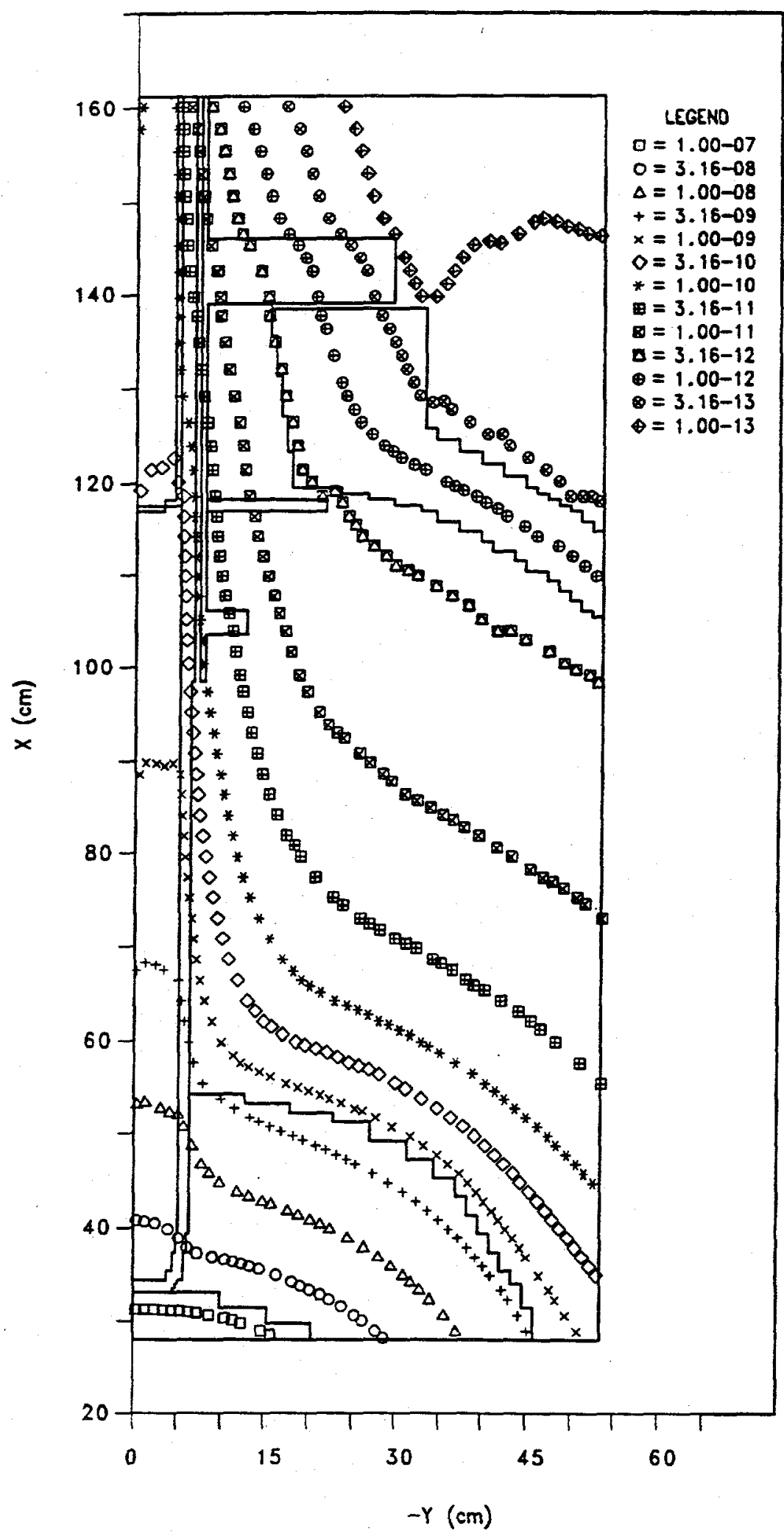

Fig. A14. Neutron plus gamma iso-dpa for HB-2 (present design). 


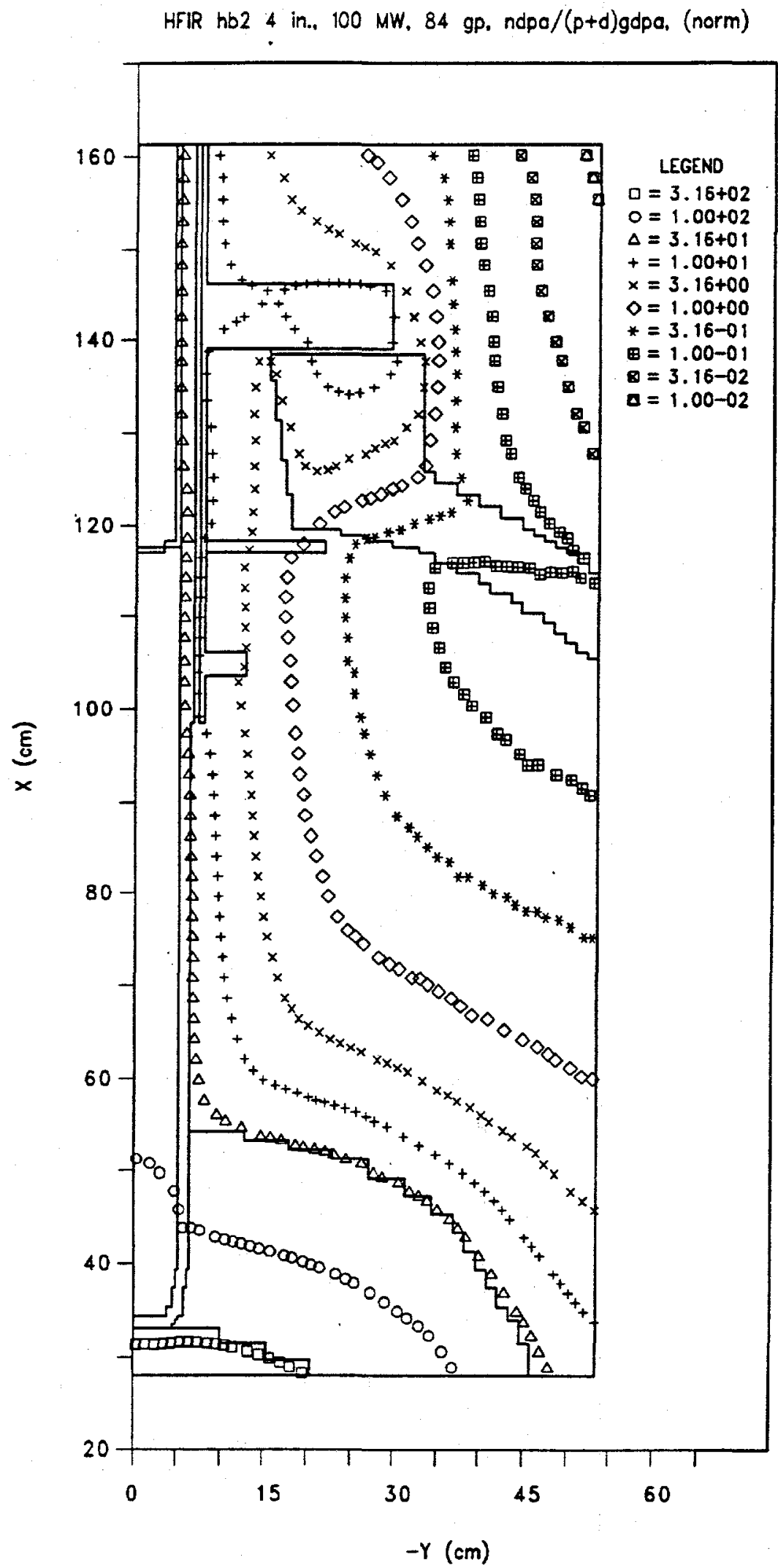

Fig. A15. Ratio of neutron to gamma iso-dpa for HB-2 (present design). 
HFIR HB2 present (4 in.) $100 \mathrm{MW} 84 \mathrm{gP}$, neutron flux > MMeV (norm)

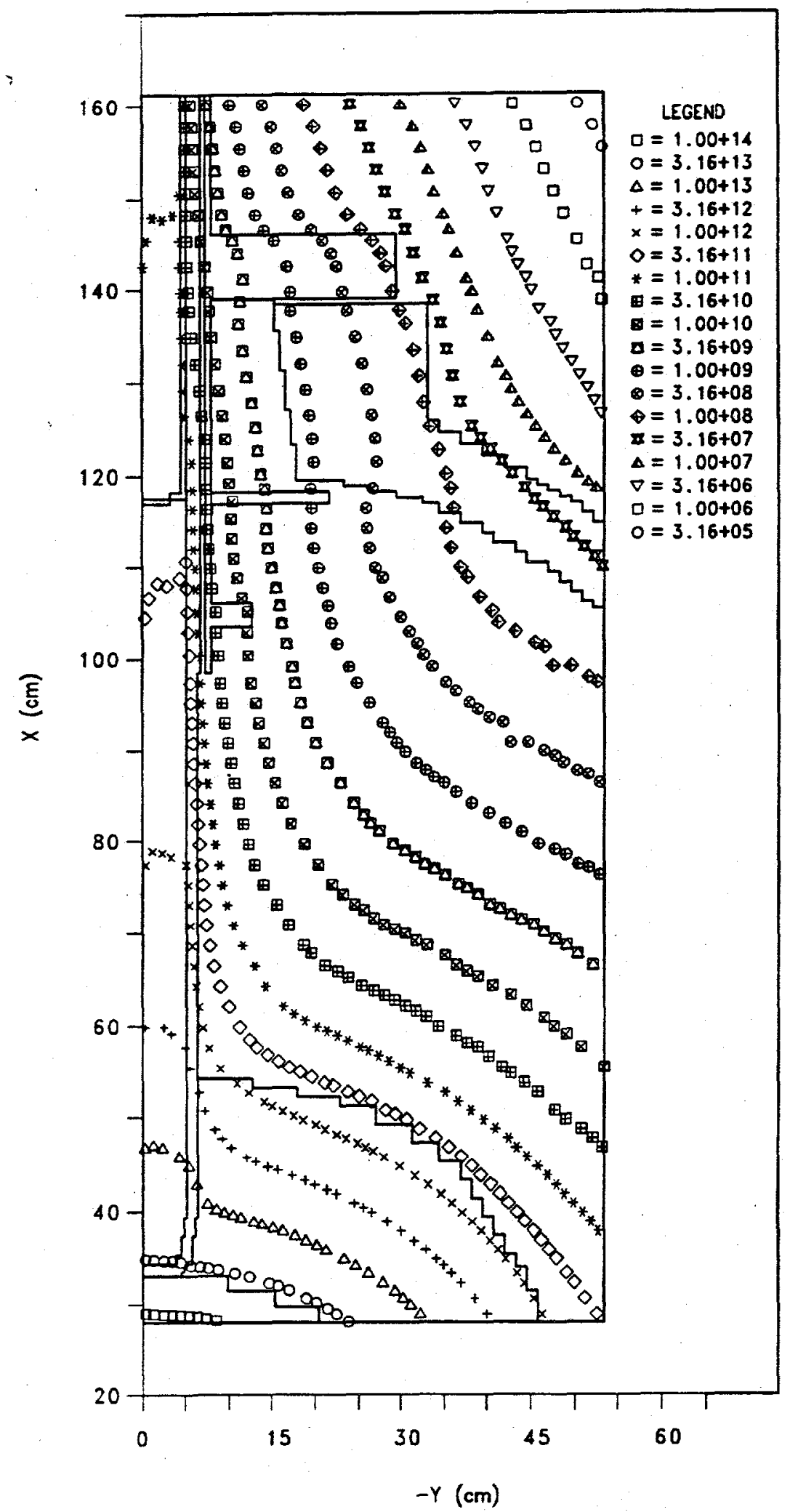

Fig. A16. Neutron iso-flux (E $>1 \mathrm{MeV}$ ) for HB-2 (present design). 
FIR HB2 present (4 in.) $100 \mathrm{MW} 84 \mathrm{gp}$, gamma flux > MeV (norm)

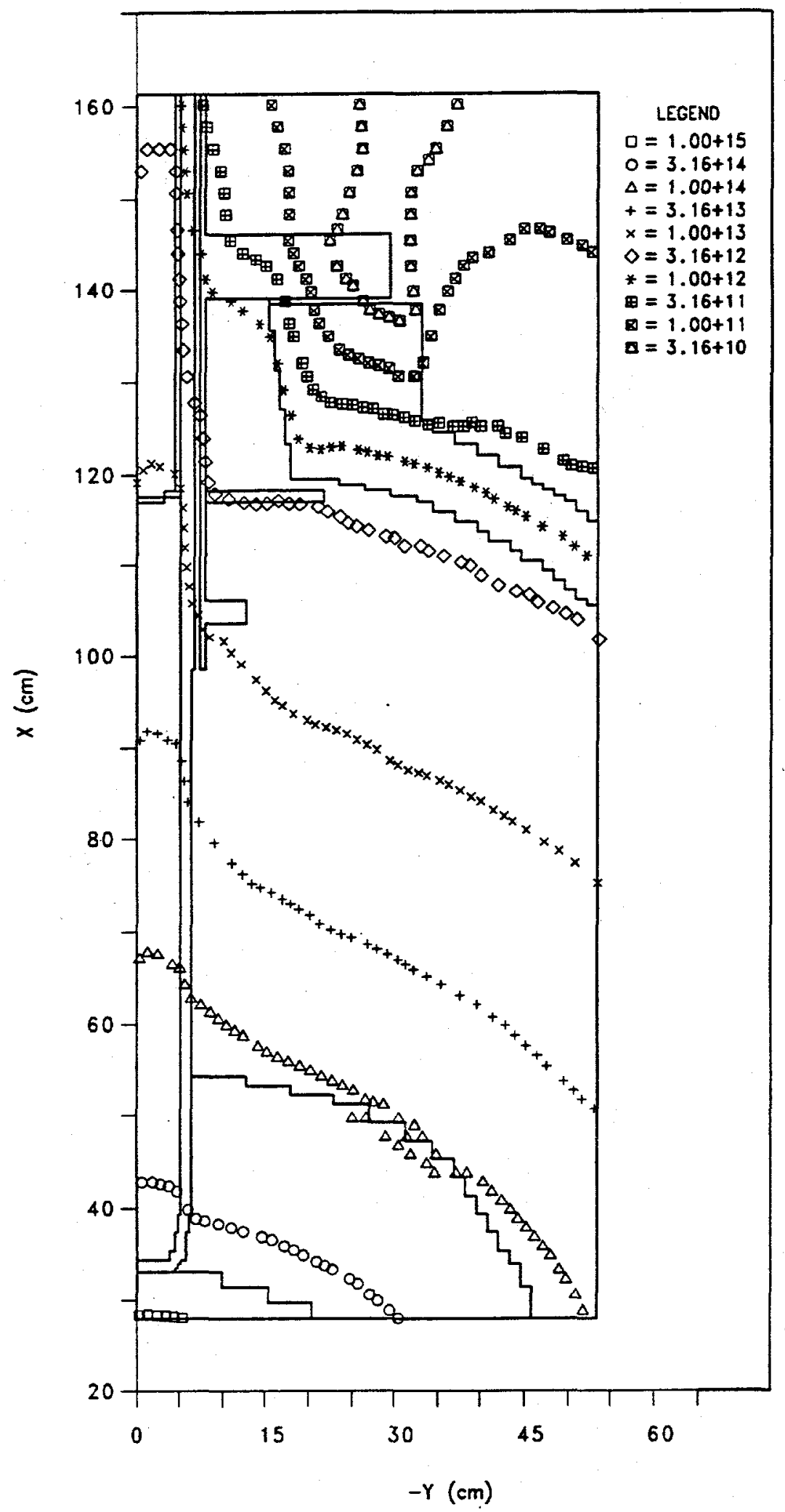

Fig. A17. Gamma iso-flux ( $\mathrm{E}>1 \mathrm{MeV}$ ) for HB-2 (present design). 
HFIR hb2 9 in., $100 \mathrm{MW}, 84 \mathrm{gp}, n$-dpo, rev 2 cor. (norm)

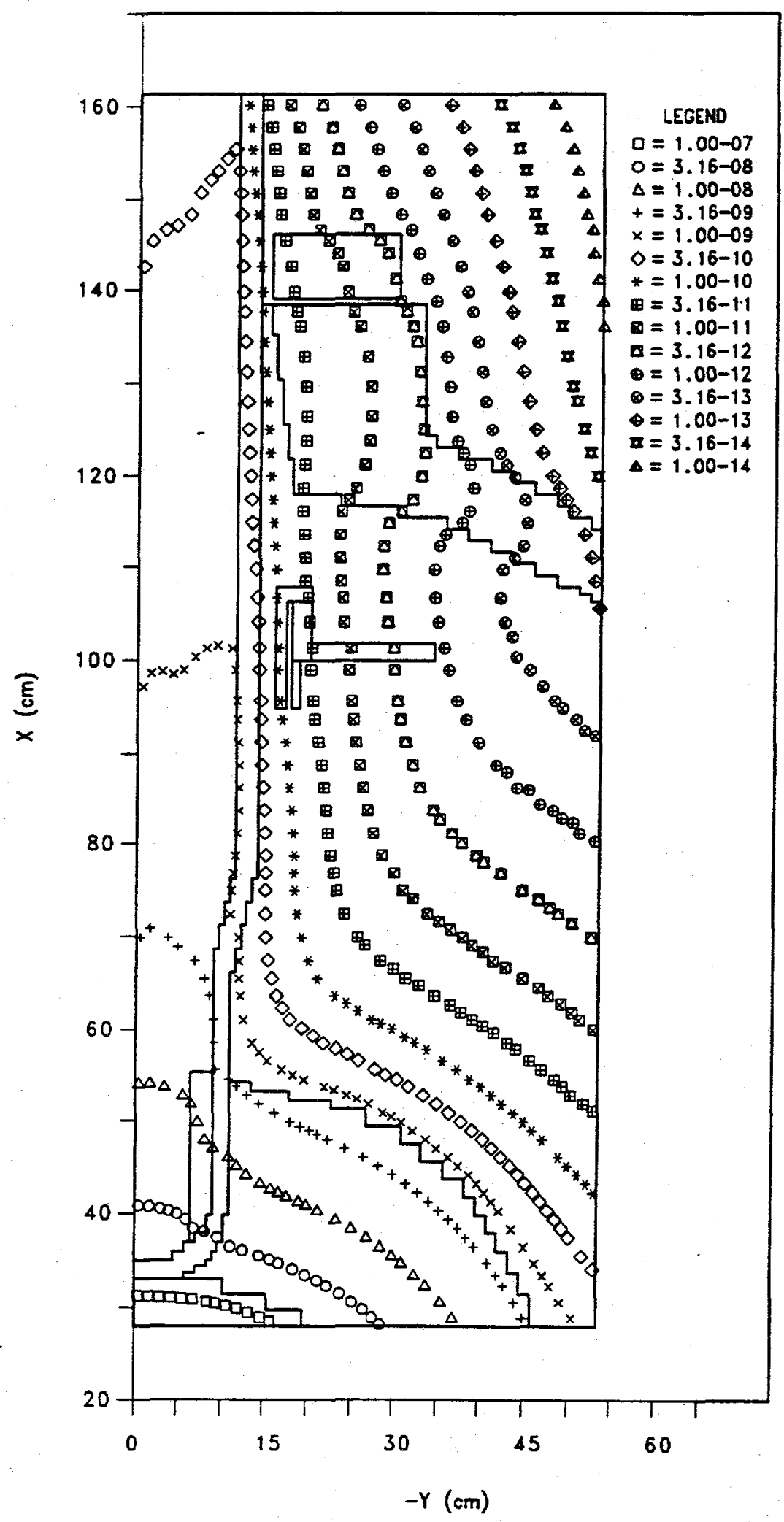

Fig. A18. Neutron iso-dpa for HB-2 (new design). 


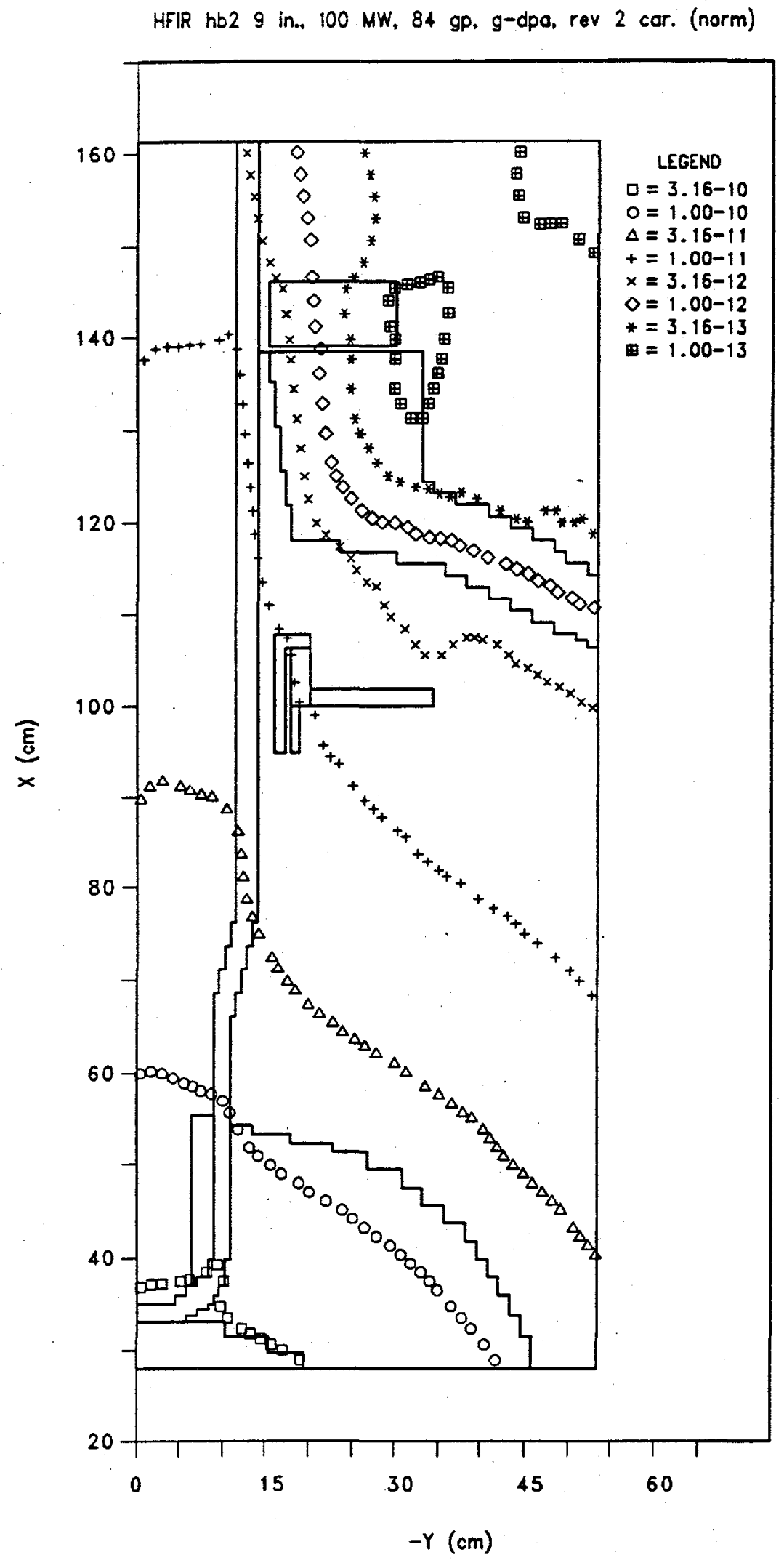

Fig. A19. Gamma iso-dpa for HB-2 (new design). 
HFIR hb2 9 in., $100 \mathrm{MW}, 84 \mathrm{gp}$, total dpo, rev 2 car. (norm)

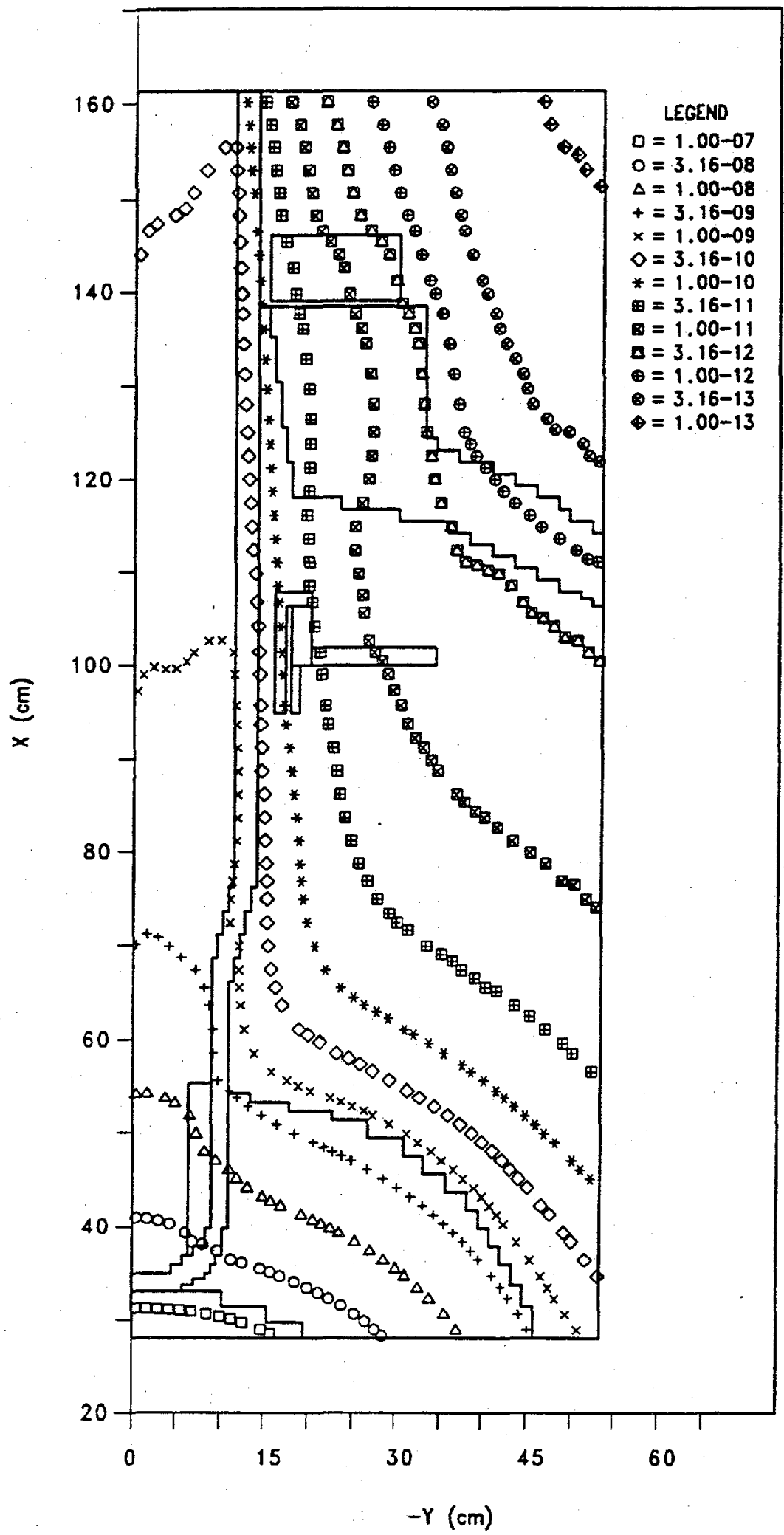

Fig. A20. Neutron plus gamma iso-dpa for HB-2 (new design). 
HFIR HB2 9 In., $100 \mathrm{MW}, 84$ gp, n/g dpo, rev 2 car. (norm)

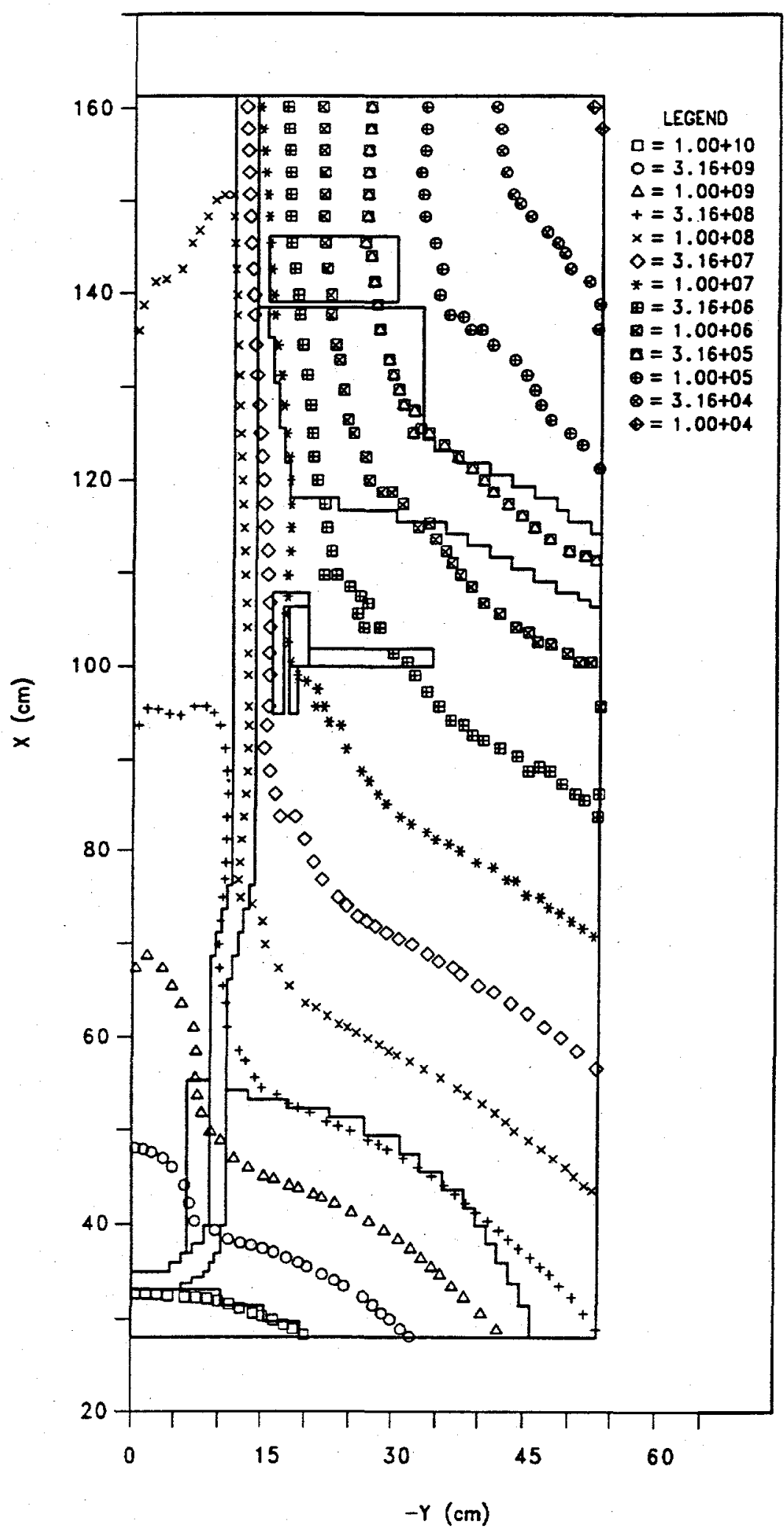

Fig. A21. Ratio of neutron to gamma iso-dpa for HB-2 (new design). 
HFIR hb2 9 in., 100 MW. 84 gP, neut. fix > IMeV, rev 2 car. (norm)

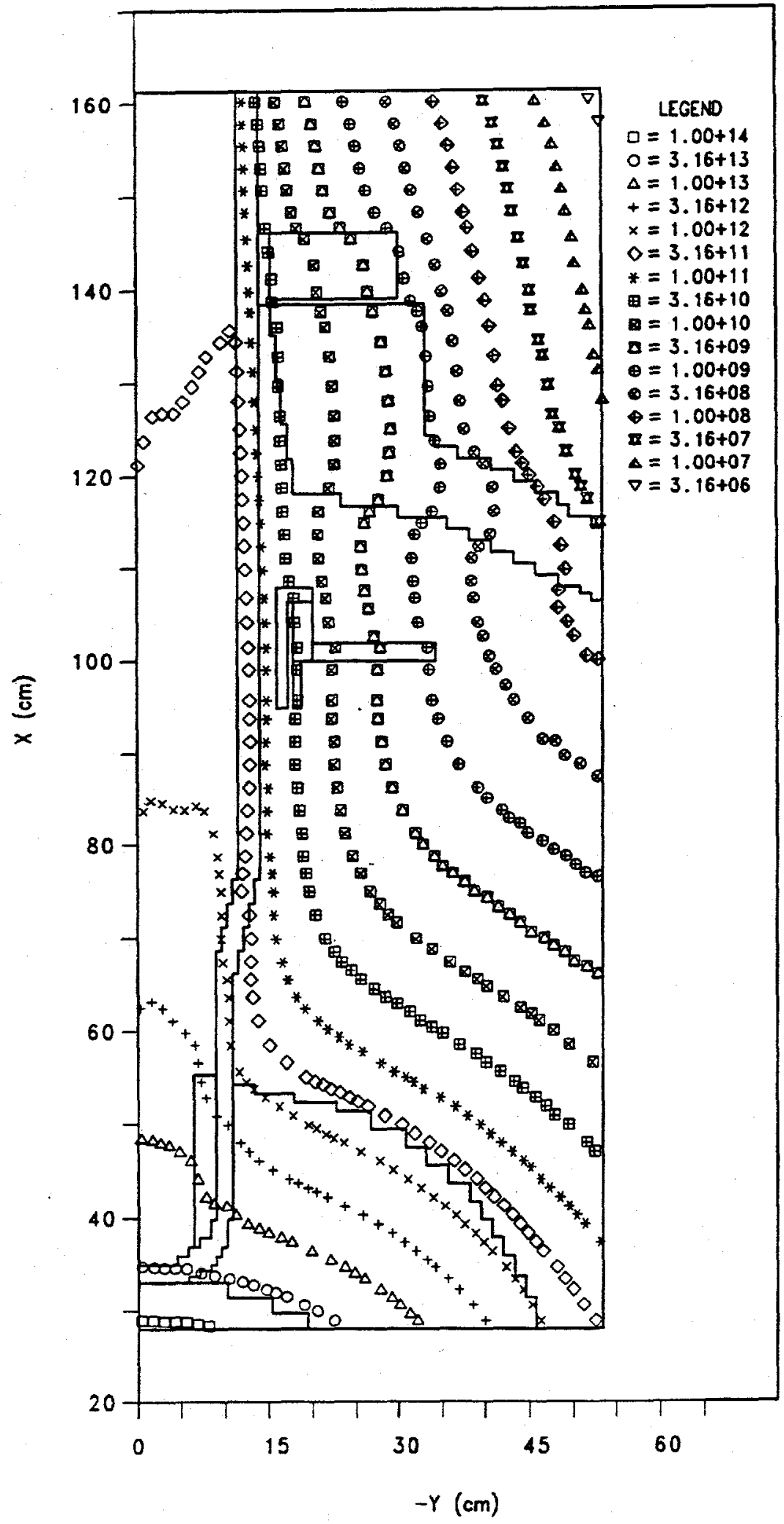

Fig. A22. Neutron iso-flux ( $E>1 \mathrm{MeV}$ ) for HB-2 (new design). 
HFIR hb2 9 in., $100 \mathrm{MW}, 84$ gP, gammo flx > MMeV, rev 2 cor. (norm)

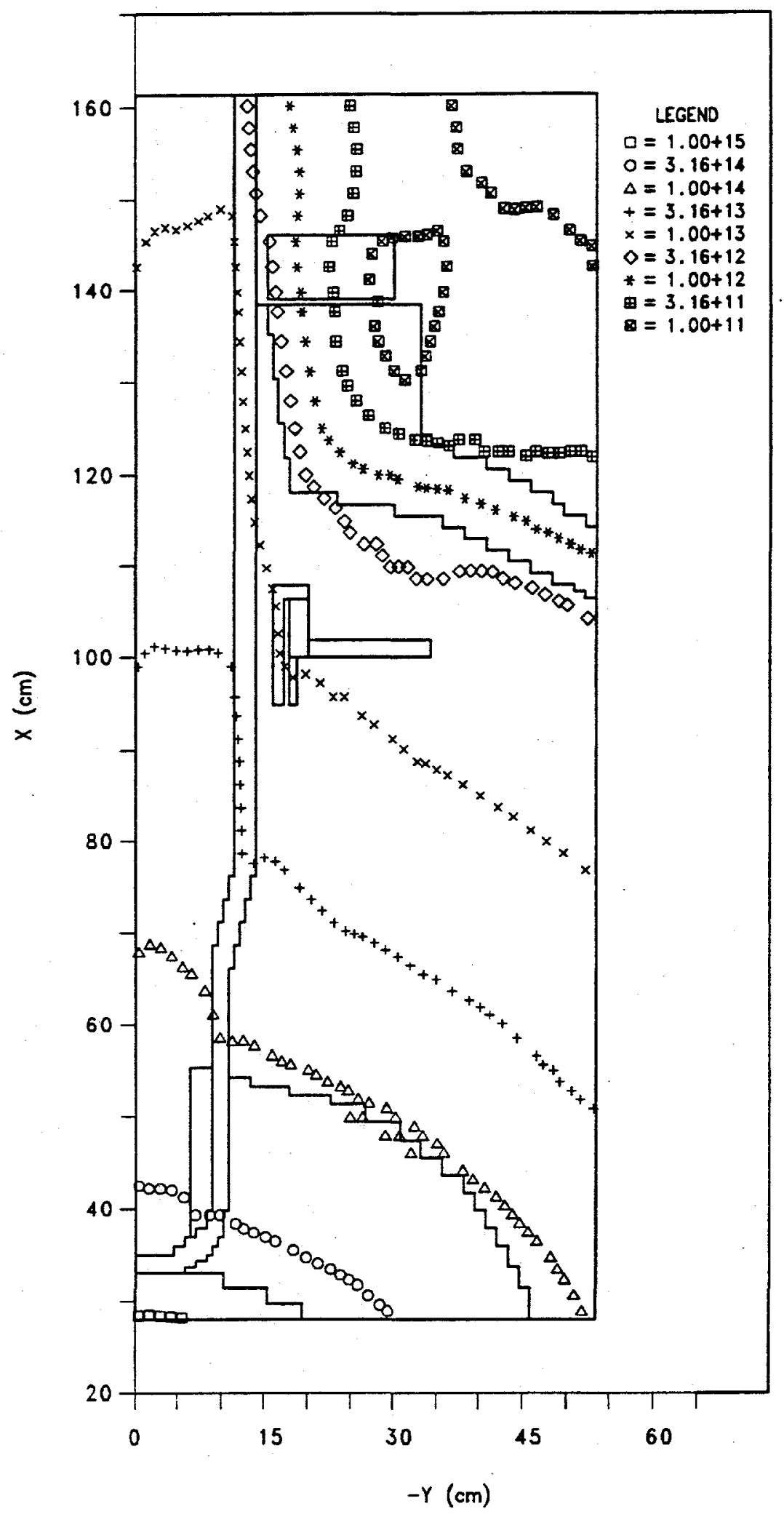

Fig. A23. Gamma iso-flux ( $\mathrm{C}>1 \mathrm{MeV}$ ) for HB-2 (new design). 
HFIR HB3 $Z$ cut noutron dpo carousel(mod $A)$ (norm)

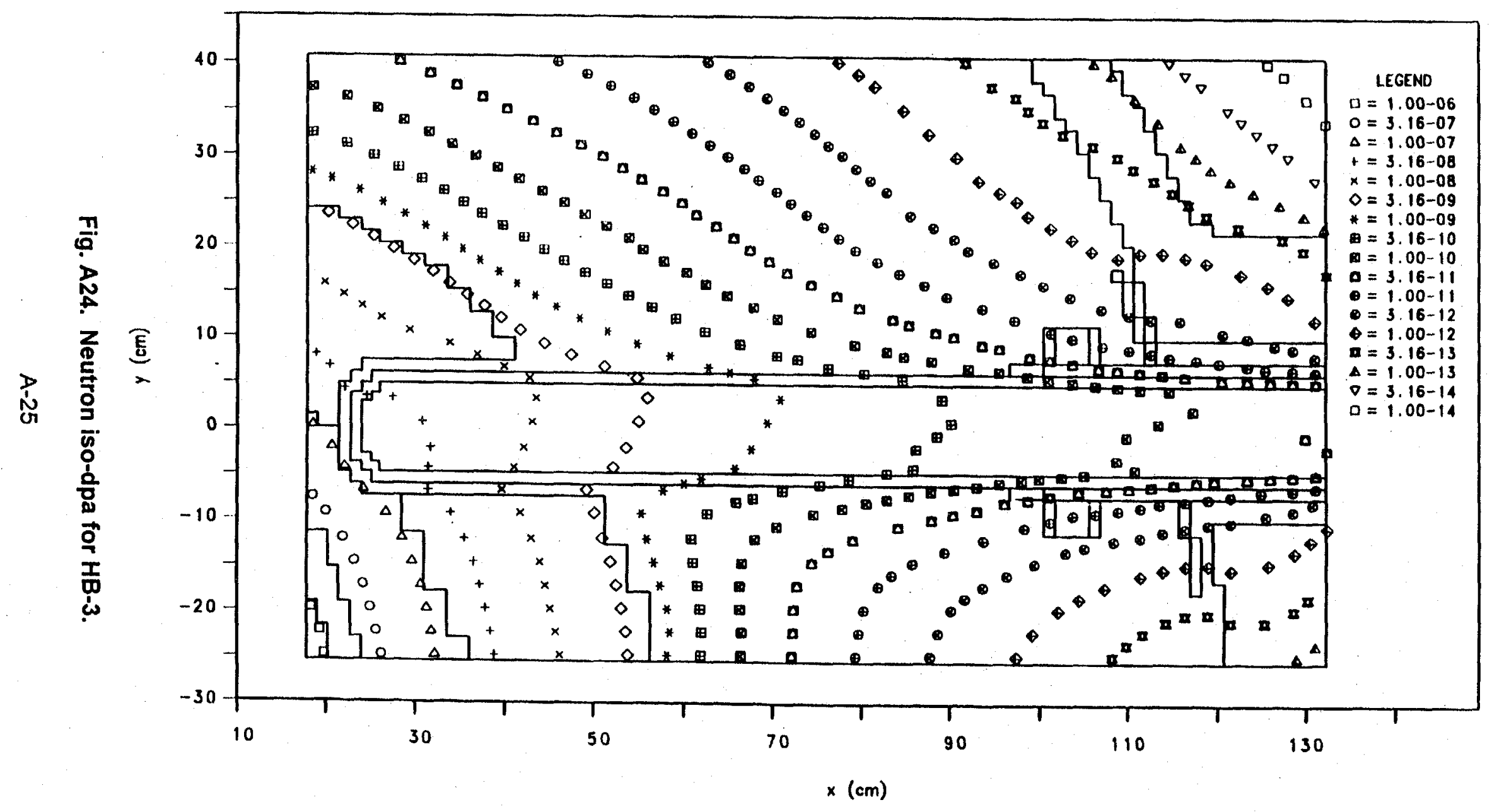




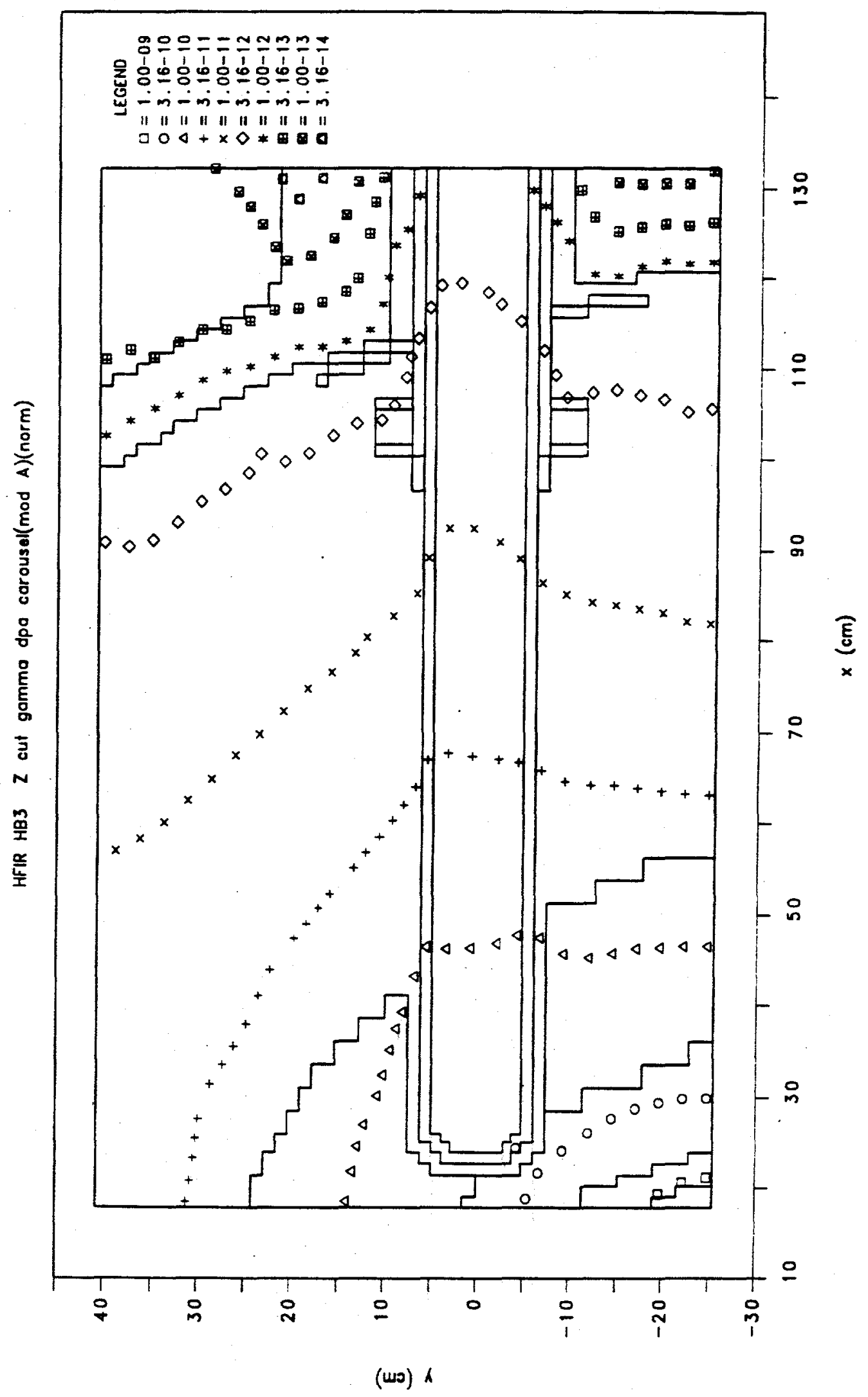

Fig. A25. Gamma iso-dpa for HB-3. 


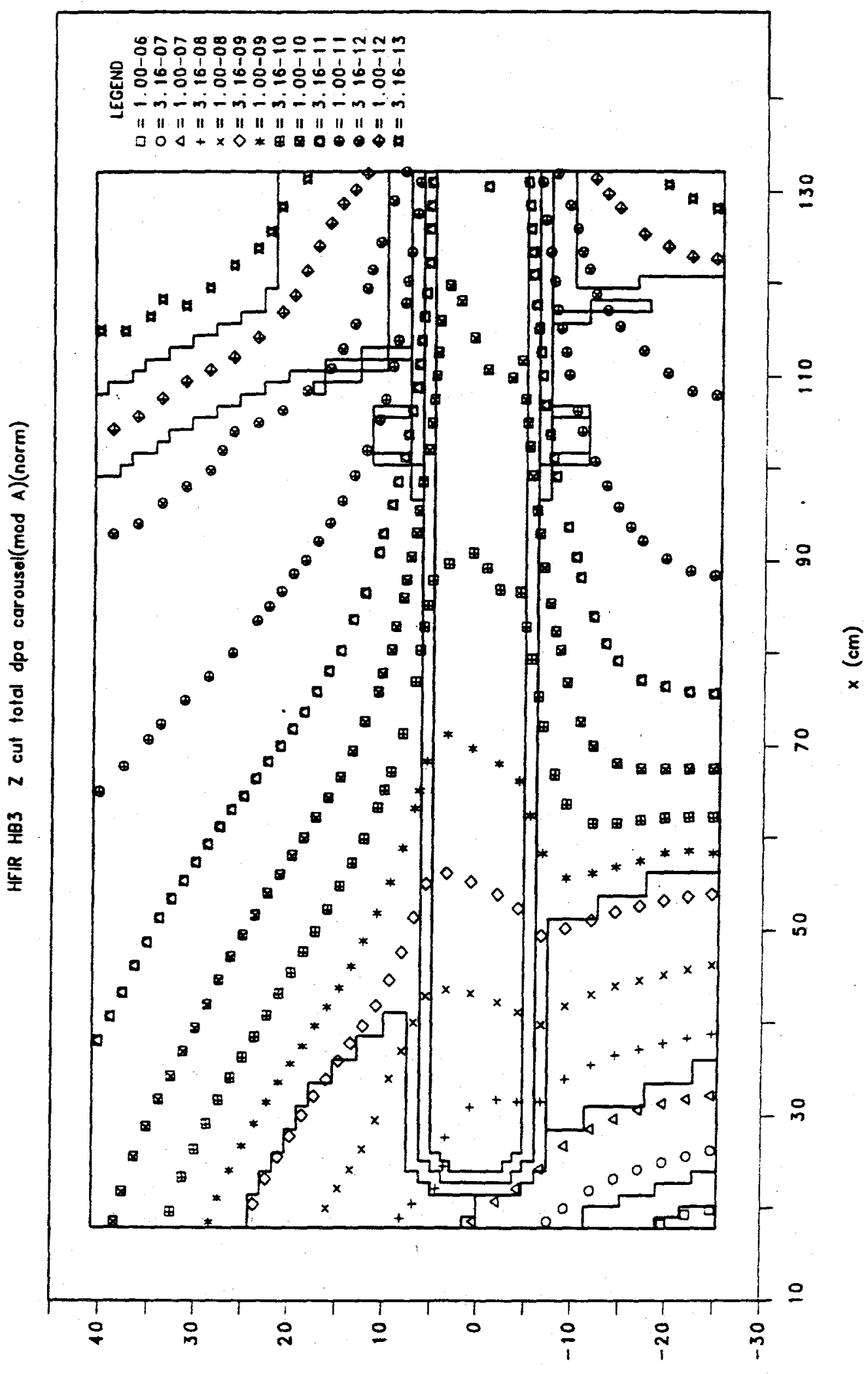

(wo) $k$

Fig. A26. Neutron plus gamma iso-dpa for HB3. 
ORNL/TM-1372/S2

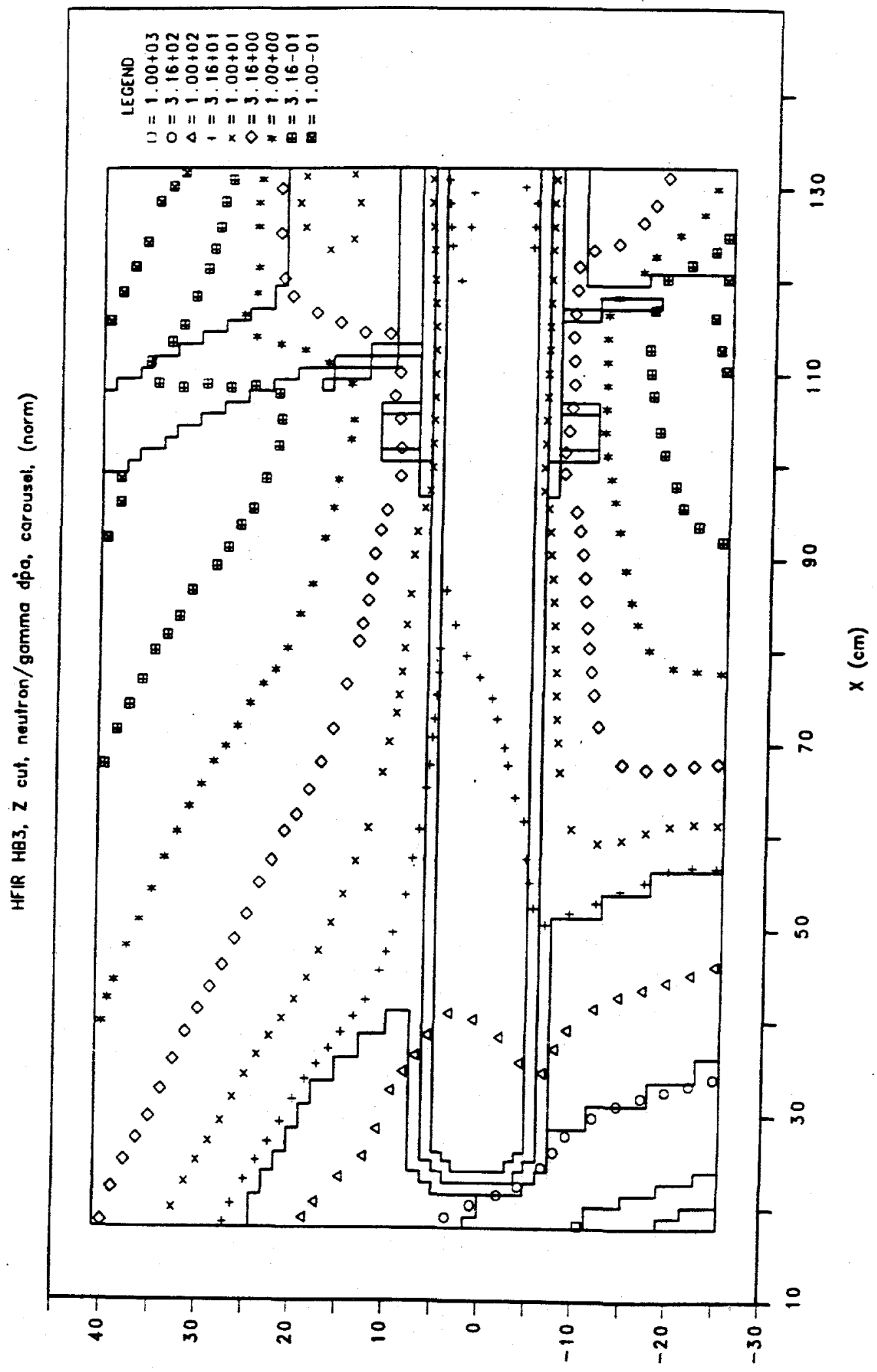

(wo) 1

Fig. A27. Ratio of neutron to gamma iso-dpa for HB-3. 
HFIR HB3 $Z$ cut noutron flux ( $>M_{0} V$ ) carousel(mod $\left.A\right)$ (norm)

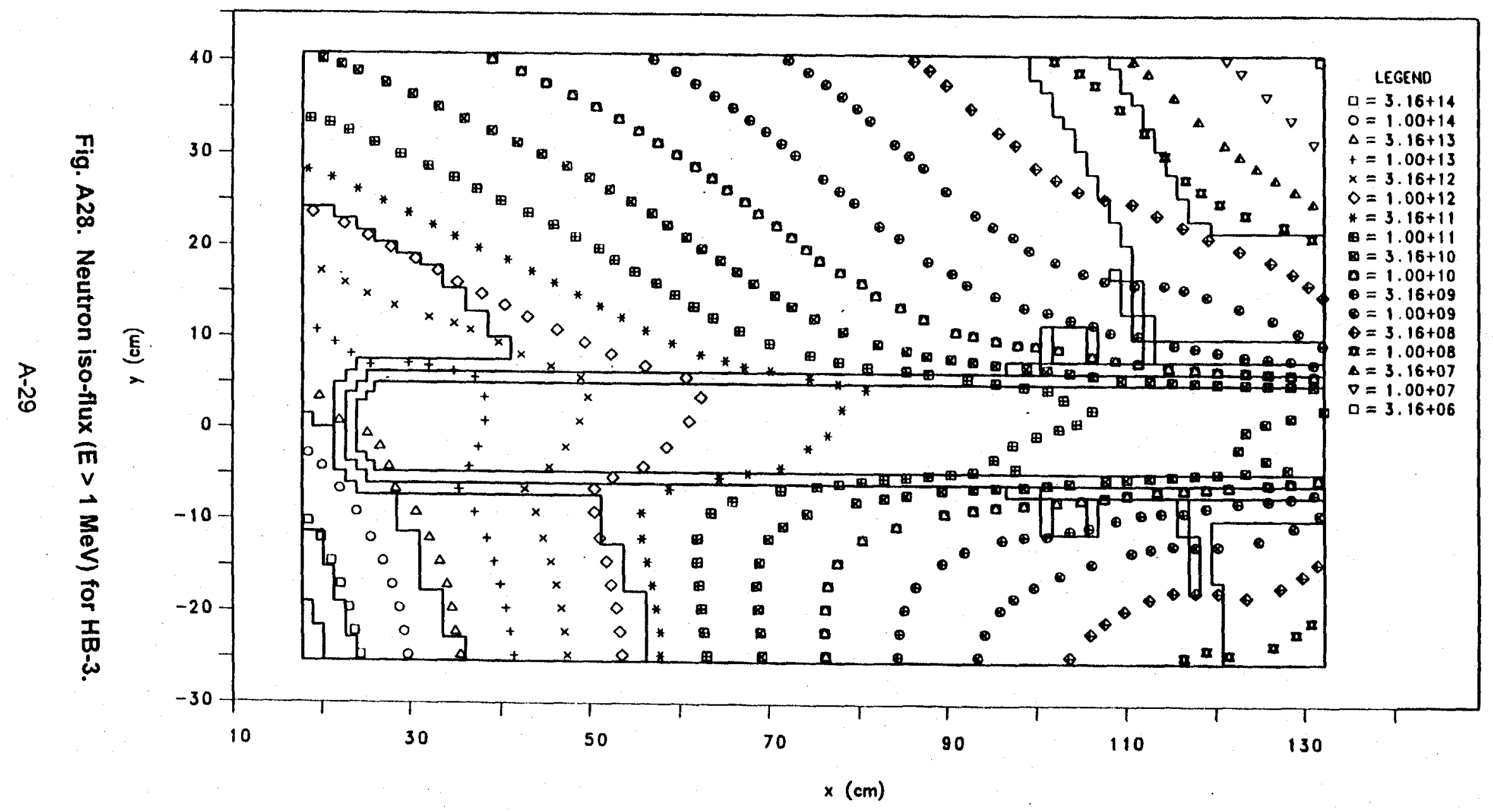




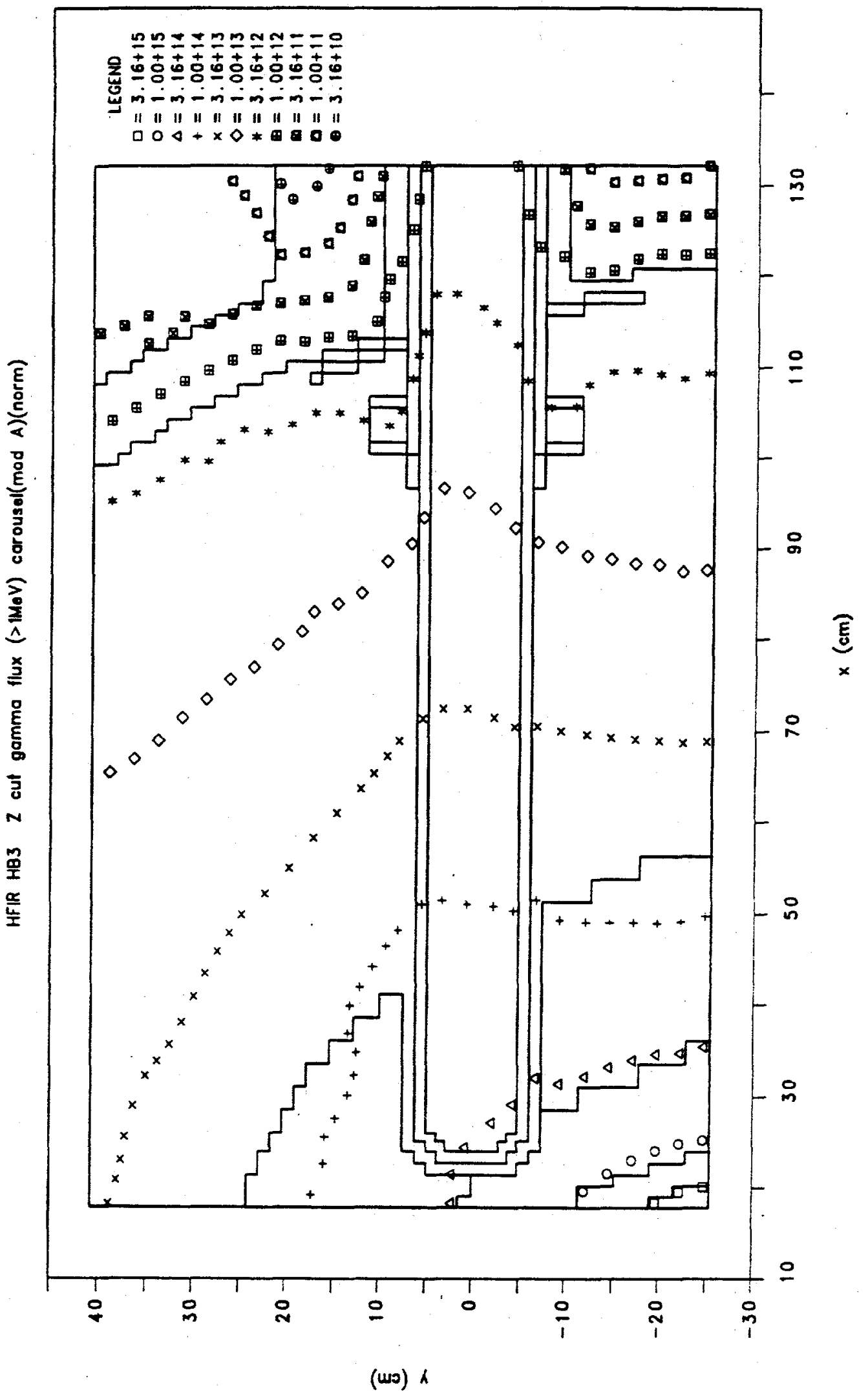

Fig. A29. Gamma iso-flux (E $>1 \mathrm{MeV}$ ) for HB-3. 


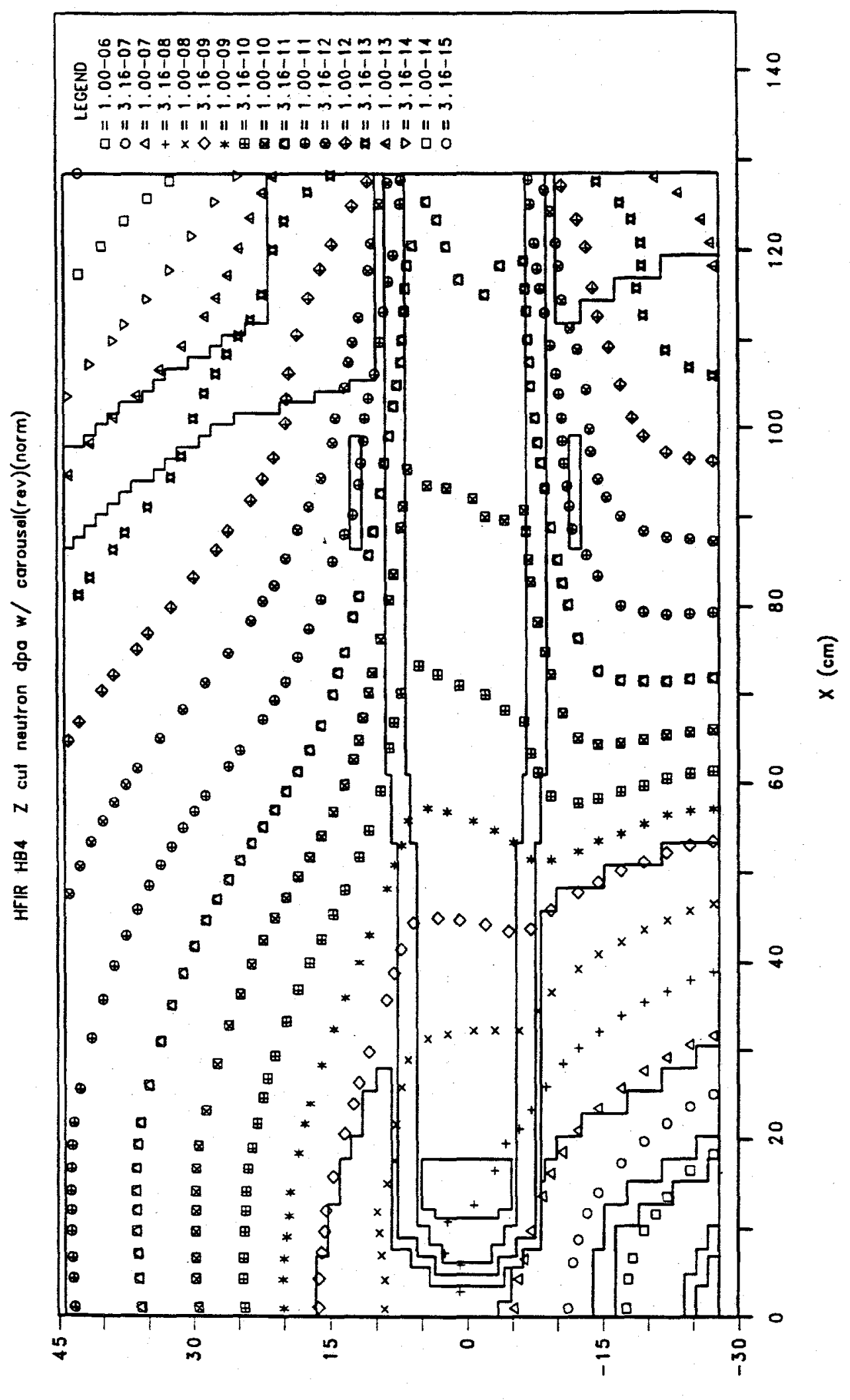

(wo) 1

Fig. A30. Neutron iso-dpa for HB-4 (new design). 


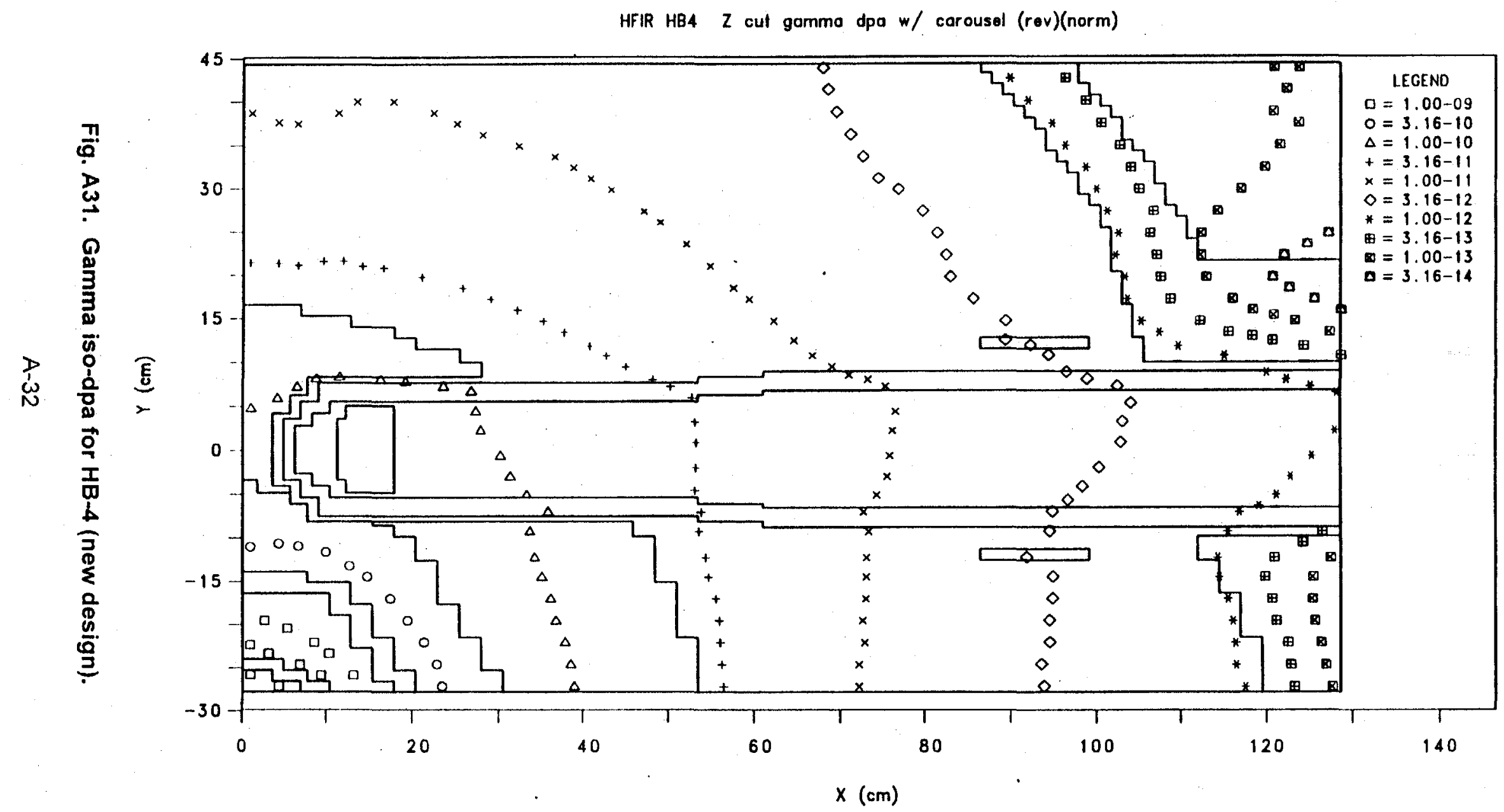




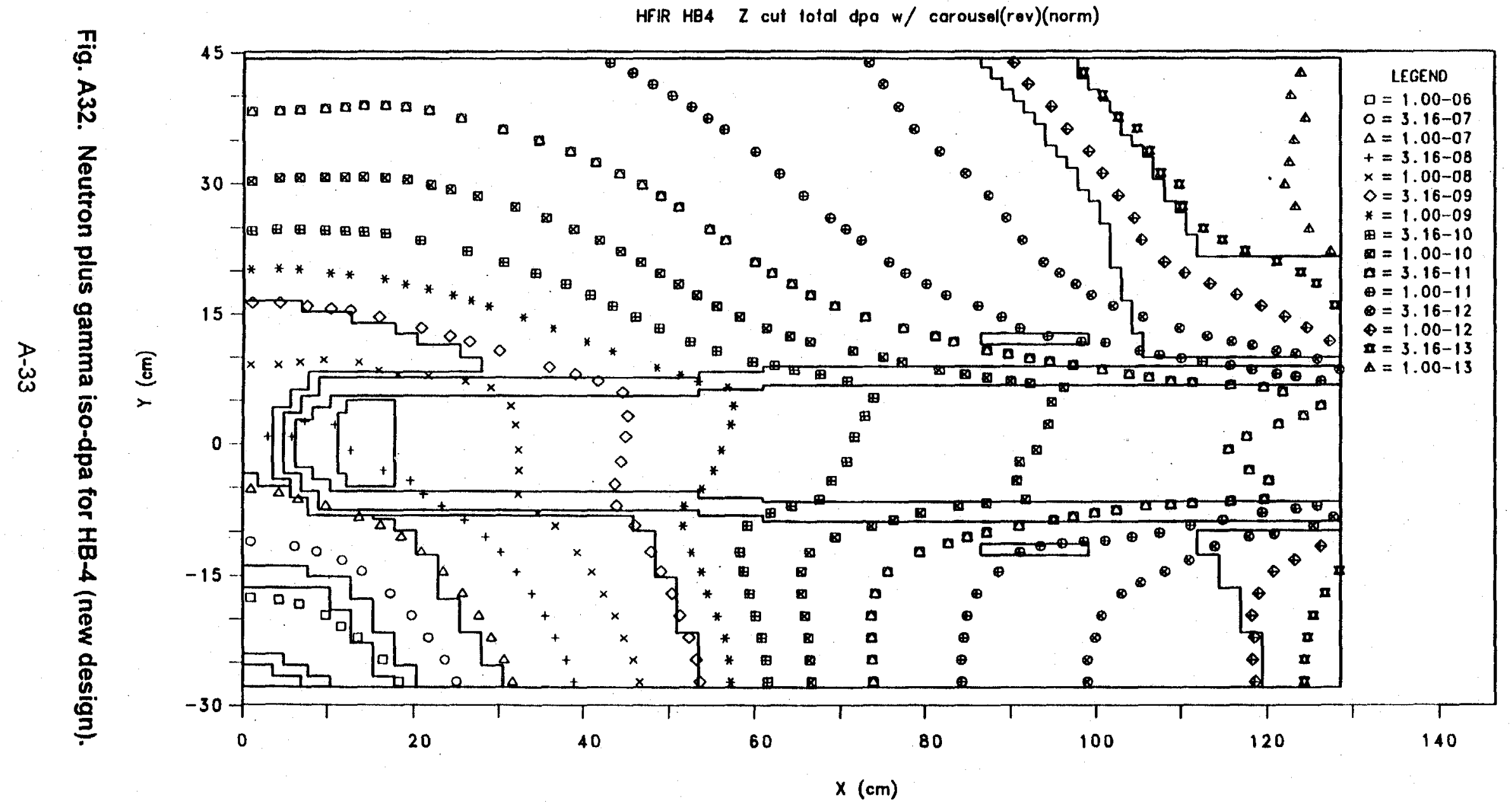




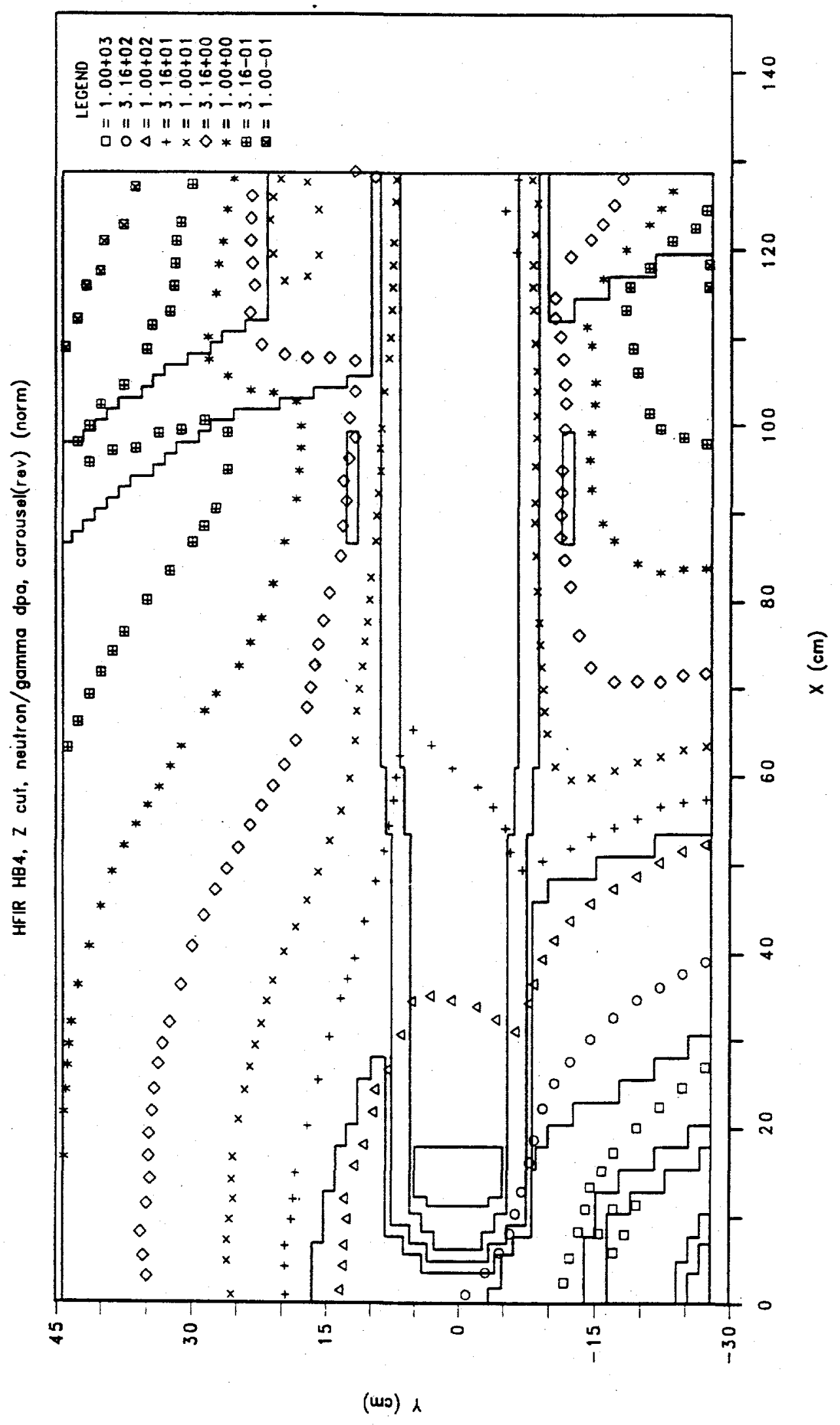

Fig. A33. Ratio to neutron to gamma iso-dpa for HB-4 (new design). 


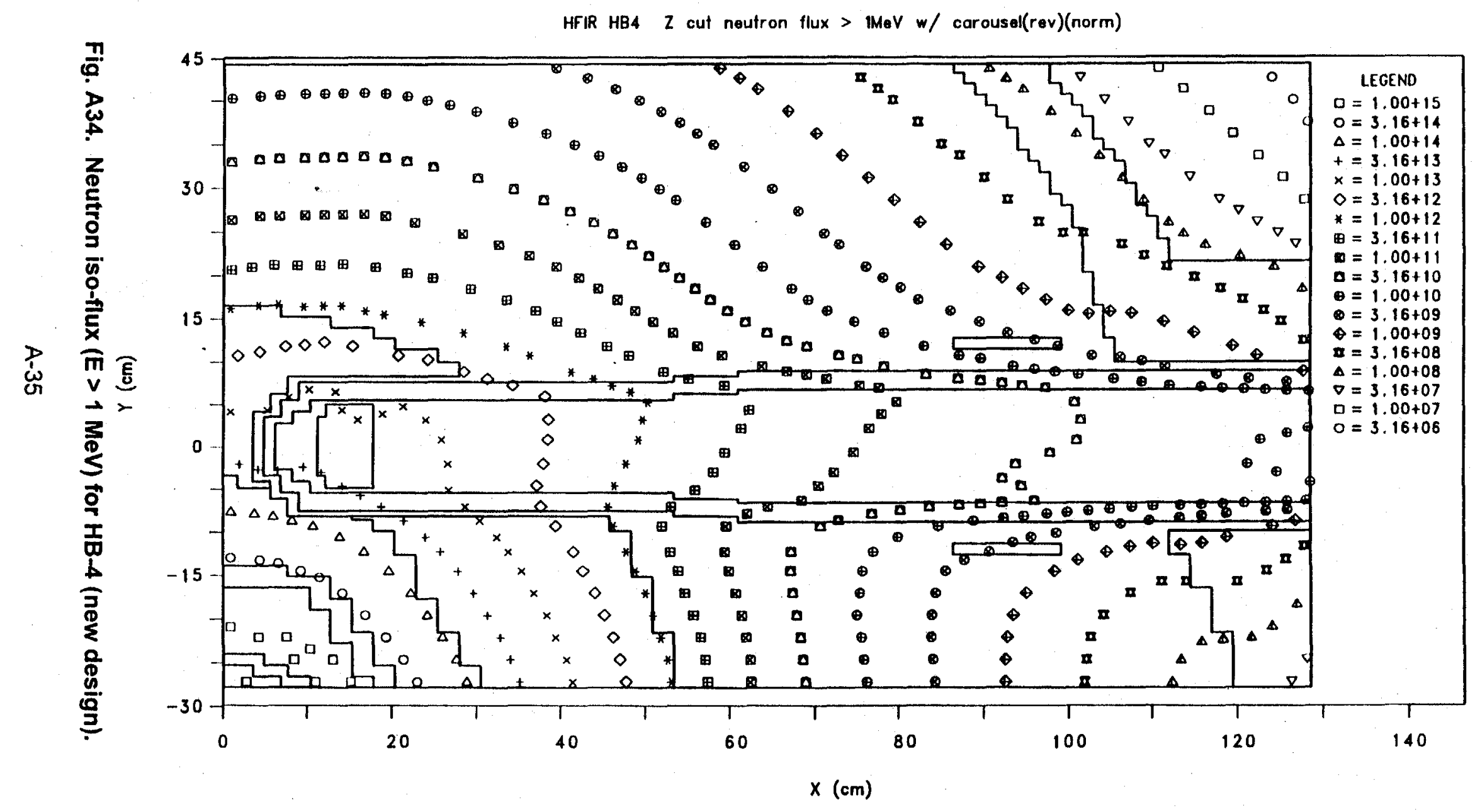




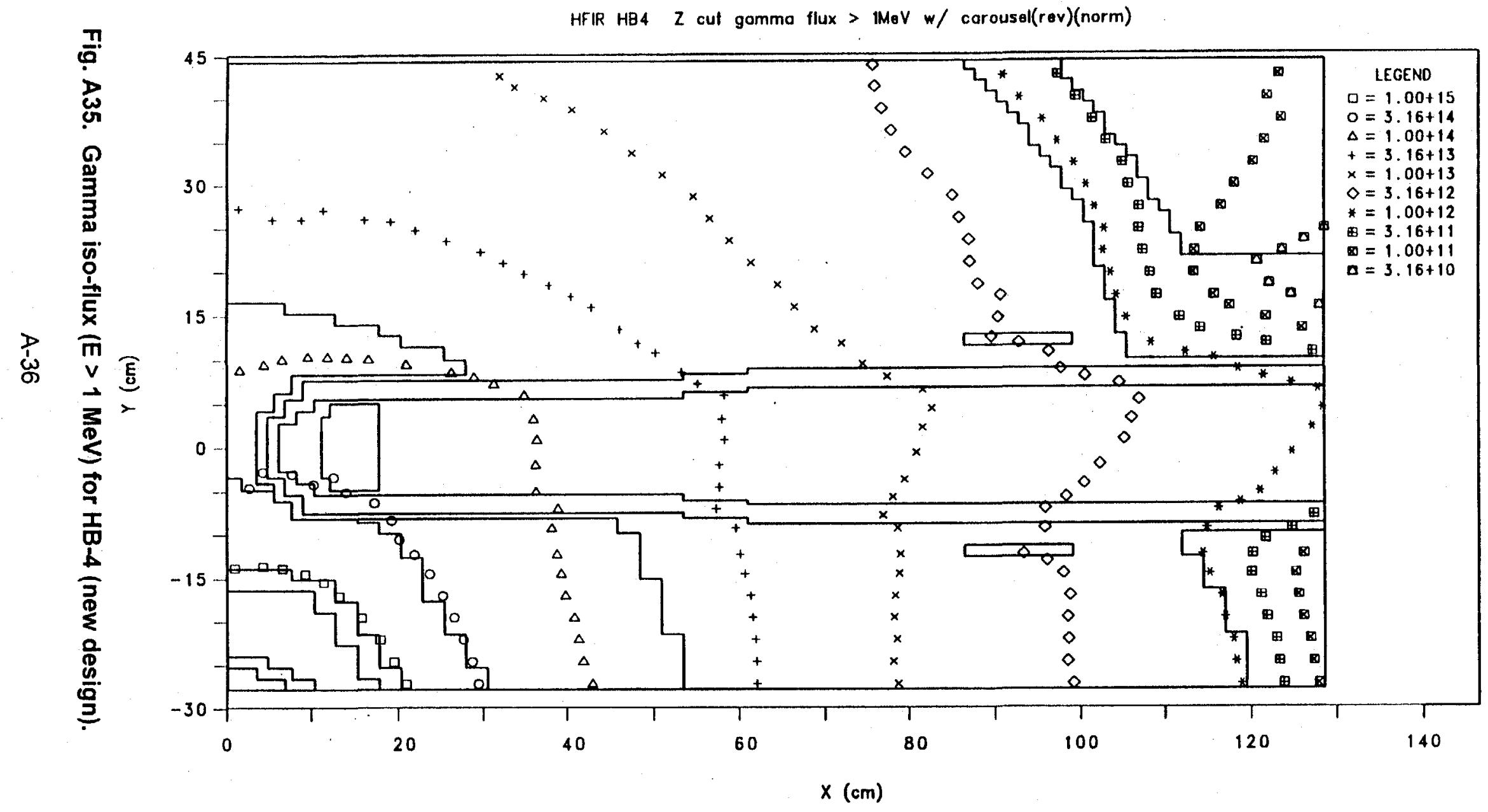




\section{APPENDIX B}

\section{DATA PERTAINING TO SURVEILLANCE SPECIMENS REMOVED AND TESTED PRIOR TO $\mathrm{t}=22.6$ EFPY $(100 \mathrm{MW})$}

Table B.1. Location, material, and dose for surveillance specimens removed and tested prior to $t=22.6 \mathrm{EFPY}(100 \mathrm{MW})$

\begin{tabular}{|c|c|c|c|c|c|c|}
\hline Capsule & $\begin{array}{c}\text { Material/ } \\
\text { orientation }\end{array}$ & Key & $\begin{array}{c}\text { Key } \\
\text { position }\end{array}$ & Date $^{a}$ & $\begin{array}{l}\text { Irradiation time } \\
\text { [EFPY }(100 \mathrm{MW})]\end{array}$ & dpa \\
\hline HB-1-21 & A105II & 1 & 1 & 1969 & 2.3 & $1.9 \times 10^{-4}$ \\
\hline HB-1-19 & A105II & 1 & 6 & $“$ & 2.3 & $1.7 \times 10^{-4}$ \\
\hline HB-2-13 & A3050LF3 & 2 & 1 & " & 2.3 & $3.5 \times 10^{-4}$ \\
\hline HB-2-10 & A3050LF3 & 2 & 14 & 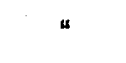 & 2.3 & $3.5 \times 10^{-4}$ \\
\hline HB-3-49 & A3050LF3 & 3 & 1 & " & 2.3 & $2.4 \times 10^{-4}$ \\
\hline HB-3-53 & A3050LF3 & 3 & 6 & $"$ & 2.3 & $3.0 \times 10^{-4}$ \\
\hline $\mathrm{HB}-4-37$ & A105II & 4 & 1 & $"$ & 2.3 & $1.7 \times 10^{-4}$ \\
\hline $\mathrm{HB}-4-36$ & A105II & 4 & 6 & $"$ & 2.3 & $1.9 \times 10^{-4}$ \\
\hline HB-1-20 & A105II & 1 & 4 & 1974 & 6.4 & $5.5 \times 10^{-4}$ \\
\hline HB-1-26 & A105II & 1 & 9 & $"$ & 6.4 & $4.8 \times 10^{-4}$ \\
\hline HB-2-15 & A3050LF3 & 2 & 4 & $"$ & 6.4 & $9.6 \times 10^{-4}$ \\
\hline HB-2-12 & A3050LF3 & 2 & 13 & $"$ & 6.4 & $9.6 \times 10^{-4}$ \\
\hline HB-3-45 & A3050LF3 & 3 & 4 & $"$ & 6.4 & $7.0 \times 10^{-4}$ \\
\hline HB-3-52 & A3050LF3 & 3 & 9 & $"$ & 6.4 & $9.1 \times 10^{-4}$ \\
\hline$H B-4-30$ & A105II & 4 & 4 & $"$ & 6.4 & $4.8 \times 10^{-4}$ \\
\hline $\mathrm{HB}-4-33$ & A105II & 4 & 9 & $"$ & 6.4 & $5.5 \times 10^{-4}$ \\
\hline HB-1-27 & A105II & 1 & 2 & 1983 & 15.0 & $1.3 \times 10^{-3}$ \\
\hline HB-2-14 & A350LF3 & 2 & 2 & $"$ & 15.0 & $2.3 \times 10^{-3}$ \\
\hline HB-3-43 & A350LF3 & 3 & 2 & $"$ & 15.0 & $1.6 \times 10^{-3}$ \\
\hline $\mathrm{HB}-4-40$ & A105II & 4 & 2 & $"$ & 15.0 & $1.1 \times 10^{-3}$ \\
\hline ICA-A-51 & $\mathrm{A} 212 \mathrm{~B} / \mathrm{LT}$ & 5 & 1 & $"$ & 15.0 & $9.0 \times 10^{-4}$ \\
\hline HB-1-A-61 & $\mathrm{A} 212 \mathrm{~B} / \mathrm{LT}$ & 6 & 1 & " & 15.0 & $1.0 \times 10^{-3}$ \\
\hline
\end{tabular}


Table B.1 (cont'd)

\begin{tabular}{|c|c|c|c|c|c|c|}
\hline Capsule & $\begin{array}{c}\text { Material/ } \\
\text { orientation }\end{array}$ & Key & $\begin{array}{c}\text { Key } \\
\text { position }\end{array}$ & Date $^{a}$ & $\begin{array}{c}\text { Irradiation time } \\
\text { [EFPY }(100 \mathrm{MW})]\end{array}$ & dpa \\
\hline HB-4-A-72 & $\mathrm{A} 212 \mathrm{~B} / \mathrm{LT}$ & 7 & 7 & $"$ & 15.0 & $9.9 \times 10^{-4}$ \\
\hline HB-1-25 & A105II & 1 & 3 & 1986 & 17.5 & $1.6 \times 10^{-3}$ \\
\hline HB-2-11 & A350LF3 & 2 & 5 & 4 & 17.5 & $2.6 \times 10^{-3}$ \\
\hline HB-2-9 & A350LF3 & 2 & 7 & $"$ & 17.5 & $2.6 \times 10^{-3}$ \\
\hline HB-3-50 & A350LF3 & 3 & 3 & $"$ & 17.5 & $1.9 \times 10^{-3}$ \\
\hline HB-3-42 & A350LF3 & 3 & 5 & $"$ & 17.5 & $1.8 \times 10^{-3}$ \\
\hline HBQ-3-48 & A350LF3 & 3 & 8 & “ & 17.5 & $2.7 \times 10^{-3}$ \\
\hline HB-4-31 & A105II & 4 & 3 & “ & 17.5 & $1.3 \times 10^{-3}$ \\
\hline HB-4-32 & A105II & 4 & 8 & “ & 17.5 & $1.6 \times 10^{-3}$ \\
\hline HB-1-A-68 & $\mathrm{A} 212 \mathrm{~B} / \mathrm{LT}$ & 6 & 2 & “ & 17.5 & $1.1 \times 10^{-3}$ \\
\hline HB-1-A-69 & $\mathrm{A} 212 \mathrm{~B} / \mathrm{LT}$ & 6 & 3 & $"$ & 17.5 & $1.1 \times 10^{-3}$ \\
\hline HB-4-A-77 & $\mathrm{A} 212 \mathrm{~B} / \mathrm{LT}$ & 7 & 6 & $"$ & 17.5 & $1.1 \times 10^{-3}$ \\
\hline HB-4-A-73 & $\mathrm{A} 212 \mathrm{~B} / \mathrm{LT}$ & 7 & 8 & $"$ & 17.5 & $1.2 \times 10^{-3}$ \\
\hline SW-1-7 & Seam weld & 1 & 7 & 1993 & 1.7 & $1.3 \times 10^{-4}$ \\
\hline SW-1-8 & Seam weld & 1 & 8 & “ & 1.7 & $1.3 \times 10^{-4}$ \\
\hline SW-1-9 & Seam weld & 1 & 9 & “ & 1.7 & $1.3 \times 10^{-4}$ \\
\hline NW-2-1 & Noz. weld & 2 & 2 & $"$ & 1.7 & $2.6 \times 10^{-4}$ \\
\hline$N W-2-4$ & Noz. weld & 2 & 6 & $"$ & 1.7 & $2.6 \times 10^{-4}$ \\
\hline NW-2-8 & Noz. weld & 2 & 16 & $"$ & 1.7 & $2.6 \times 10^{-4}$ \\
\hline HB-1A-64 & $\mathrm{A} 212 \mathrm{~B} / \mathrm{LT}$ & 6 & 7,4 & " & $17.5,1.7$ & $1.2 \times 10^{-3}$ \\
\hline HB-1A-71 & $\mathrm{A} 212 \mathrm{~B} / \mathrm{LT}$ & 6 & 8,5 & $"$ & $17.5,1.7$ & $1.2 \times 10^{-3}$ \\
\hline $\mathrm{HB}-4 \mathrm{~A}-76$ & $\mathrm{~A} 212 \mathrm{~B} / \mathrm{LT}$ & 7 & 1,4 & " & $17.5,1.7$ & $1.2 \times 10^{-3}$ \\
\hline
\end{tabular}

'Year specimens removed from vessel. 


\section{APPENDIX C}

\section{CALCULATION OF SURVEILLANCE-SPECIMEN DOSE RATES FOR ACHIEVING DESIRED LEAD TIME}

\section{C.1 Derivation of Equations}

The value of dpa at a point in the vessel after the upgrade design has been implemented is

$$
d p a_{v}\left(t_{2}\right)=d p a_{v}\left(t_{1}\right)+\left(t_{2}-t_{1}\right) d p a_{v}\left(t>t_{1}\right)
$$

and for a surveillance specimen that is intended to provide a lead time for that point in the vessel

$$
d p a_{s}\left(t_{3}\right)=d p a_{s}\left(t_{1}\right)+\left(t_{3}-t_{1}\right) d p a_{s}\left(t>t_{1}\right)
$$

where

$$
\begin{array}{ll}
t_{1} & =\text { time of restart after upgrade implemented } \\
t_{2} & =\text { operating time of vessel for which a lead time is desired }\left(t_{2}>t_{1}\right) \\
t_{3}-t_{1} & =\text { irradiation time for surveillance specimen after } t=t_{1} \\
t_{3} & =\text { time at which a surveillance specimen is removed and tested }
\end{array}
$$

In order to accelerate the rate of embrittlement, the surveillance specimen is positioned such that

$$
d \dot{p} a_{s}\left(t>t_{1}\right)=F \cdot d \dot{p} a_{v}\left(t>t_{1}\right)
$$

where $F>1$.

The required condition determining the lead time is

$$
d p a_{s}\left(t_{3}\right)=d p a_{v}\left(t_{2}\right)
$$

$\therefore d p a_{v}\left(t_{1}\right)+\left(t_{2}-t_{1}\right) d \dot{p} a_{v}\left(t>t_{1}\right)=d p a_{s}\left(t_{1}\right)+\left(t_{3}-t_{1}\right) F \cdot d \dot{p} a_{v}\left(t>t_{1}\right)$

or

$$
t_{3}=t_{1}+\frac{1}{F}\left[t_{2}-t_{1}+\frac{d p a_{v}\left(t_{1}\right)-d p a_{s}\left(t_{1}\right)}{d \dot{p} a_{v}\left(t>t_{1}\right)}\right]
$$

and

$$
t_{2}=t_{1}+F\left(t_{3}-t_{1}\right)-\left[\frac{d p a_{v}\left(t_{1}\right)-d p a_{s}\left(t_{1}\right)}{d p a_{v}\left(t>t_{1}\right)}\right]
$$




\section{C.2 Calculations}

\section{C.2.1 HB-2 nozzle corner, $t_{1}=22.6$ EFPY $(100 \mathrm{MW})$}

From Ref. 13, page E.3,

$$
\begin{aligned}
& d p a_{v}\left(t<t_{1}\right)=1.21 \times 10^{-4} / E F P Y(100 M W) \\
& \therefore d p a_{v}\left(t_{1}\right)=1.21 \times 10^{-4} \times 22.6=2.73 \times 10^{-3} \\
& d p a_{v}\left(t>t_{1}\right)=1.25 \times 10^{-3} / E F P Y(100 M W)
\end{aligned}
$$

For new A350LF3 surveillance specimens, $d p a_{s}\left(t_{1}\right)=0$.

$$
\therefore t_{3}=22.6+\frac{1}{F}\left[t_{2}-22.6+\frac{2.73 \times 10^{-3}}{1.25 \times 10^{-3}}\right]
$$

Corresponding values of $t_{3}$ for $t_{2}=40$ and 50 EFPY $(100 \mathrm{MW})$ are as follows:

\begin{tabular}{llr} 
& \multicolumn{2}{c}{$t_{3}$, EFPY $(100 \mathrm{MW})$} \\
\hline $\mathrm{F}$ & $t_{2}=40$ & 50 \\
\hline 1 & 42.2 & 52.2 \\
2 & 32.4 & 37.4 \\
3 & 29.1 & 32.5 \\
4 & 27.5 & 30.0 \\
\hline
\end{tabular}

\section{C.2.2 HB-2 nozzle weld, $t_{1}=22.6$ EFPY $(100 \mathrm{MW})$}

From Ref. 13, page E.4,

$$
\begin{aligned}
& d p a_{v}\left(t<t_{1}\right)=\quad 6.68 \times 10^{-5} / \text { EFPY }(100 \mathrm{MW}) \\
& \therefore d p a_{v}\left(t_{t}\right)=6.68 \times 10^{-5} \times 22.6=1.51 \times 10^{-3}
\end{aligned}
$$$$
d p a_{v}\left(t>t_{1}\right)=1.17 \times 10^{-4} / \text { EFPY }(100 \mathrm{MW})
$$

For NW specimens

$$
\begin{aligned}
& d p a_{s}\left(t<t_{1}\right)=4.79 \times 10^{-12} \times 3.15 \times 10^{7}=1.51 \times 10^{-4} \\
& \therefore d p a_{s}\left(t_{1}\right)=1.51 \times 10^{-4}(22.6-17.5)=7.70 \times 10^{-4} \\
& \therefore t_{3}=22.6+\frac{1}{F}\left[t_{2}-22.6+\frac{1.51 \times 10^{-3}-7.7 \times 10^{-4}}{1.17 \times 10^{-4}}\right]
\end{aligned}
$$


Corresponding values of $t_{3}$ for $t_{2}=40$ and 50 EFPY $(100 \mathrm{MW})$ are as follows:

\begin{tabular}{lll} 
& \multicolumn{2}{c}{$t_{3}, \operatorname{EFPY}(100 \mathrm{MW})$} \\
\hline $\mathrm{F}$ & $t_{2}=40$ & 50 \\
\hline 1 & 46.3 & 56.3 \\
2 & 34.5 & 39.5 \\
3 & 30.5 & 33.8 \\
4 & 28.5 & 31.0 \\
\hline
\end{tabular}




\section{APPENDIX D}

\section{HEAT GENERATION AND TEMPERATURES IN SURVEILLANCE SPECIMENS}

\section{Source of Heat Generation Data}

Gamma and neutron heat generation rates were calculated for HB-2 and are given in Figs. D1 and D2 and in Ref. 15. It is of interest to note that the neutron heating rate is several orders of magnitude less than the gamma heating rate.

As indicated by the gamma iso-dpa plots in Appendix $A$, the gamma heating rates at the HB-2 surveillance-specimen capsule mount (Key 2) are higher than at the other capsule mounts, and the rate at Key $2 \mathrm{C}$ is greater than at Key $2 \mathrm{~W}$ (see Fig. 5 for distinction between Key $2 \mathrm{C}$ and Key $2 \mathrm{~W}$ ). The calculated rate at the center of a CVN specimen in Key $2 \mathrm{C}$ is 1.6 watts $/ \mathrm{cm}^{3}\left(1.5 \times 10^{5} \mathrm{Btu} / \mathrm{hr} \cdot \mathrm{ft}^{3}\right)$.

\section{Method of Analysis for Calculating temperature of Surveillance Specimen}

The method of analysis assumes that the capsule can be represented by a semi-infinite slab submerged in water, as depicted in the diagram below. For this model

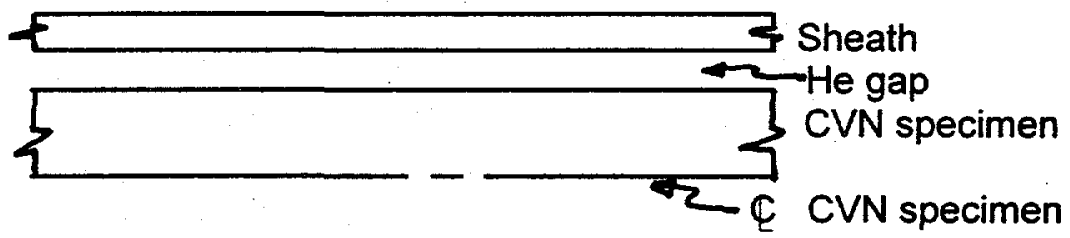

$$
T_{C V N}=T_{C}+\Delta T_{T}
$$

and

$$
\Delta T_{T}=\Delta T_{C V N}+\Delta T_{\text {gap }}+\Delta T_{S}+\Delta T_{F F}
$$

where $T_{C V N}=$ centerline temperature of $\mathrm{CVN}$ specimen

$T_{C}=$ temperature of bulk coolant

$\Delta T_{C V N}=$ temperature drop from centerline to surface of CVN specimen

$\Delta T_{\text {gap }}=$ temperature drop across He gap

$\Delta T_{S}=$ temperature drop across sheath

$\Delta T_{F F}=$ temperature drop across fluid film

$$
\Delta T_{C V N}=\frac{Q W_{C V N}^{2}}{2 k_{C V N}}
$$




$$
\begin{gathered}
\Delta T_{g a p}=\frac{Q W_{C V N} W_{g a p}}{k_{H \theta}} \\
\Delta T_{S}=\frac{Q W_{s}^{2}}{2 k_{s}}\left(\frac{2 W_{C V N}}{W_{s}}+1\right) \\
\Delta T_{F F}=\frac{Q\left(W_{C V N}+W_{s}\right)}{\overline{h_{F F}}},
\end{gathered}
$$

where $Q \quad=\quad$ heat generation rate per unit volume in CVN specimen and sheath $W_{\text {CVN }}=$ thickness of CVN specimen $/ 2$

$W_{\text {gap }}=$ thickness of He gap

$W_{s}=$ thickness of sheath

$k_{C V N}=$ thermal conductivity of CVN specimen

$k_{\mathrm{He}}=$ thermal conductivity of $\mathrm{He}$

$k_{s}=$ thermal conductivity of sheath

$\bar{h}_{F F}=$ average fluid-film heat transfer coefficient

For natural-convection heat transfer, which is assumed for the capsule because of the very low flow rate in the water reflector/shielding, $\bar{h}_{\mathrm{FF}}$ is obtained as follows[25]:

$$
\begin{gathered}
\bar{N} u=C(G r \cdot P r)^{n}=C \cdot R a^{n} \\
\bar{N} u=\frac{\overline{h_{F F} L}}{k}=\text { average Nusselt number } \\
G r=\frac{L^{3} \rho^{2} g \beta \Delta T_{F F}}{\mu^{2}}=\text { Grashof number } \\
\operatorname{Pr}=\frac{C \mu}{k}=\text { Prandtl number } \\
\operatorname{Ra}=\operatorname{Gr} \cdot \operatorname{Pr}=\text { Rayleigh number, }
\end{gathered}
$$


ORNL/TM-1372/S1

where $\quad C=$ constant depending on orientation of heat-transfer surface area

$c=$ specific heat of water

$g=$ gravitational constant $=4.17 \times 10^{8} \mathrm{ft} / \mathrm{hr}^{2}$

$k=$ thermal conductivity of water

$L=$ characteristic dimension of heat-transfer area

$n=$ exponent dependent on orientation of heat-transfer surface area

$\beta=$ volumetric coefficient of thermal expansion of water

$\mu=$ viscosity of water

$\rho=$ density of water

All properties of the coolant (water) are evaluated at

$$
T_{F F} \cong \frac{T_{s}+T_{c}}{2}
$$

where $T_{F F}=$ fluid-film temperature

$T_{s} \quad=$ temperature of sheath outer surface

$=T_{c}+\Delta T_{F F}$

$T_{c}=$ temperature of bulk coolant

\section{Calculations}

3.1 Input for Eqs. (D3-D5):

$Q=2.0$ watts $/ \mathrm{cm}^{3}=1.9 \times 10^{5} \mathrm{Btu} / \mathrm{hr} \cdot \mathrm{ft}^{3}$; includes an uncertainty factor of 1.25 .

$k_{\text {CVN }}=26 \mathrm{Btu} / \mathrm{hr} \cdot \mathrm{ft} \cdot{ }^{\circ} \mathrm{F}$

$k_{s}=9 \mathrm{Btu} / \mathrm{hr} \cdot \mathrm{ft} \cdot{ }^{\circ} \mathrm{F}$

$k_{\text {He }}=9 \times 10^{-2} \mathrm{Btu} / \mathrm{hr} \cdot \mathrm{ft} \cdot{ }^{\circ} \mathrm{F}$

$W_{\text {CVN }}=0.197$ in. $=1.64 \times 10^{-2} \mathrm{ft}$

$W_{s}=0.0313 \mathrm{in} .=2.61 \times 10^{-3} \mathrm{ft}$

$W_{\text {gap }}=1 \times 10^{-3}$ in. $=8.33 \times 10^{-5} \mathrm{ft}$

$\Delta T_{C V N}=\frac{1.9 \times 10^{5}\left(1.64 \times 10^{-2}\right)^{2}}{2 \times 26}=1.0^{\circ} \mathrm{F}$

$\Delta T_{\text {gap }}=\frac{1.9 \times 10^{5} \times 1.64 \times 10^{-2} \times 8.33 \times 10^{-5}}{9 \times 10^{-2}}=2.9{ }^{\circ} \mathrm{F}$

$$
\Delta T_{s}=\frac{1.9 \times 10^{5} \times\left(2.61 \times 10^{-3}\right)^{2}}{2 \times 9}\left(\frac{2 \times 1.64 \times 10^{-2}}{2.61 \times 10^{-3}}+1\right)=1.0^{\circ} \mathrm{F}
$$




\subsection{Calculation of $\Delta T_{F F}$}

The dependence of $C$ and $n$ on $\mathrm{Gr}$ and Pr requires an initial estimation of these latter two parameters.

$$
\text { Let } T_{F F}=\frac{T_{c}+T_{s}}{2}=\frac{120+30+120}{2}=135^{\circ} \mathrm{F}
$$

Then

$$
\begin{aligned}
c & =1.0 \mathrm{Btu} / \mathrm{lb} \cdot{ }^{\circ} \mathrm{F} \\
k & =0.375 \mathrm{Btu} / \mathrm{hr} \cdot \mathrm{ft} \cdot{ }^{\circ} \mathrm{F} \\
\beta & =2.6 \times 10^{-4}{ }^{\circ} \mathrm{F}^{-1} \\
\mu & =1.19 \mathrm{lb} / \mathrm{hr} \cdot \mathrm{ft} \\
\rho & =61.5 \mathrm{lb} / \mathrm{ft}^{3}
\end{aligned}
$$

Also, $L \cong 4$ in. $=33 \mathrm{ft}$.

From Eqs. (D9)-(D11),

$$
\begin{aligned}
G r & =\frac{(0.33)^{3}(61.5)^{2} \times 4.17 \times 10^{8} \times 2.6 \times 10^{-4} \times 30}{(1.19)^{2}} \\
& =3.1 \times 10^{8} \\
\operatorname{Pr} & =\frac{1.0 \times 1.19}{0.375}=3.2 \\
\therefore R a & =3.1 \times 10^{8} \times 3.2=9.9 \times 10^{8}
\end{aligned}
$$

For this value of $\mathrm{Ra}$, Eq. (D7) becomes, [25]

$$
\bar{N} u=0.10 R a^{1 / 3},
$$

for vertical flat plates;

$$
\bar{N} u=0.15 R a^{1 / 3},
$$

for the top surface of a horizontal flat plate;

$$
\bar{N} u=0.27 R a^{1 / 4} \text {. }
$$

for the bottom surface of a horizontal flat plate.

Because Eqs. (D15) and (D16) are not the same, the value of $\bar{h}_{F F}$ in Eq. (D6) will not necessarily be the same for the top and bottom surfaces. However, using $R a=9.9 \times$ 
$10^{8}$ and the above initial estimation of $\mathrm{Gr}$ and $\mathrm{Pr}$, Eqs. (D15) and (D16) are nearly equal. Thus, to simplify the analysis, it will be assumed that Eq. (D15) applies to both top and bottom of the plate. Having made this assumption, it is apparent that $L$ drops out of Eq. (D7), and thus

$$
\overline{h_{F F}}=k C\left[\frac{\rho^{2} g \beta \Delta T_{F F} c}{\mu k}\right]^{n}
$$

The values of $Q, W_{C V N}$ and $W_{s}$ are the same for the vertical and horizontal orientations of Key $2 \mathrm{C}$, and thus Eq. (D14) results in the largest value of $\Delta T_{F F}$ [Eq. (D6)]. Therefore, the desired value of $\bar{h}_{F F}$ is obtained from

$$
\overline{h_{F F}}=0.10 k\left[\frac{\rho^{2} g \beta \Delta T_{F F} c}{\mu k}\right]^{1 / 3}
$$

Because of the dependence of the properties of water on $T_{F f}=\left(T_{s}+T_{c}\right) / 2$, a trial-anderror solution is required. The solution for $T_{c}=120^{\circ} \mathrm{F}$ yields $\Delta T_{F F}=32^{\circ} \mathrm{F}$, and thus

$$
\Delta T_{T}=1.0+2.9+1.0+32=37^{\circ} \mathrm{F}
$$

and $T_{\text {CVN }}=120+37=157^{\circ} \mathrm{F}$

The corresponding properties of the coolant are those given above.

The maximum permissible value of $T_{\mathrm{CVN}}$ without significantly affecting the $\triangle N D T T$ vs dpa relation is $\sim 250^{\circ} \mathrm{F}[19,22,23,24]$. Thus, an uncertainty factor $(F)$ of

$$
F=\frac{32}{250-(120+1.0+2.9+1.0)}=0.36
$$

applied to $\bar{h}_{\mathrm{FF}}$ is accommodated. This is sufficient to account for modest flow restrictions around the capsules in Key $2 \mathrm{C}$ (Fig. 5). 
HFIR hb2 9 in., 100 MW, 84 gp, gamma heating, rev 2 cor. (norm)

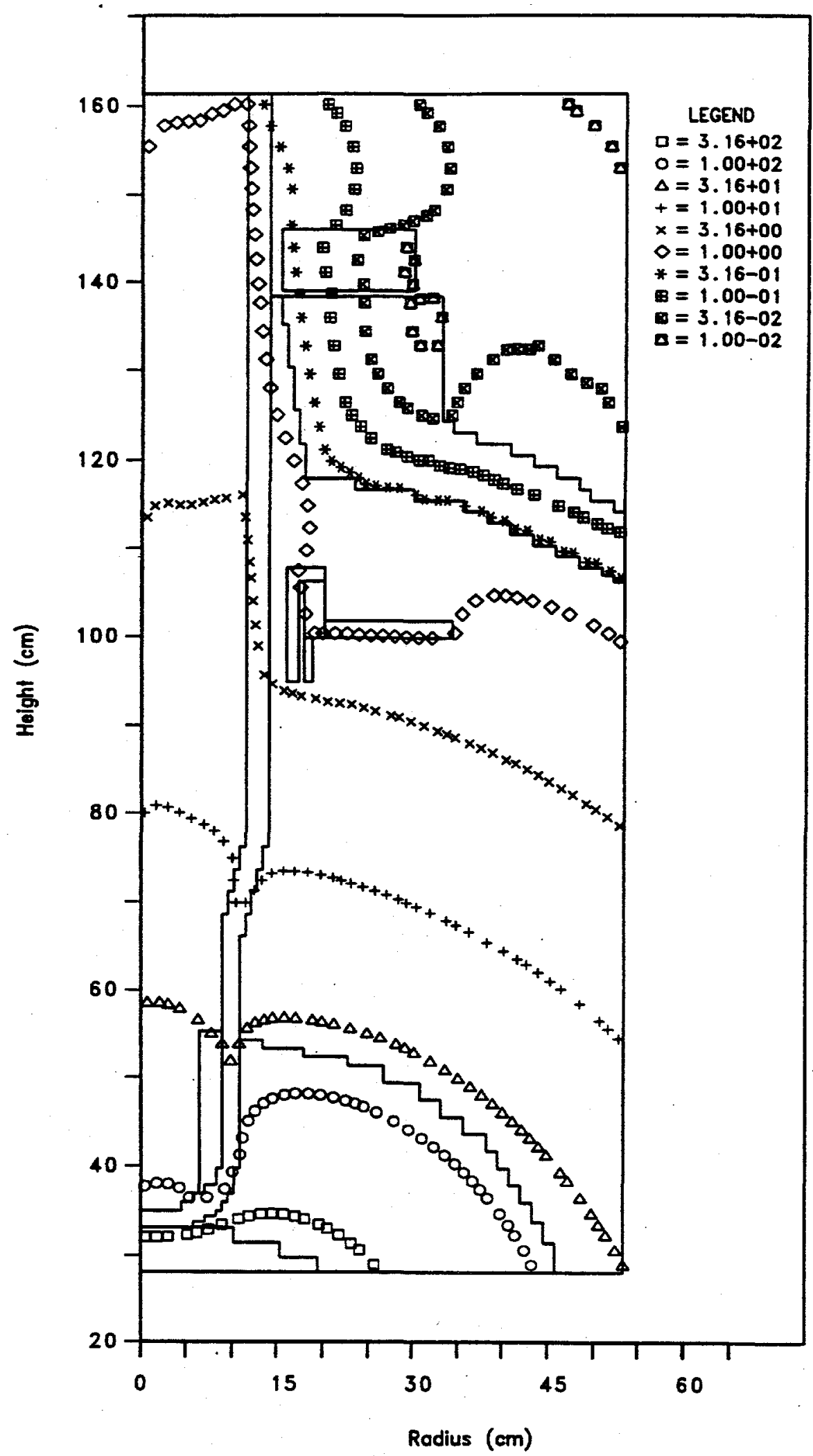

Fig. D1. Gamma iso-heating rates for HB-2 (new design) (watts/cm3 in iron). 
ORNL/TM-1372/S1

HFIR hb2 9 in., $100 \mathrm{MW}, 84 \mathrm{gP}$, neutron heating, rev 2 cor. (norm)

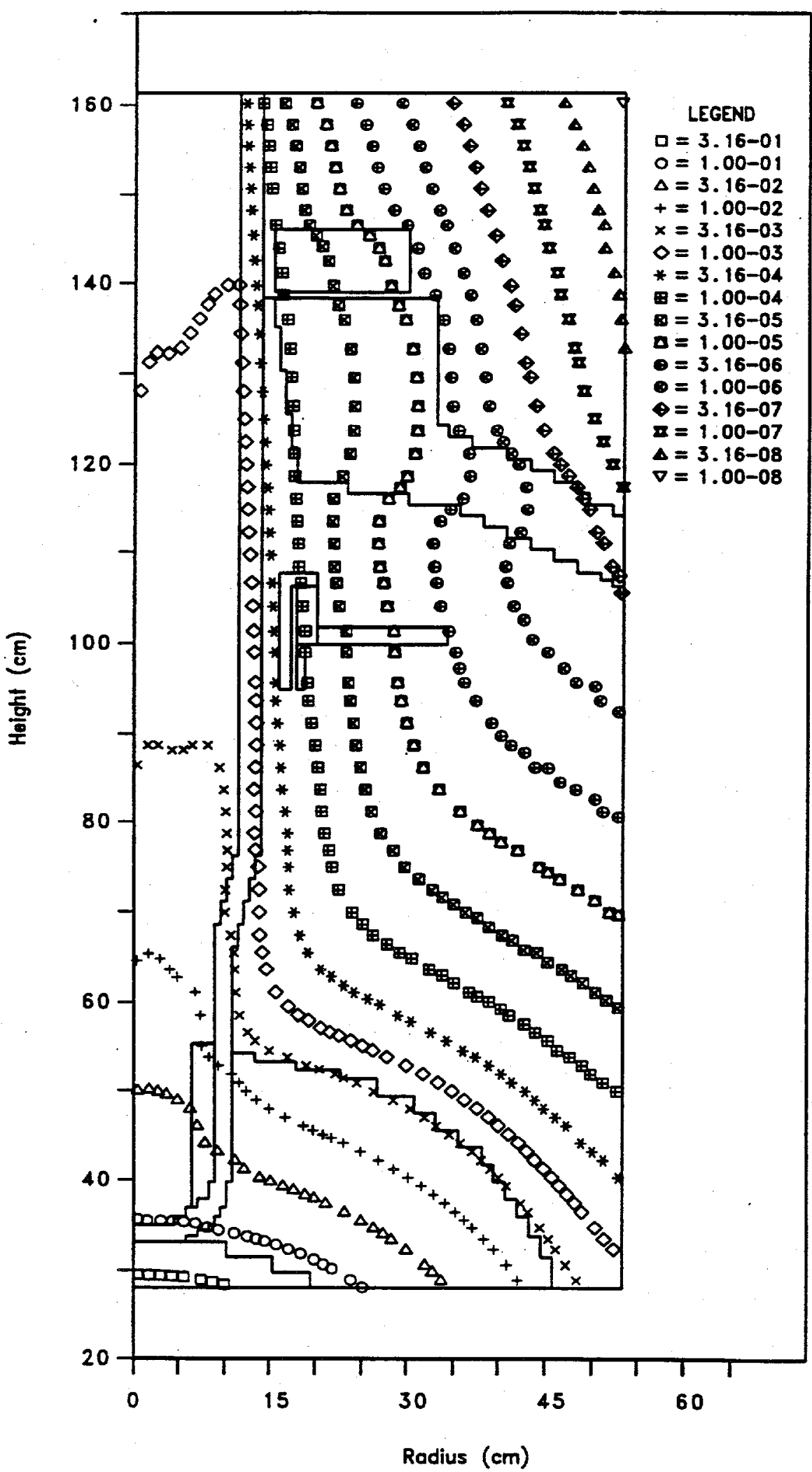

Fig. D2. Neutron iso-heating rates for HB-2 (new design) (watts/cm3 in iron). 
INTERNAL DISTRIBUTION

\begin{tabular}{|c|}
\hline $\begin{array}{l}\text { C. A. Baldwin } \\
\text { E. D. Blakeman } \\
\text { W. K. Brown } \\
\text { S. E. Burnette } \\
\text { S. J. Chang } \\
\text { R. D. Cheverton } \\
\text { D. H. Cook } \\
\text { R. E. Daniels (DOE-ORO) } \\
\text { T. L. Dickson } \\
\text { H. R. Fair } \\
\text { M. B. Farrar } \\
\text { K. Farrell } \\
\text { G. F. Flanagan } \\
\text { M. L. Gildner } \\
\text { R. E. Hale } \\
\text { R. M. Harrington } \\
\text { R. W. Hobbs } \\
\text { J. R. Inger } \\
\text { S. K. Iskander } \\
\text { M. W. Kohring }\end{array}$ \\
\hline
\end{tabular}

$\begin{array}{ll}34 . & \text { J. E. Lee } \\ 35 . & \text { M. A. Linn } \\ 36 . & \text { R. S. McKeehan } \\ 37 . & \text { J. G. Merkle } \\ 38 . & \text { L. D. Merryman } \\ 39 . & \text { R. K. Nanstad } \\ 40 . & \text { J. V. Pace III } \\ 41 . & \text { L. D. Proctor } \\ 42 . & \text { I. Remec } \\ 43 . & \text { J. B. Roberto } \\ 44 . & \text { R. B. Rothrock } \\ 45 . & \text { D. L. Selby } \\ 46 . & \text { R. M. Stinnett } \\ 47 . & \text { P.T. Williams } \\ 48 . & \text { RRD-DCC-RC } \\ 49 . & \text { Central Research Library } \\ 50 . & \text { Document Reference Section } \\ 51-52 . & \text { Laboratory Records } \\ 53 . & \text { Laboratory Records (RC) } \\ & \end{array}$

\section{EXTERNAL DISTRIBUTION}

54. H. Amirmokri, Office of Nuclear Energy, NE-40-GTN, Department of Energy, Germantown, MD 20874-1290.

55. E. G. Cumesty, ORNL Site Manager, Department of Energy, Oak Ridge National Laboratory, Oak Ridge, TN 37831-6269.

56-57. Office of Scientific and Technical Information, Post Office Box 62, Oak Ridge, TN 37831 